\title{
MODELLING OF HVDC WALL BUSHING FLASHOVER DUE TO UNEVEN WETTING
}

BY

LIANG TANG

\author{
A Thesis \\ Submitted to the Faculty of Graduate Studies \\ in Partial Fulfillment of the Requirements \\ for the Degree of
}

DOCTOR OF PHILOSOPHY
Department of Electrical and Computer Engineering University of Manitoba
Winnipeg, Manitoba, Canada

(C)April, 2002 
National Library of Canada

Acquisitions and Bibliographic Services

395 Wellington Street Ottawa ON K1A ON4 Canada
Bibliothèque nationale du Canada

Acquisitions et services bibliographiques

395, rue Wellington Ottawa ON K1A ON4 Canada
Your file Votre référence

Our file Notre rélérence
The author has granted a nonexclusive licence allowing the National Library of Canada to reproduce, loan, distribute or sell copies of this thesis in microform, paper or electronic formats.

The author retains ownership of the copyright in this thesis. Neither the thesis nor substantial extracts from it may be printed or otherwise reproduced without the author's permission.
L'auteur a accordé une licence non exclusive permettant à la Bibliothèque nationale du Canada de reproduire, prêter, distribuer ou vendre des copies de cette thèse sous la forme de microfiche/film, de reproduction sur papier ou sur format électronique.

L'auteur conserve la propriété du droit d'auteur qui protège cette thèse. $\mathrm{Ni}$ la thèse ni des extraits substantiels de celle-ci ne doivent être imprimés ou autrement reproduits sans son autorisation. 
THE UNIVERSITY OF MANITOBA

FACULTY OF GRADUATE STUDIES

COPYRIGHT PERMISSION PAGE

\section{MODELLING OF HVDC WALL BUSHING FLASHOVER \\ DUE TO UNEVEN WETTING}

BY

\section{LIANG TANG}

A Thesis/Practicum submitted to the Faculty of Graduate Studies of The University of Manitoba in partial fulfillment of the requirements of the degree

of

Doctor of Philosophy

LIANG TANG $\odot 2002$

Permission has been granted to the Library of The University of Manitoba to lend or sell copies of this thesis/practicum, to the National Library of Canada to microfilm this thesis and to lend or sell copies of the film, and to University Microfilm Inc. to publish an abstract of this thesis/practicum.

The author reserves other publication rights, and neither this thesis/practicum nor extensive extracts from it may be printed or otherwise reproduced without the author's written permission. 


\begin{abstract}
One of the serious problems in HVDC transmission is that of wall bushing flashover initiated by rain, fog or wet snow. All utilities engaged in dc transmission experience such problems and have adopted countermeasures with varying degrees of success. The consensus of opinion is that there is a need to better understand the phenomena and devise effective remedial measures or an improved design.
\end{abstract}

The problem of HVDC wall bushing flashover due to uneven wetting is introduced and reviewed, with emphasis on recent progress in understanding the phenomena. The physics of discharges, particularly for flashover of an unevenly wetted HVDC wall bushing, is discussed and various processes and mechanisms responsible for discharge initiation and propagation are clarified and discussed in detail.

A numerical model is developed in order to predict flashover voltages for a wall bushing based on the results of accurate electric field computation carried out on a bushing, prior to initiating flashover. This analysis is done under a variety of practical conditions. The simulation results are in agreement with experimental data and, in general, explain well certain aspects of uneven wetting flashover.

The results of this research, particularly the proposed models are important supplements to large-scale experiments, which are costly and time consuming. The use of such model will be very helpful in selecting and designing HVDC wall bushings for future HVDC transmission schemes and to improve the performance of wall bushings in the existing HVDC transmission schemes. 


\section{ACKNOWLEDGMENTS}

The author would like to express his sincere appreciation to his advisor professor M. R. Raghuveer for his profound patience, great guidance and invaluable discussions. The author would also like to thank Mr. John Kendall from the High Voltage Lab, University of Manitoba, for his assistance during the course of this work.

Many thanks go to Mr. W. McDermid, N. Tarko, and Dr. M. Rashwan from Manitoba Hydro for their helps in data collection and invaluable discussions. The research would have been impossible without the generous financial support from Manitoba Hydro and testing equipment from Manitoba HVDC Research Center.

Last but not least, thanks also go to my family, and my parents for their understanding, support and encouragement. 


\section{TABLE OF CONTENTS}

ABSTRACT

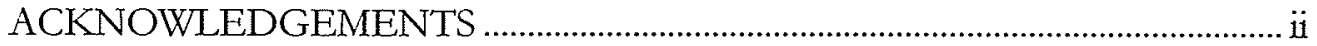

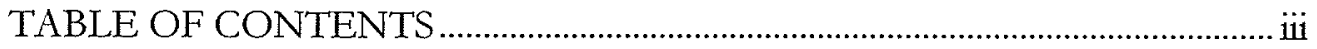

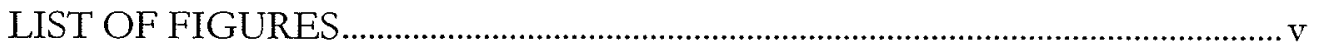

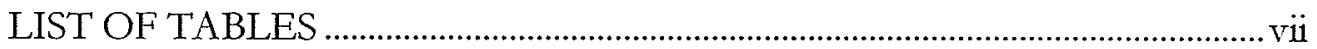

LIST OF SYMBOLS AND ABBREVIATIONS................................................. viii

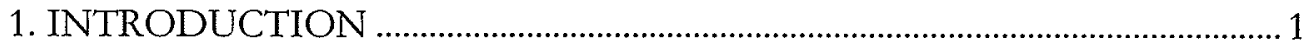

1.1 Flashover of HVDC Wall Bushings and Its Characteristics ....................... 3

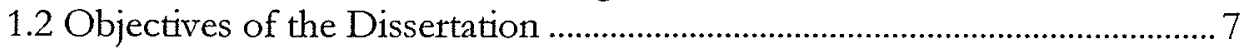

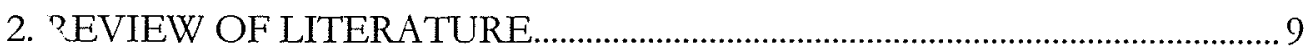

2.1 Uneven Wetting and Abnormal E-field Distribution.................................... 9

2.. Dominating Factors in HVDC Wall Bushing Uneven Wetting

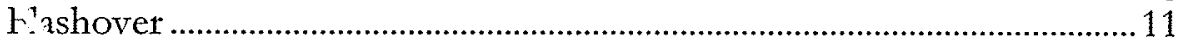

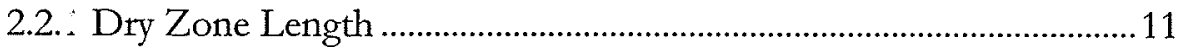

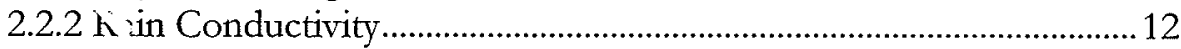

2.2.3 Wai? Bushing Configuration................................................................. 14

2.2.4 Voltag Polarity and Voltage Type .................................................. 15

2.2.5 Mitigating Measures ........................................................................... 16

2.3 Existing Models tc · Uneven Wetting Flashover for Wall Bushings ......... 18

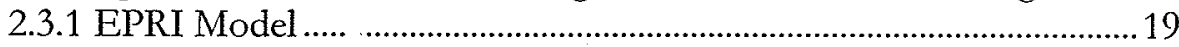

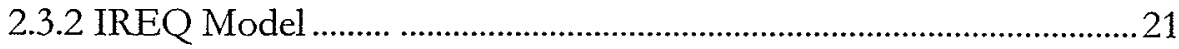

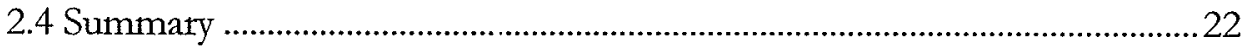

3. PHYSICS OF DISCHARGES AND NUMERICAL MODEL FOR UNEVEN WETTING FLASHOVER …..................................................... 24

$3.1 \mathrm{dc}$ Discharges in Air....................................................................................24

3.2 HVDC Wall Bushing Flashover under Uneven Wetting Conditions .......26

3.2.1 Wetting Process .......................................................................................26

3.2.2 Influence of Uneven Wetting Pattern on E-field Distribution ........28

3.2.3 Role of Raindrops in the Flashover Process ......................................36

Discharges Due to the Disintegration of Raindrop ......................37

Corona Discharges in the Vicinity of Raindrops ...........................41

Other Factors .......................................................................................... 42

3.2.4 Propagation of Discharges in Uneven Wetting Caused Flashover.. 42

3.2.5 Discharge Propagation on an Electrolytic Surface 
3.2.6 Sequence of Events for Uneven Wetting Flashover of HVDC Wall Bushing. .47

3.3 E-field Based Numerical Model for Prediction of HVDC Wall

Bushing Flashover due to Uneven Wetting................................................ 48

3.3.1 Mathematical Description of E-field..................................................48

3.3.2 Electric Field Modelling for HVDC Wall Bushing .............................49

3.3.3 HVDC Wall Bushing Uneven Wetting Flashover Criterion............. 52

3.3.4 Prediction of the Critical Flashover Voltage under (-ve) Polarity ................................................................................5

3.3.5 Modification in Procedure to Determine the Critical Flashover Voltage of a HVDC Wall Bushing Operating under +ve Polarity. 56

3.4 Summary .58

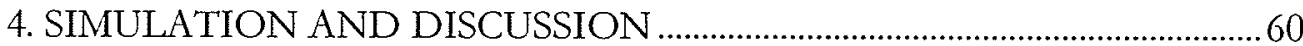

4.1 Description of Modelled HVDC Wall Bushing …………..............................60

4.2 Effect of Dry Zone Length, Its Location and Critical Dry Zone

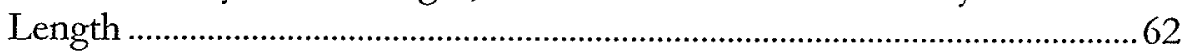

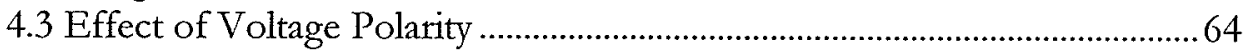

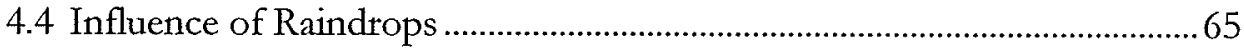

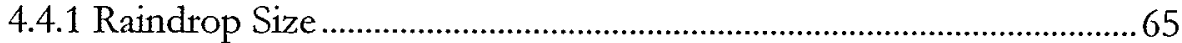

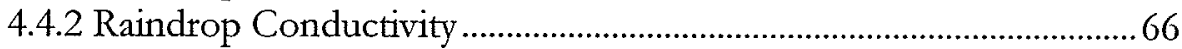

4.5 Influence of Air Pressure and Altitude .........................................................68

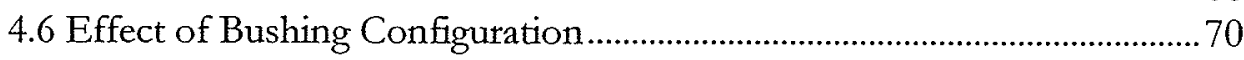

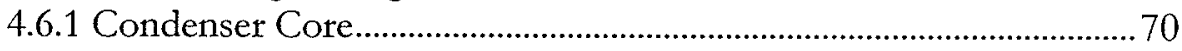

4.6.2 Specific Length ................................................................................... 72

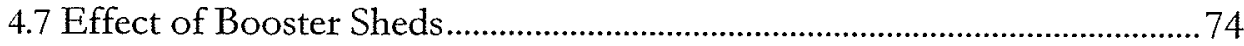

4.8 Effect of RTV and Other Surface Coatings................................................ 76

4.8.1 Influence of Surface Conditions on E-field Distribution.................. 76

4.8.2 Impact of RTV Coatings on Critical Flashover Voltage ...................8 80

4.9 Comparison of Results from Proposed Model with Experimental

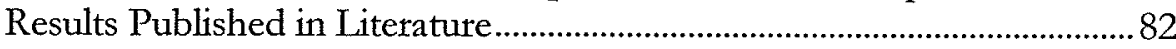

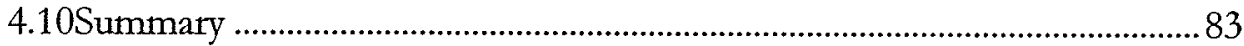

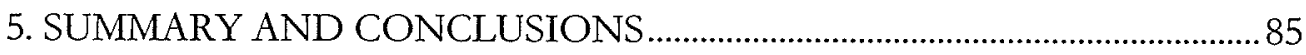

REFERENCES

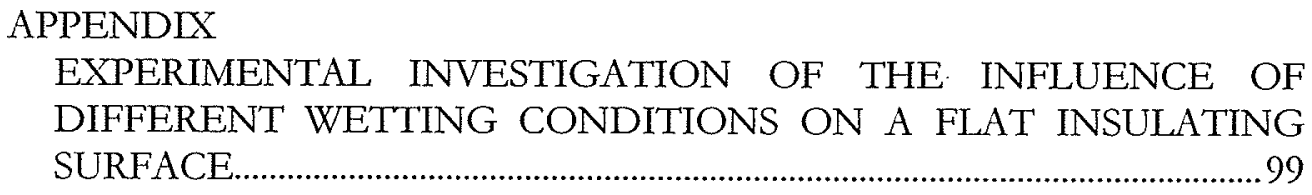

iv 


\section{LIST OF FIGURES}

Number

Page

Fig. $1.1500 \mathrm{kV}$ and $350 \mathrm{kV}$ dc wall bushings at the Dorsey Station, Manitoba Hydro.

Fig. 1.2 Diagram of HVDC wall bushing related processes ...................................

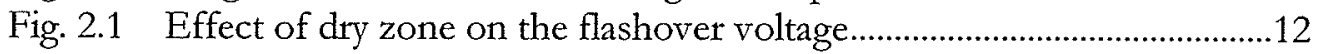

Fig. 2.2 Effect of rain conductivity on the flashover voltage .................................13

Fig. 2.3 Uneven wetting flashover voltage under the ac and dc voltage ..............16

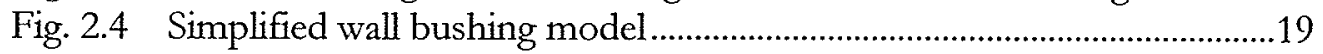

Fig. 2.5 Schematic diagram of IREQ model ........................................................21

Fig. 3.1 Surface tensions and contact angle for water drop on a dielectric

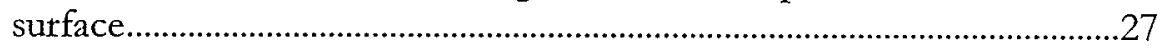

Fig. 3.2 Shielding effect of hall wall under rain with wind ....................................29

Fig. 3.3 E-field computation model for a $110 \mathrm{kV}$ wall bushing.............................30

Fig. 3.4 Impact of dry zone length on E-field contours.........................................31

Fig. 3.5 E-field intensity at shed tips under -ve unit voltage...................................32

Fig. 3.6 E-field intensity in the air close to the bushing surface ...........................33

Fig. 3.7 Influence of the dry zone length on E-field intensity ..............................34

Fig. 3.8 Electric field distortion due to the presence of a water drop ...................37

Fig. 3.9 Critical E-field for the disintegration of a raindrops ...............................40

Fig. 3.10 Discharge propagation with different polarity ….........................................43

Fig. 3.11 Illustration of propagation of discharges on an electrolytic

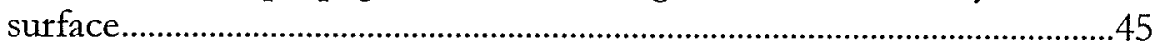

Fig. 3.12 Minimum voltage for arc propagation along wetted surface with respect to the arc length ................................................................................46

Fig. 3.13 Potential contours for a 600kV HVDC wall bushing .............................50

Fig. 3.14 E-field contours for a $600 \mathrm{kV}$ HVDC wall bushing....................................50

Fig. 3.15 Electric field distribution along the critical line for a $600 \mathrm{kV}$ HVDC wall bushing ..................................................................................51

Fig. 3.16 Block diagram of predicting uneven wetting HVDC wall bushing critical flashover voltage ...............................................................55

Fig. 4.1 Schematic drawing of a $600 \mathrm{kV}$ wall bushing...........................................61

Fig. 4.2 Influence of dry zone length on flashover stress for a $600 \mathrm{kV}$ HVDC wall bushing (-ve)

Fig. 4.3 Critical flashover voltage versus the size of raindrops for a $600 \mathrm{kV}$ HVDC wall bushing with $30 \%$ length of dry zone located at the ground end

Fig. 4.4 Influence of rain conductivity on the critical flashover voltage for the $600 \mathrm{kV}$ HVDC wall bushing 
Fig. 4.5 CFO vs. water conductivity for a $600 \mathrm{kV} \mathrm{HVDC}$ wall bushing with $30 \%$ length of dry zone.

Fig. 4.6 Streamer inception voltage due to photo-ionization for a $600 \mathrm{kV}$ HVDC wall bushing with $30 \%$ length of dry zone under various altitude

Fig. 4.7 Influence of altitude on the relation between $\mathrm{CFO}$ and raindrop

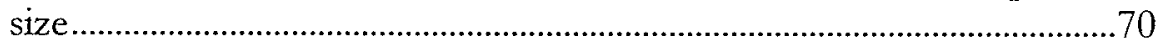

Fig. 4.8 E-field contours and E-fields at shed tips for housing shells .................71

Fig. 4.9 Profile of underrib-type shed and dry strip .................................................74

Fig. 4.10 Booster shed profile and dry band illustration.........................................75

Fig. 4.11 E-field distribution along the critical line for a $600 \mathrm{kV}$ HVDC wall bushing with and without booster sheds (30\% length of dry zone located at the ground end)

Fig. 4.12 Dependence of E-field intensity on the length of dry zone for a $110 \mathrm{kV}$ bushing with various surface conditions..

Fig. 4.13 E-field intensity at shed tips for a $110 \mathrm{kV}$ bushing with various coatings.

Fig. 4.14 Comparison of E-field distributions along the critical line with and without RTV coating (30\% dry zone located at the ground end)

Fig. 4.15 CFOs versus dry zone length for a $600 \mathrm{kV}$ HVDC wall bushing with and without RTV coating.

Fig. $4.16 \mathrm{CFOs}$ for a $600 \mathrm{kV}$ HVDC wall bushing with different coatings..............82 


\section{LIST OF TABLES}

Number

Page

Table 1.1 Performance of Wall Bushings

Table 2.1 Critical Flashover Stress for Uneven Wetting Flashover..........................11

Table 3.1 Streamer Propagating Gradients..............................................................25

Table 3.2 Key Dimensions of the 110kV Bushing Model ..........................................30

Table 3.3 Conductivity of Different Materials..........................................................52

Table 3.4 Comparison of Predicted Flashover Voltage and Standard Data

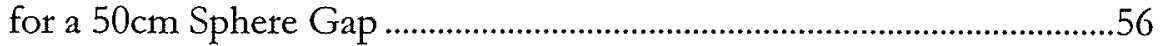

Table 4.1 Critical Dimensions of the 600kV HVDC Wall Bushing.........................61

Table 4.2 Predicted Flashover Voltages for the $600 \mathrm{kV}$ Wall Bushing with Various Dry Zone Lengths ................................................................62

Table 4.3 Critical Flashover Stress vs. Critical Dry Zone Length (-ve polarity) ..................63

Table 4.4 Predicted Critical Flashover Stress vs. Specific Lengths............................73

Table 4.5 Conductivities for Surface Film with Different Coatings..........................77

Table 4.6 Maximum Nominal E-fields in Different Locations $\left(\mathrm{cm}^{-1}\right)$.....................79

Table 4.7 Comparison of CFO Stresses between the Proposed and IREQ

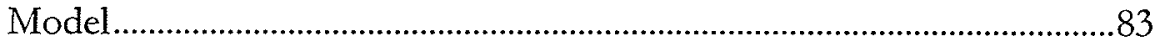




\section{LIST OF SYMBOLS AND ABRREVIATIONS}

$\begin{array}{llr}\text { Symbol } & \text { Description } & \text { Unit } \\ \rho_{s} & \text { Surface resistivity } & \Omega \\ \gamma & \text { Conductivity } & \mu \mathrm{S} / \mathrm{cm} \\ \sigma & \text { Surface tension } & \mathrm{N} / \mathrm{m} \\ \varepsilon & \text { Permittivity } & \mathrm{F} / \mathrm{m} \\ Q_{R} & \text { Rayleigh charge limit } & \mathrm{C} \\ \text { CFO } & \text { Critical flashover voltage } & \mathrm{kV}\end{array}$




\section{Chapter 1}

\section{INTRODUCTION}

The operating experience of HVDC transmission schemes indicates that the proliferation of external flashovers in HVDC converter stations has been a source of serious concern. In a span of 7.5 years from Jan. 1983 to Jul. 1990, HVDC wall bushings had suffered the highest flashover rate among all HVDC equipment, i.e., a total of 126 flashovers had been reported in 23 stations [LaA191]; horizontal wall bushings accounted for a majority of the reported flashover (50\%). Such a flashover usually occurs in both newly constructed or upgraded converter stations, with voltage larger than $400 \mathrm{kV}$, where suitable countermeasures have not been undertaken. On average, the flashover rate of HVDC wall bushings of $400 \mathrm{kV}$ or above is about 1.1/unityear [Cai96]. Table 1.1 shows survey results of HVDC wall bushing performance conducted by EPRI in early $90^{\prime}$ s.

To understand the phenomena, a large amount of experimental work has been conducted on HVDC wall bushings under severe operating conditions. Results of related work at EPRI (US), IREQ, ABB, NGK, EPRI (China), CEPEL, and CESI have been reported in literature. Equivalent circuit based models of HVDC wall bushing flashover have been proposed [ScLu91], [RiKa91]. To improve the performance of HVDC wall bushings, various mitigating measures have also been suggested; polymeric booster sheds and RTV silicone rubber coatings are the most effective, although the mechanism responsible for improvement in performance is still a topic of interest. 
Table 1.1 Performance of Wall Bushings [CEA95]

\begin{tabular}{|c|c|c|c|c|c|c|c|}
\hline \multirow{2}{*}{ Site } & \multicolumn{2}{|c|}{ Stress (Nominal) } & \multicolumn{4}{c|}{ Performance } \\
\cline { 2 - 8 } & $\begin{array}{c}\text { Voltage } \\
(\mathrm{kV})\end{array}$ & $\mathrm{kV} / \mathrm{m}$ & $\begin{array}{c}\text { Specific } \\
\text { length } \\
\text { (cm/kV) }\end{array}$ & $\begin{array}{c}\text { Total } \\
\text { Flashovers }\end{array}$ & $\begin{array}{c}\text { Insulator } \\
\text { years }\end{array}$ & $\begin{array}{c}\text { Flashovers } \\
\text { 1000uit ycass }\end{array}$ & $\begin{array}{c}\text { Polarity } \\
\text {-ve/total } \\
(\%)\end{array}$ \\
\hline Dorsey B1 & 450 & 129 & 3.29 & 4 & 6 & 667 & 100 \\
\hline Dorsey B1 & 300 & 123 & 3.39 & 4 & 175 & 23 & 100 \\
\hline Dorsey B2 & 500 & 92 & 4.37 & 2 & 36 & 56 & 100 \\
\hline Radisson B1 & 450 & 129 & 3.29 & 5 & 12 & 471 & 60 \\
\hline Des Cantons & 450 & 77 & 4.65 & 0 & 6.6 & 0 & NA \\
\hline Comerford & 450 & 81 & 4.55 & 48 & 6.6 & 7273 & 75 \\
\hline Dickinson & 400 & 80 & 4.00 & 0 & 20 & 0 & NA \\
\hline Celilo U & 500 & 81 & 4.01 & 0 & 48 & 0 & NA \\
\hline Celilo O & 399 & 154 & 2.30 & 16 & 160 & 100 & - \\
\hline Sylmar & 500 & - & 4.00 & 3 & 12 & 250 & 100 \\
\hline Sylmar & 400 & 154 & 2.50 & 6 & 13 & 462 & 33 \\
\hline Sylmar & 266 & - & 2.50 & $>1$ & 140 & $>7$ & 100 \\
\hline Adelanto & 500 & 66 & 4.95 & 3 & 23 & 130 & 100 \\
\hline Adelanto & 250 & 53 & 5.99 & 0 & 45 & 0 & - \\
\hline Mandarins & 270 & 96 & 3.70 & 5 & 110 & 45 & 40 \\
\hline
\end{tabular}


In this chapter, the HVDC wall bushing flashover phenomena is briefly introduced. Further, some important characteristics of wall bushing flashover are discussed in detail and the objectives of the research are outlined.

\subsection{Flashover of HVDC Wall Bushings and Its Characteristics}

$500 \mathrm{kV}$ and $375 \mathrm{kV}$ HVDC wall bushings, equipped with booster sheds, at the Dorsey Station of Manitoba Hydro, are shown in Fig. 1.1. These HV bushings typically employ a condenser core to provide alternative-voltage grading inside the porcelain housing.

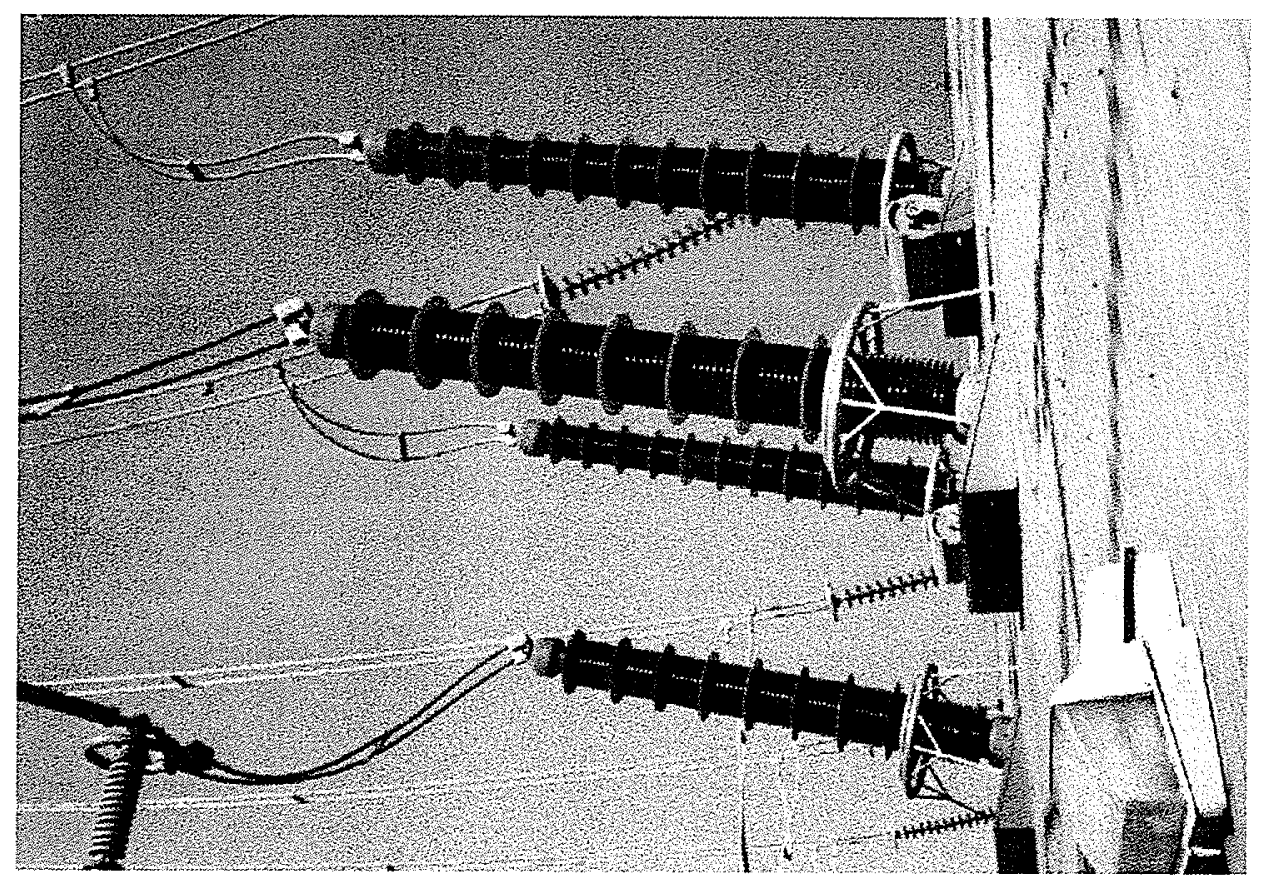

Fig. 1.1 $500 \mathrm{kV}$ and $375 \mathrm{kV}$ dc wall bushings at the Dorsey Station, Manitoba Hydro

Several processes, which can finally lead to catastrophic failure of a wall bushing, are listed in Fig.1.2. The electric field inside or outside a bushing may be substantially modified due to reasons such as contamination, and wetting. Local electric field enhancement causes ionization and when sufficient, triggers either a surface flashover or internal discharges. For a dc wall 
bushing, the electric field distribution is mainly determined by the resistivity of materials. Since the resistance of the internal insulation is always significantly high, the voltage distribution along the external surface is very sensitive to surface conditions such as pollution and wetting. As a result, dc wall bushings are particularly vulnerable to severe weather conditions, which often result in electric field distortion and flashover [LaWJ91].

Contamination is one of the major causes for abnormal low flashover voltage of external insulation in both ac and dc systems. Contamination flashover is initiated when a certain amount of pollutant together with moisture (fog or drizzle) develops a certain, critical conductivity. Once a conductive current of more than 5-10 $\mathrm{mA}$ has been established, dry-band arcing takes place. These current bursts, which in the case of dc may last for several seconds, increase to about $100 \mathrm{~mA}$ prior to a contamination flashover.

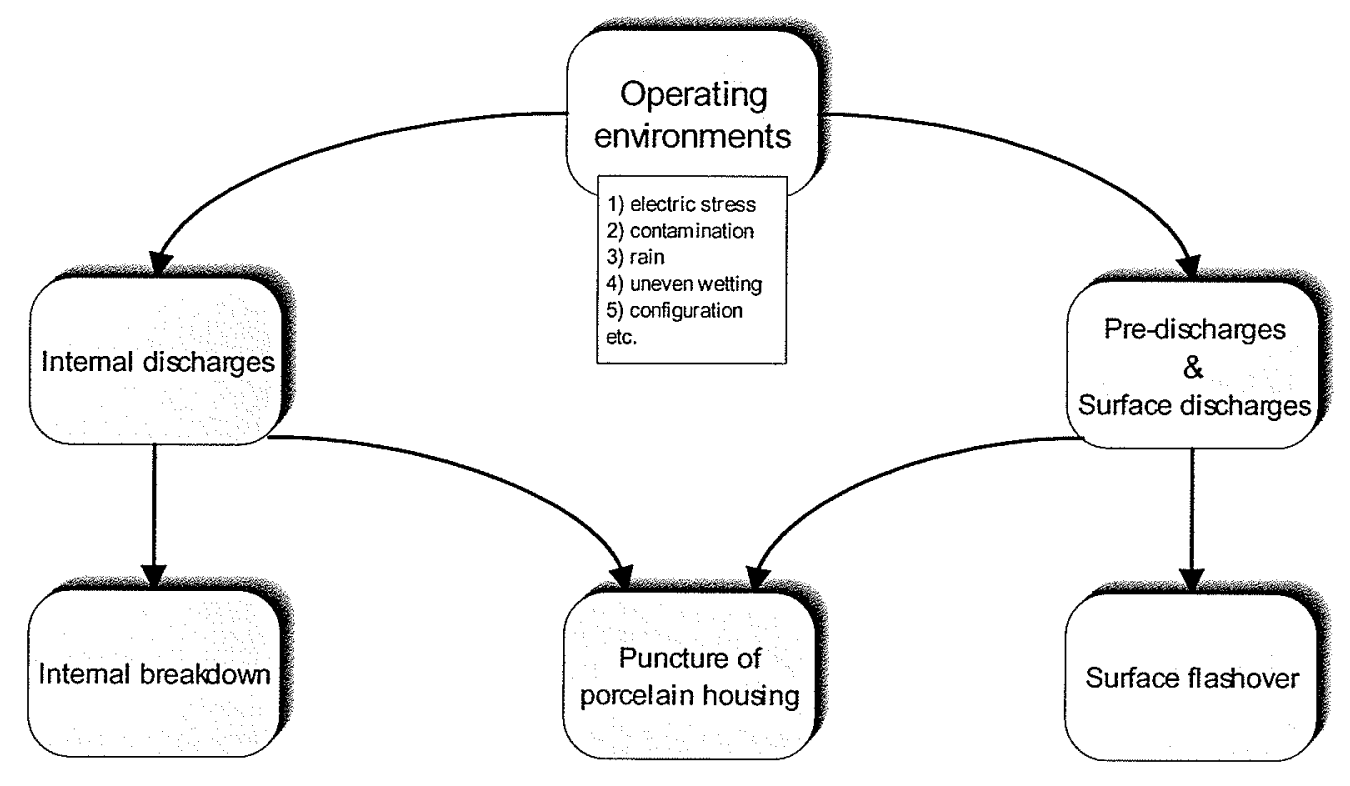

Fig. 1.2 Diagram of HVDC wall bushing related processes 
External flashover can also occur due to rain alone and especially in non-uniform rain. In a rain test for insulators, the flashover stress under dc may vary from $170 \mathrm{kV} / \mathrm{m}$ to $400 \mathrm{kV} / \mathrm{m}$. Therefore, for dc station insulators, a design stress lower than $100 \mathrm{kV} / \mathrm{m}$ is normally used. Such a design criterion works well for insulators under rain conditions. As shown in Table 1.1, the operating stresses for wall bushings range from $50 \mathrm{kV} / \mathrm{m}$ to $154 \mathrm{kV} / \mathrm{m}$. However, flashover stresses as low as $60 \sim 70 \mathrm{kV} / \mathrm{m}$ have been recorded for horizontal HVDC wall bushings under rain [Lamp88]. Hence, occurrence of abnormal flashovers is likely high under certain conditions.

Since the contamination level is light in most converter stations, with a typical Equivalent Salt Deposit Density (ESDD) value of $3 \sim 5 \mu \mathrm{g} / \mathrm{cm}^{2}$, the majority of wall bushing flashovers are likely caused by uneven wetting [Lamp88]. Thus, uneven wetting is a critical condition for the performance of HVDC wall bushings. Statistical data [LaA191] has confirmed that uneven wetting is the main cause of HVDC wall-bushing flashover, although contamination flashover might also occasionally occur. Comprehensive rain and contamination experiments in laboratories and observations in the field, has led to the conclusion that uneven wetting due to rain is the decisive triggering mechanism for most observed flashovers in horizontal HVDC wall bushings [Lamp88], [NaMI89], [Lamb90].

Uneven wetting is caused by a dry zone near the ground end of the bushing which is created due to its partial shielding by the wall of a converter building. The non-uniform voltage distribution across this "dry" zone leads to streamer breakdown of the "dry" zone followed by spark formation and complete flashover of the whole bushing. The uneven wetting caused flashover process involves a streamer-spark mechanism and differs from that for contamination flashovers. 
Compared to the contamination flashover of insulators, flashover phenomena of HVDC wall bushings under uneven wetting due to rain have the following interesting and exclusive characteristics.

1. The flashover voltage value seems independent of the rain intensity. Flashovers have occurred under almost every type of precipitation, from fog to heavy rain; flashovers occur most frequently under light rain [Lamp88], [SCHN91].

2. Flashover can occur at a very light contamination level or even with a clean surface, i.e. ESDD $<10 \mu \mathrm{g} / \mathrm{cm}^{2}$, which is only $1 / 10$ th of that necessary to cause a contamination flashover in a laboratory setting [Lamp88],[ScLu91], [ScHN91]. As a maintenance measure, cleaning has not always been sufficient to eliminate such flashover. Also, increasing the leakage path does not significantly improve performance. As an example, bushings with specific length as high as $6.1 \mathrm{~cm} / \mathrm{kV}$ [ZhSC91] still suffered flashovers during rain.

3. It appears that such a flashover is selective in polarity and system voltage. A majority of flashovers have occurred under negative polarity with system voltage of $400 \mathrm{kV}$ or greater [RiKa91].

4. Several parameters such as dry zone length, surface resistance, and configuration of bushings have a decisive influence on the flashover value rather than mainly ESDD as is the case with contamination caused flashovers [NaMI89], [Lamb90].

5. The characteristics of discharges are different. In a contamination flashover, slow dry banding dominates, discharges are slow to develop and last about seconds. Under uneven wetting, flashover formation is fast, has a short front time, of the order of tens microseconds [NaMI89]. 
6. Under non-uniform wetting, sometimes there are glow type discharges across the dry zone which later develop into streamers, and then extend along a bushing; in other cases, a few streamer type discharges are seen across the dry zone and then a flashover occurs suddenly. Sometimes, discharges are observed circumferentially around a bushing at the end of the dry zone. In the case of withstand, filamentary discharges are sometimes observed extending from the ground end to as much as $80 \sim 90 \%$ of the distance toward the high voltage terminal [EPRI90]. Unlike propagation of the arc root across the wet contaminated layer, the flashover across the wet zone proceeds by bridging the tips of the sheds.

\subsection{Objectives of the Dissertation}

This research work comprises the following objectives,

1. Study the mechanism of the wall bushing flashover problem due to uneven wetting and find out the criteria responsible for flashover.

2. Establish a model, which describes the criteria and sequence of flashover development.

3. Explain different aspects of the wall bushing flashover phenomena using the developed model.

4. Explain how and why RTV coating or booster sheds provide mitigating effects against the flashover.

5. Suggest new principles of designing wall bushings in order to improve their performance under unevenly wetted conditions.

Development of a comprehensive model is important because it provides a useful simulation tool in selecting, designing and evaluating HVDC wall bushings for future HVDC 
transmission schemes, and improving the performance of wall bushings in existing HVDC transmission schemes. The construction of a suitable validated model will enable the simulation of the flashover process for a wall bushing of given configuration under different operating conditions. With help of the simulation, the HVDC wall bushing performance may be assessed economically without resorting to expensive testing under various critical conditions. 


\section{Chapter 2}

\section{REVIEW OF LITERATURE}

For unevenly wetted HVDC wall bushings, flashover stresses were observed as low as 60$70 \mathrm{kV} / \mathrm{m}$ in field and laboratory investigations [Lamp88]. This is significantly lower than that caused by contamination or a typical rain flashover. In this section, peculiarities of the phenomena as well as existing models will be reviewed in detail.

\subsection{Uneven Wetting and Resulting Abnormal E-field Distribution}

A typical wall bushing is installed at a $15^{\circ}$ angle. Field observations and experimental investigations in laboratories have shown that HVDC wall bushing performance is significantly affected by the angle to the horizontal of the wall bushing axis since this affects shielding from rain and hence the surface resistance. This is because the steady state dc electric field distribution along a wall bushing is essentially determined by the prevailing conductivity. If a "dry" zone with relatively high resistance is created close to the flange end due to shielding effects of a wall, the electric field will be modified and redistributed. The perturbation leads to a significant increase in local electric fields, possible 4 times the original electric stress in some particular regions [TaRa95].

Local E-field enhancement can cause the initiation of streamer discharges. If the local fields are sufficiently high, streamer discharges will be developed, mainly dependent on streamer criterion, and propagate across the active regions. The presence of water droplets either in air or on the hydrophobic surface favors streamer facilitation and therefore further lowers the inception voltage for streamer discharges. 
During the progress of a streamer, if the local electric stress in front of streamer is larger than the critical value for propagation, say, $4.55 \mathrm{kV} / \mathrm{cm}$ [AlGh93], the streamer will advance. Otherwise, it will become inactive and eventually extinguish.

As a streamer approaches the opposite electrode, a streamer-spark transition will occur; if enough energy can be drawn from the surrounding electric field. The bushing type configuration favors such an occurrence, leading to a complete external flashover.

The E-field distribution along a $600 \mathrm{kV}$ wall bushing has been measured under different conditions in a laboratory environment. The results [LaW]91] show that the field stress increases sharply when a dry zone is introduced. The shorter the dry zone, the higher the increase. The E-field enhancement can easily exceed five times the stress under a uniform rain condition. In the same experiment, the impact of hydrophobicity was also investigated. It was also found that a hydrophobic surface prevents field enhancement in the dry zone and substantially reduces the radial field stress. As a result, significant reduction in discharges and surface current was observed during the experiment.

Further investigations on voltage distribution across the critical dry zone have been conducted at IREQ and at Dorsey, Manitoba Hydro [LaBK96]. The result shows that under different weather conditions there are large variations in surface resistivity, a high degree of nonunifomity in voltage distribution, which results in discharges across the dry zone. The maximum voltage across the critical dry zone under worst case scenario is nearly 3 times the value for uniform voltage distribution. HVDC wall bushings under these conditions would have experienced flashovers, had they not been adequately protected with booster sheds. 


\subsection{Dominating Factors in HVDC Wall Bushing Uneven Wetting Flashover}

Considerable laboratory investigations have been conducted to understand the dominating factors in HVDC wall bushing performance. The following is a brief summary of the findings.

\subsubsection{Dry Zone Length}

One of the conspicuous characteristics of uneven wetting flashover is the U-shaped relationship between the flashover voltage and the "dry" zone length as shown in Fig. 2.1. A drastic reduction in flashover voltage can been seen due to uneven wetting. There is no doubt that a critical "dry" zone length or range does exist corresponding to the minimum flashover voltage. In general, minimal withstand stresses in the range of $60 \sim 75 \mathrm{kV} / \mathrm{m}$ can be expected for critical "dry" zone lengths of about 10 30\% as shown in Table 2.1[NaMI89], [ScHN91], [Lamp88], [Lamb90].

Table 2.1 Critical Flashover Stress for Uneven Wetting Flashover

\begin{tabular}{|c|c|c|c|}
\hline $\begin{array}{c}\text { Critical Flashover } \\
\text { Stress (kV/m) }\end{array}$ & 75 & 63 & 67 \\
\hline Dry zone length (\%) & 18 & 10 & $17 \sim 30$ \\
\hline Reference & [Lamp88] & [ScHN91] & [Lamb90] \\
\hline
\end{tabular}




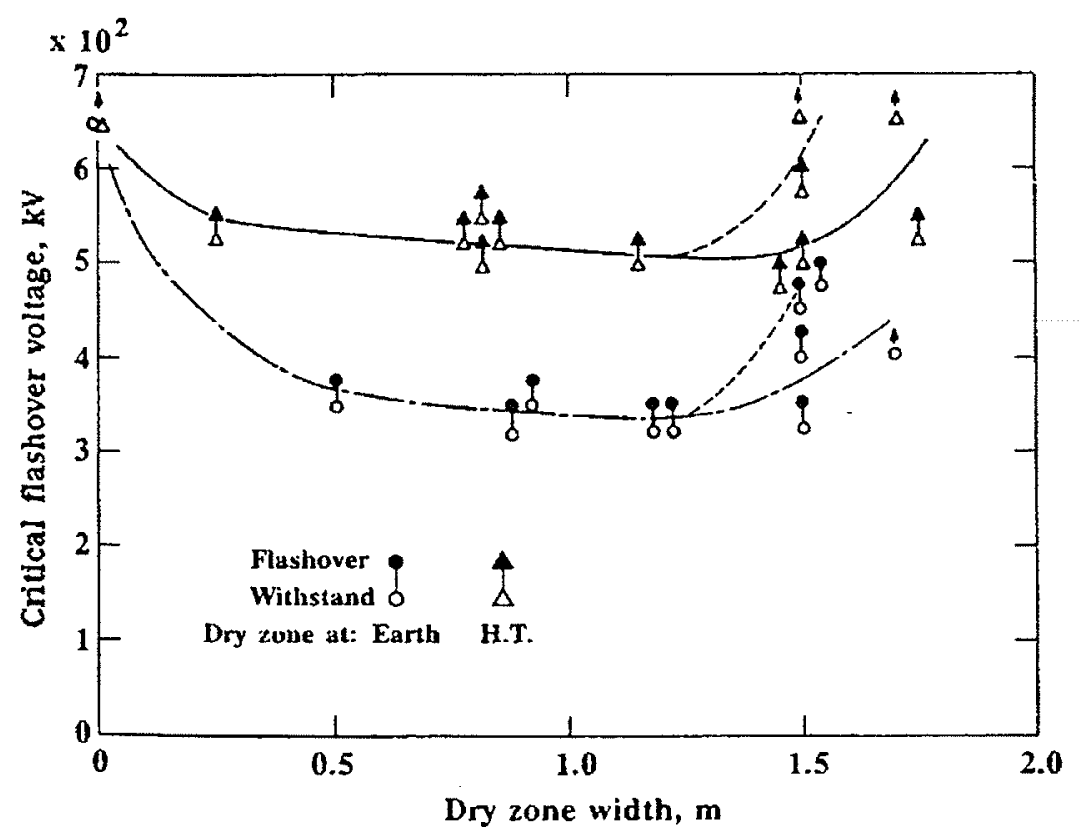

Fig. 2.1 Effect of dry zone on the flashover voltage [Lamb90] (Rain conductivity: $280 \mu \mathrm{S} / \mathrm{cm}$; Rain rate: $0.65 \mathrm{~mm} / \mathrm{min}$ )

Fig. 2.1 also indicates that the location of the dry zone is important. When it is located next to the HV terminal, the flashover voltage can be $100 \mathrm{kV}$ greater than when the dry zone is located at the ground end. The results of Fig. 2.1 were obtained under negative polarity.

A single dry zone at the ground end, under negative polarity, yields a flashover voltage lower than that obtained when a single dry zone is located anywhere else on the bushing, at either polarity. It is likely that the above is true even if the zone were split into several distributed zones so that the total dry zone lengths ate equal.

\subsubsection{Rain Conductivity}

The conductivity of natural rain varies from time to time. It is also likely that the rain conductivity changes during a rain fall, being higher in the initial minutes and then decreasing. Spot measurements of natural rain conductivity at BPA and EPRI show that it could be as low as 2 $\sim 10 \mu \mathrm{S} / \mathrm{cm}[\mathrm{ScHN} 91]$. 
The effect of rain conductivity in the range of $30 \sim 300 \mu \mathrm{S} / \mathrm{cm}$ was investigated on a $600 \mathrm{kV}$ wall bushing with about $30 \%$ length of dry zone at the ground end [Lamb90]. Fig.2.2 shows results obtained from an uncoated bushing and a bushing with a partial kaolin coating. The consistent results suggest that with increase of rain salinity the flashover voltage decreases. A linear correlation is found between the logarithm of the minimum flashover voltage $\left(V_{\mathrm{F} O}\right)$ and the logarithm of the rain conductivity. In the relationship $V_{1: 0} \propto$ (conductivity) $^{v}$, the exponent $v$ falls in the range of -0.09 to -0.11 . W. Lampe has also proposed a similar formula, i.e., dependence of flashover voltage on the water salinity $(\kappa)$ is $V_{\mathrm{FOO}} \propto \kappa^{-(1.18}[\mathrm{LaWJ91]}$.

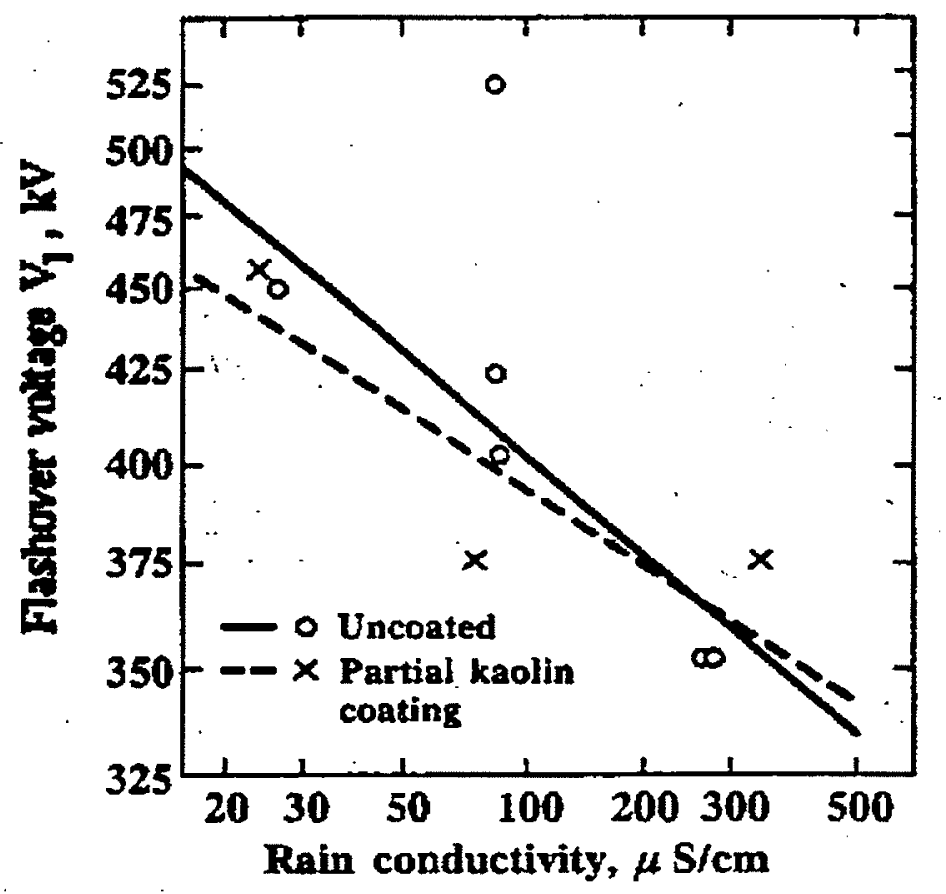

Fig. 2.2 Effect of rain conductivity on the flashover voltage [Lamb90]

In tests conducted under uneven wetting with low rain conductivity values, i.e. $5-10 \mu \mathrm{S} / \mathrm{cm}$, a higher flashover voltage was observed [ScHN91], much more pronounced than the above 
power law relation. It has also been observed that, the lower the rain conductivity, the more the influence of uneven wetting on the critical flashover voltage (CFO) [SuCL91].

When the salinity of the rain is increased to a certain value, the transition of flashover mechanism can be expected, from the uneven wetting caused flashover to a contamination caused flashover mechanism. Such a transition could take place at rain salinity of $500-$ $1000 \mu \mathrm{S} / \mathrm{cm}$ [LaWJ91], [Lamp88].

Besides rain conductivity, flashover of uneven wetted wall bushings are also slightly influenced by pre-deposited surface contaminants.

\subsubsection{Wall Bushing Configuration}

It has been experimentally confurmed that the flashover voltage of an unevenly wetted wall bushing is influenced by its internal and external design.

In contrast to the observations made with a wall bushing type configuration, an investigation [WuHÅ95] has revealed that an uneven wetting pattern has a negligible influence on the flashover of post insulators. In other words, uneven wetting flashover is particularly dependent on the configuration.

It is known that the flashover voltage of an empty shell is higher than that of a complete bushing, especially during the critical non-uniform rain. The minimum withstand voltage of an oil filled shell with protruded electrode, may be as low as $70 \%$ of the corresponding value for an empty shell, and as low as $60 \%$ of the withstand value under uniform rain [NaMI89]. In the discussion section of the same paper, it is also reported that the flashover stress of empty porcelain is nearly twice of that of an actual bushing. However, the shed profiles were not 
identical; the hollow shell in the test was substantially smaller than the full size bushing under the test.

Creepage length is an important parameter to improve the HV performance under severe service conditions, particularly for contamination flashover. However, increase in specific length may not be necessarily helpful in improving the HV performance of HVDC wall bushing. The efficacy of the specific length may be compromised due to the fact that the flashover occurs along the tips of sheds under a typical uneven wetting condition.

A significant improvement of wall bushing performance was reported by using additional booster sheds [Lamb90]. Also, some improvement of insulation strength under non-uniform wet condition can be expected with a wider shed spacing and water drip sheds having a larger shed diameter with an adequate interval [NaMI89]. The flashover voltages also increase with decreasing average shed diameter.

\subsubsection{Voltage Polarity and Voltage Type}

Field experience has shown that more flashover occurs under negative than positive polarity for HVDC wall bushings. As shown in Table 1.1, over $70 \%$ of teported HVDC wall bushing flashovers have occurred under negative polarity. This is consistent with experimental investigations, which show that critical flashover voltage is lower with negative polarity.

In [ScHN91], PIU 500kV bushings flashovered in laboratory tests with (-ve) polarity at 390kV but withstood under positive polarity at $500 \mathrm{kV}$ under uneven wetting condition with rain conductivity of $50 \sim 70 \mu \mathrm{S} / \mathrm{cm}$. The results confirmed the PIU service experience at Sylmar station where flashovers have occurred only with negative polarity. 
To verify the influence of voltage type, uneven wetting flashover tests under both ac and dc voltages were conducted on a bushing. As shown in Fig.2.3, uneven wetting flashover voltage is comparatively lower under the dc voltage than under the ac voltage.

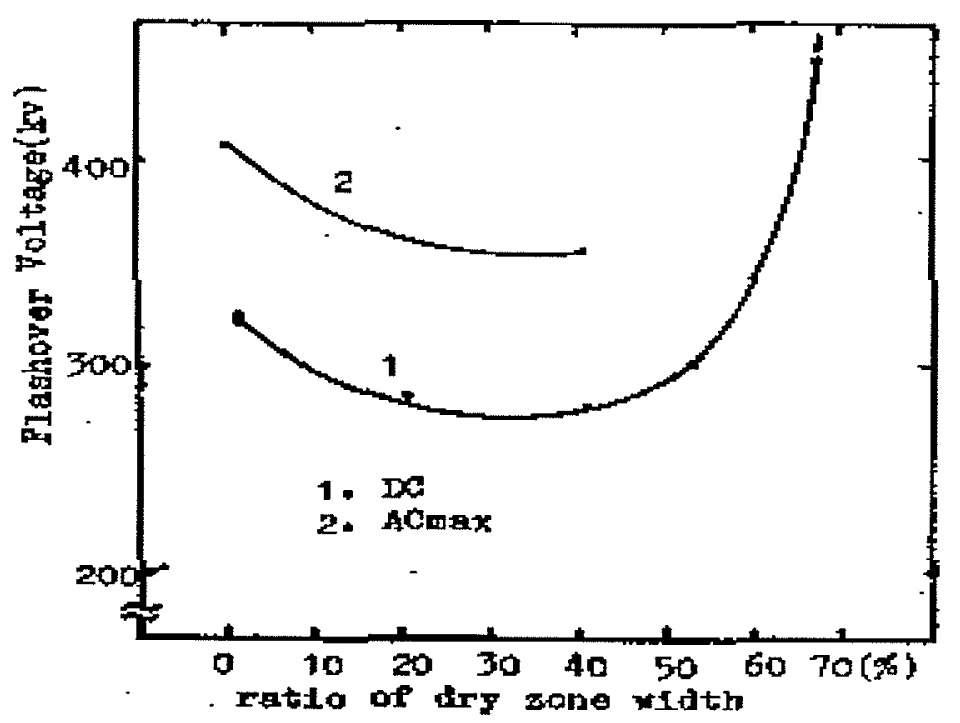

Fig. 2.3 Uneven wetting flashover voltage under the ac and (-ve) dc voltage [SuCL91]

\subsubsection{Mitigating Measures}

To improve the performance of HVDC wall bushings, the following mitigating measures have been used with different degrees of success.

- Hot-line washing or de-energized cleaning

- Periodic grease coating (both silicone and hydrocarbon)

- RTV silicone tubber coating

- Installation of polymeric booster sheds

Cleaning is helpful and has been widely used but often it fails to completely eliminate the problem. Silicone grease has been proven to be effective at some sites, although there are 
failures reported even with silicone grease coating. The biggest concern arising from the use of grease is carbonization due to local spark, which may further cause the puncture of porcelain housing. It is also costly and time-consuming process to regularly replace the grease in order to maintain the surface hydrophobicity.

Room temperature vulcanizing (RTV) silicone rubber was originally used to coat ceramic and glass insulators to enhance their electrical performance in wet and contaminated environments. The RTV coating provides water repellency (hydrophobicity), which prevents the formation of continuous water films on the surface and thus suppresses leakage current and flashover. The high resistance in surface layer of the coatings also diminishes the energy available for streamer discharge, since recharging of the stray capacitance takes a lot longer. Therefore, suppression of the flashover becomes possible. A $70 \%$ increase in the critical flashover voltage was observed in experimental investigation [SuSu96]. Ageing of RTV coating has been a source of concern, although the RTV coating have been generally effective in preventing wall bushing flashover. Loss of water repellence was identified as the cause of the flashovers of two RTV coated $400 \mathrm{kV}$ wall bushings at Sylmar [CEA95]. Laboratory experiments indicated the surface resistance with new RTV coating was about 1000 times that of the bare porcelain housing [ScLu91]. However, the surface resistance can be as low as 10 times that of the bare porcelain housing for a field aged RTV coating.

As another alternative, booster sheds can be used to improve the performance of a wall bushing. These supplementary plastic sheds may be added very easily to existing bushings and replaced quickly if necessary. They were originally designed to counter the effects of heavy wetting on large, near vertical, ac station posts and bushings by preventing the cascading of water shott-circuiting the gaps between sheds. On horizontal bushings, they probably intro- 
duce a series of relative "dry" zones to improve the voltage distribution. Also, booster sheds may serve as barriers to the propagation of a leader. It has been verified [Lamb89] that the presence of the booster sheds prevented flashover at operating voltage, while a $600 \mathrm{kV}$ wall bushing without booster sheds may suffer a flashover at $400 \mathrm{kV}$ under uneven wetting condition. However, there is still some reluctance in the industry to the use of booster sheds [Rash91]. The use of booster sheds has been very successful in eliminating wall-bushing flashovers in Manitoba Hydro since the middle 80's. The flashover voltages may be increased by $13 \sim 20 \%$ as reported in [SuSu96].

HVDC wall bushings with silicone rubber sheds have been available since late 1980 s. Manitoba Hydro has had a $500 \mathrm{kV}$ composite wall bushing in service for ten years with no flashovers and no need to clean it [McDe02].

It has also been reported [ScGG91] that vertical bushings were used to avoid the uneven wetting conditions. The bushings were washed using a permanently installed water spray system. The regular washing helped to minimize the potential contamination due to the proximity of the bushings to the sea.

\subsection{Existing Models for Uneven Wetting Flashover for Wall Bushings}

It is of practical interest to study the phenomena either by experiments or by modeling with the objective of improving the performance of wall bushings. In contrast to full-scale tests, which are very costly and time consuming, an appropriate model is an economical alternative to study the problem. There are two mathematical models available to describe the flashover of a HVDC wall bushing, both of which are based on the equivalent circuit concept. 


\subsubsection{EPRI Model [ScLu91]}

In 1991, H. M. Schneider and A. E. Lux suggested a simple model, which can be used to determine a criterion for the dry-zone flashover of HVDC wall bushings under non-uniform rain, based on their experimental observations. The model assumes that

- A wall bushing can be approximated by a horizontal cylindrical insulator of uniform diameter along its length as shown in Fig.2.4.

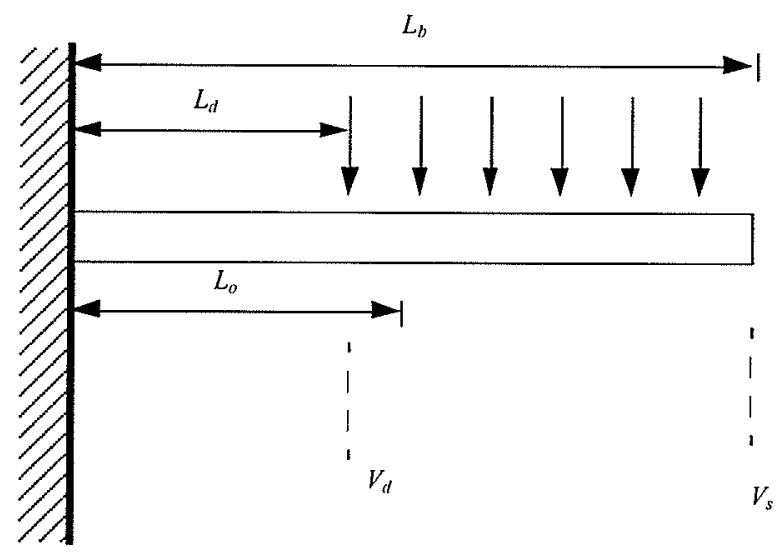

Fig. 2.4 Simplified wall bushing model [ScLu91]

$\mathrm{L}_{\mathrm{b}}$ is the physical length (strike distance) of a bushing;

$L_{0}$ is the initial length of the dry zone;

and $L_{d}$ denotes instantaneous length of the dry zone

- The 'wet' zone of the bushing is thoroughly wet with a resistance per unit length of $\mathrm{R}_{\mathrm{wo}}$.

- The 'dry' zone is initially dry with a resistance per unit length of $\mathrm{R}_{\mathrm{do}}$. The actual length of the 'dry' zone is a function of time and linearly decreases as the rain continues.

- When the voltage $V_{d}$ across the instantaneous 'dry' zone reaches the value of the breakdown voltage $V_{b d}$, breakdown of the 'dry' zone occurs. Consequently, an impulse essentially equal to the entire applied voltage appears across the remaining wet region. This impulse voltage is capable of propagating toward the high voltage electrode especially 
under negative polarity, which is positive streamer, and thus causes possible complete flashover of a whole bushing.

Based upon the above assumptions, conditions for flashover of the 'dry' zone are,

$$
\begin{aligned}
& \frac{R_{w o}}{R_{d o}}<\frac{V_{s}}{E_{o} L_{b}} \\
& L_{o}>\frac{\left(\frac{V_{s}}{E_{o}}-\frac{R_{w o} L_{d o}}{R_{d o}}\right)}{1-\frac{R_{w o}}{R_{d o}}}
\end{aligned}
$$

In other words, if the ratio of the resistance per unit length of the wet region to the resistance per unit length of the drier region is high enough, then flashover will not occur. On the other hand, a flashover will occur if the initial dry region length is less than a certain critical value. The relative values of resistance per unit length of the wet and dry region determine whether or not the dry zone flashovers.

Equations (2.1) and (2.2) yield necessary criteria for flashover of HVDC wall bushings under non-uniform rain. The above conditions are not sufficient to cause a complete bushing flashover, since the model only considers the breakdown of the dry region without considering the propagation mechanism of such a partial flashover.

The model successfully explains that either increasing wet surface resistance by a RTV coating or decreasing the dry surface resistance by a resistive glaze on the surface can improve the performance of the wall bushing significantly under critical uneven wetting conditions. 


\subsubsection{IREQ Model [RiKa91]}

In later 1991, Farouk. A. M. Rizk and Sherif I. Kamel proposed a more intricate model, which provides the necessary and sufficient conditions for flashover a HVDC wall bushing under uneven wetting conditions.

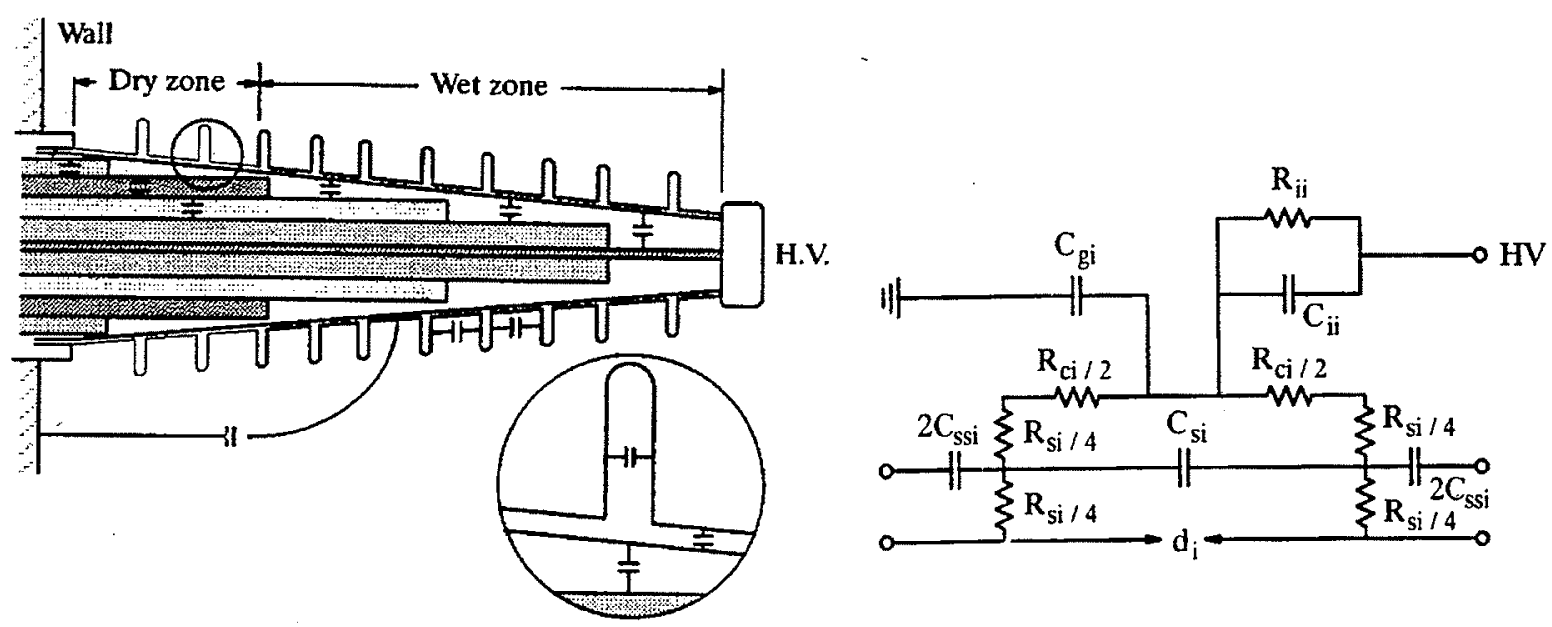

Rci: core and inter-shed surface resistance of section $i$

Rsi: the extreme shed surface resistance

Cgi: the stray capacitance of the section to ground

Cii: the capacitance to the HV conductor

Rii: tepresents the associated dielectric losses

Csi: the equivalent inter-shed capacitance

Cssi: the extreme shed self capacitance

di: accounts for the air gap length determined by the shortest distance in air between the tips of the extreme sheds of the section

Fig. 2.5 Schematic diagram of IREQ Model [RiKa91]

As shown in Fig.2.5, a wall bushing was modeled by a complex network of resistors, representing the surface layer, shunted by spark gaps corresponding to spacing between consecutive sheds, as well as capacitors accounting for the stray capacitance of the layer to ground (wall) and the internal bushing capacitance. It is suggested that flashover is initiated by 
streamer bridging of the dry zone which is enhanced by the non-uniform voltage distribution along a bushing. Any gaps within the dry zone will sparkover when the average applied voltage gradient, due to non-uniform voltage distribution, teaches the minimum streamer gradient $E_{\mathrm{s}}$, which for a rod-rod configuration, under dc voltage, amounts to approximately $5.4 \mathrm{kV} / \mathrm{cm}$. Due to energy stored in the bushing stray capacitance, fast voltage collapse across the dry zone leads to impulsive stressing of the wet part of a bushing. The non-uniform distribution of that impulse stress and the process of streamer bridging, fast voltage collapse as well as subsequent recharging of the bushing capacitors can lead to continued discharge propagation and flashover of the entire bushing.

In [RiKa91], the findings of the model have been compared with the results of field observations and experiments at IREQ. The model accounts for the following aspects of the flashover mechanism: critical dry zone length, polarity effect, specific leakage path, wet layer conductance per unit length as well as the dc system voltage.

\subsection{Summary}

The chapter reviews the literature dealing with HVDC wall bushing flashover. The finding of the literature review may be summarized as following:

1. An uneven wetting condition has been identified as the main cause of flashovers in HVDC wall bushing. This type of flashover is significantly different from typical HVDC insulator failure mode caused by contamination.

2. HVDC wall bushings are very susceptible to the external environment. Substantial E-field enhancement can be expected, which may lead to a flashover, once a dry zone is created. 
3. There is a U-shaped relationship between flashover voltage and dry zone length. A minimal flashover stress in the range of $60-75 \mathrm{kV} / \mathrm{m}$ is expected for the critical dry zone length of $10-30 \%$.

4. Impact of rain conductivity decreases with increase of rain conductivity. Uneven wetting flashover is the predominant mechanism until rain salinity corresponds to a water conductivity $1000 \mu \mathrm{S} / \mathrm{cm}$, when contamination flashover mechanism may start to take over.

5. The bushing type of configuration is most susceptible to the uneven wetting flashover. An increase in the creepage length will not have any significant improvement in performance under the uneven wetting.

6. Both effect of voltage polarity and the effect of voltage type have been observed. Over $70 \%$ of reported HVDC wall bushing flashovers occurred under negative polarity. The positive polarity strength is $30 \%$ higher than the negative polatity strength under nonuniform rain [ScHN91].

7. Mitigating measures such as cleaning, greasing, RTV coating, and booster sheds have been used to prevent the uneven wetting flashovers. Among those, RTV and booster sheds offer most effective prevention.

8. There are two mathematical models available to explain the phenomena of uneven wetting flashovers. Both are based on the equivalent circuit concept. The IREQ model is presented in [RiKa91] where it is shown to explain some results of experimental and field observations, such as critical dry zone length, polarity effect, specific length. 


\section{PHYSICS OF DISCHARGES AND NUMERICAL MODEL FOR UNEVEN WETTING FLASHOVER}

Knowledge of the physics of discharges in air is of paramount importance in order to explain, interpret and, to some extent, predict the dielectric behavior of external insulation based on physical considerations. In this chapter, a brief review of the physics of gaseous discharges is presented followed by a proposed description of fundamental processes involved in an uneven vetting caused HVDC wall bushing flashover. Mechanisms that are responsible for the initiation of a streamer, streamer propagation, as well as the sequence of discharges are discussed. Furthermore, a numerical model is proposed to predict the flashover voltage.

\section{1 dc Discharges in Air}

Two types of discharges exist, namely streamer discharge and leader discharge. The transition from a streamer to leader depends upon the availability of the energy stored in the gap and current through the gap. However under dc voltage, leader propagation is not favoured [Thio79]. Soon after its formation the leader stops, the channel is cooled the potential of the leader tip decreases and the discharge is extinguished. Therefore, a dc flashover is essentially governed by streamer discharges.

There are two theories, namely the Townsend and Streamer criteria, available to account for discharge inception. While the Townsend criterion relates discharge inception to the selfsustaining ability of the primary avalanche, the Streamer criterion links the discharge inception to the transition of the primary avalanche to a secondary avalanche. 
However, for non-uniform field gaps, the inception of discharges is a necessary but not sufficient condition for flashover. To flashover a gap, the electric field along a gap is required to be sufficiently high to sustain the propagation of discharges.

Practically, the streamer can be represented by a slightly conductive channel with a longitudinal gradient of $4.55 \mathrm{kV} / \mathrm{cm}$ [AlGh93] for + ve streamers and $11.5 \mathrm{kV} / \mathrm{cm}$ [Thio79] for -ve streamers. They are the critical gradients required for streamer propagation. Table 3.1 lists the measured electric gradients for streamer propagation in air by several researchers. Streamer propagation is also dependent upon the availability of photoelectrons in front of it. The critical value for electric field is about $600 \mathrm{~V} / \mathrm{cm}$ [NaSh69]; above this level the external field is strong enough to overcome random thermal motion, and photoelectrons are able to drift into the high field region around the space charge. When the space charge energy is insufficient to propagate into the low field region or the drift velocity of electrons due to the external field does not significantly exceed the thermal velocity, a streamer will terminate.

Table 3.1 Streamer Propagating Gradients at RAD = 1[AlGh93]

\begin{tabular}{|c|c|c|c|}
\hline Researcher & Stress (kV/m) & $\begin{array}{c}\text { Gap Type and } \\
\text { Length (cm) }\end{array}$ & Humidity $\left(\mathbf{g} / \mathbf{m}^{3}\right)$ \\
\hline Phelps \& Griffiths & 451 & Parallel Plane & 9 \\
\hline Allen \& Boutlendi (a) & 487 & Parallel Plane & 0 \\
(b) & 590 & 66 & 11 \\
\hline Geldenhuys & 464 & Rod Plane 50 & 11 \\
\hline Allen \& Dring & 414 & Rod Plane 60 & 11 \\
\hline \multirow{2}{*}{ Aalen \& Ghaffar } & 375 & Parallel Plane & 11 \\
& 422 & 15 & 0 \\
\hline
\end{tabular}


The equivalent mean velocity of streamer advancement is of the order of several tens of $\mathrm{cm} / \mu \mathrm{s}$. Once streamers reach the opposite electrode, the final jump will be initiated. At that moment, electrons are emitted from the electrode, the current and the propagating velocity of discharges increase exponentially, and as a result the channel becomes totally ionised and voltage inside the channel collapses.

\subsection{HVDC Wall Bushing Flashover under Uneven Wetting Conditions}

In general, a wet surface resulting from rain can significantly lower the surface strength of an insulator. For a dc insulator under uniform rain, the flashover stress shows a large scatter and varies between $170 \sim 400 \mathrm{kV} / \mathrm{m}$. A flashover stress of $200 \mathrm{kV} / \mathrm{m}$ was obtained for a dc station

post insulator in both uniform and non-uniform rain under both polarities [WuHÅ95]. Furthermore, both field and experiment results show that flashover stresses as low as $60 \sim 70 \mathrm{kV} / \mathrm{m}$ can be expected for unevenly wetted wall bushings, which implies that additional mechanisms are inrolved in HVDC wall bushing flashovers.

The mechanisms and peculiarities of the phenomena will be discussed in this section in details.

\subsubsection{Wetting Process}

During the process of wetting, a water drop is initially dropped on to an insulating surface as shown in Fig. 3.1. The contact angle and surface tension are related by the Young's Equation,

$$
\sigma_{i}=\sigma_{w}+\sigma_{a} \cdot \cos \theta
$$

Where $\theta$ is the static contact angle and $\sigma_{\mathrm{i}}, \sigma_{\mathrm{w}}, \sigma_{\mathrm{a}}$ are the surface tensions of insulator, water and air respectively. The contact angle is customarily measured through the liquid. The larger the angle, the greater the hydrophobicity. For hydrophilic surfaces such as porcelain, the 
contact angle is normally less than $90^{\circ}$, while for a hydrophobic surface such as composite material the contact angle is larger than $90^{\circ}$. Under rain, continuous highly conductive water layers normally $0.1 \sim 0.3 \mathrm{~mm}$ thick may be expected to form on a porcelain surface [Lamp88]. On the other hand, for a RTV coated porcelain surface or other composite material, continuous rain only increases the density of water drops on the surface without leading to the formation of a continuous water film. Hence, rain results in the formation of a layer of low conductivity; the layer may be covered by movable conductive droplets.

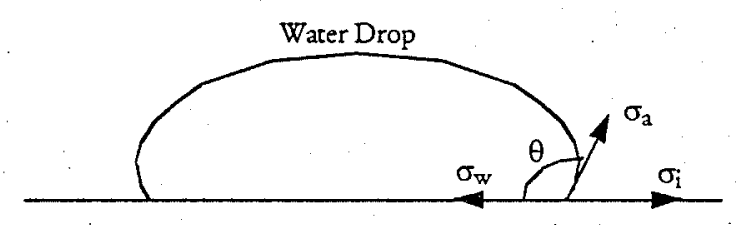

Fig. 3.1 Surface tensions and contact angle for water drop on a dielectric surface

The resistance of one section of a full scale $(500 \mathrm{kV})$ wall bushing under rain with conductivity of $90 \mu \mathrm{S} / \mathrm{cm}$, was found to be about $1000 \mathrm{M} \Omega$, initially, and then decayed to $10 \mathrm{M} \Omega$ [ScLu91]. The surface resistivity of wetted porcelain, can therefore be estimated by the following formula,

$$
\rho_{s}=R \cdot \frac{\pi D}{L}
$$

Where $R$ is the measured surface resistance, $D$ is the diameter of the insulator and $L$ is the creepage length. In this case, $D$ is $73.5 \mathrm{~cm}$ and $\mathrm{L}$ is $640 \mathrm{~cm}$. Thus the surface resistivity is about $4 \times 10^{8} \Omega$ for a dry porcelain surface and about $4 \times 10^{6} \Omega$ for a wetted surface. For wetted 
porcelain with RTV coating, the surface resistivity may be of the order of $10^{7} \Omega$. If it is assumed that the conductance is mainly due to the presence of an electrolytic film on the surface, the surface resistivity and volume conductivity of rain are related by

$$
\rho_{s}=\frac{k_{1}}{\gamma \cdot d}
$$

Where $\gamma$ is the volume conductivity of rain, $d$ the thickness of the water film $(0.01 \sim 0.03 \mathrm{~cm})$, and $\mathrm{k}_{1}$ is a quantity accounting for both surface condition and pre-deposit contaminant level. , In this case, $\mathrm{k}_{1}$ is 3.6 , since $\gamma$ is $90 \mu \mathrm{S} / \mathrm{cm}$ and $\mathrm{d}$ is $0.01 \mathrm{~cm}$.

\subsubsection{Influence of Uneven Wetting Pattern on E-field Distribution}

Due to the shielding effect of a wall on a horizontally mounted HVDC wall bushing, an uneven wetting pattern is created, particularly when rain is accompanied by wind having the direction shown in Fig.3.2 [Forr88], [McDe88]. The existence of an uneven wetting pattern has been confirmed by field investigations. The wetting pattern is strongly influenced by wind direction, rain intensity, and also the time duration of rain. The rain intensity at the $\mathrm{HV}$ and ground ends may differ by a factor of $10-100$, which could lead to a much more significant difference in surface conductance.

Hence, an uneven wetting pattern can substantially change the potential distribution and electric fields. With a critical length of dry zone, both internal and external electric fields could be several times higher than those under dry conditions [TaRa95] and therefore render a favourable condition to initiate and sustain discharges. 


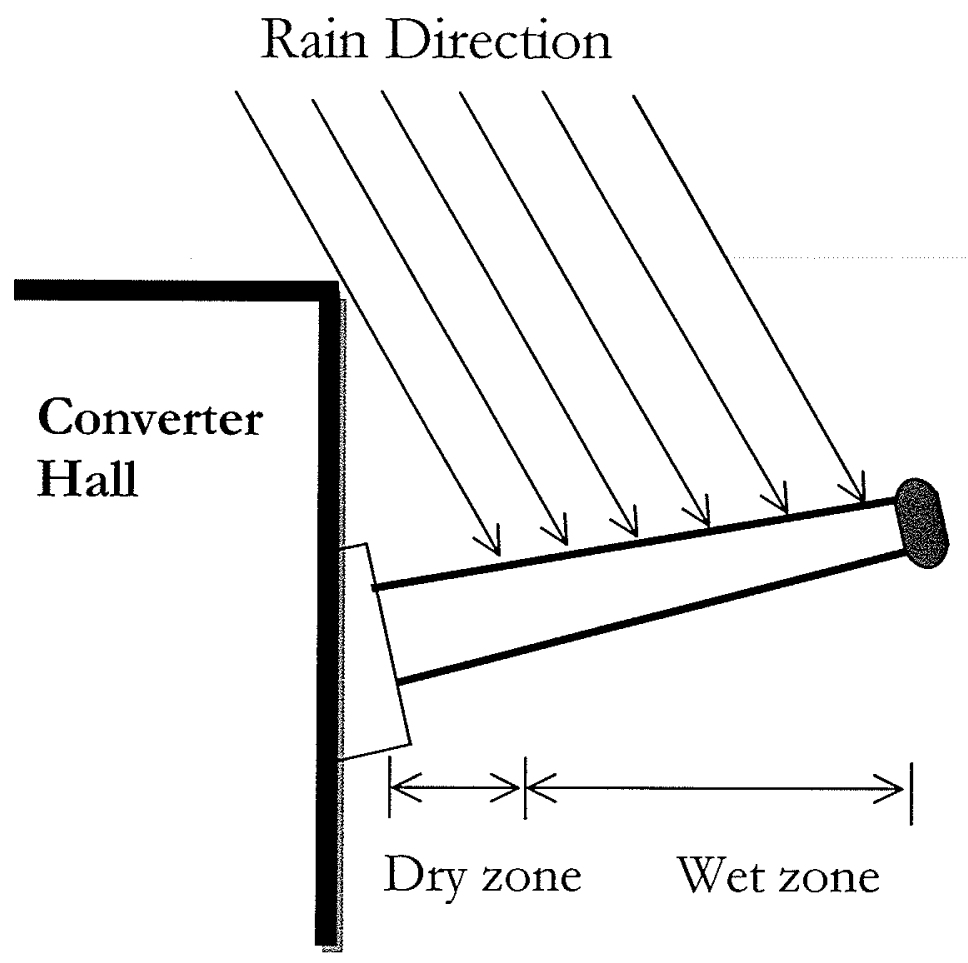

Fig. 3.2 Shielding effect of hall wall under rain with wind

The influence of an uneven wetting pattern on the dc electric field distribution is investigated [TaRa95] with a $110 \mathrm{kV}$ dc bushing model shown in Fig.3.3 and Table 3.2. In the computation model, actual profile of bushing sheds has been taken into consideration. The edge of the condenser core is treated as known boundary with a linear potential distribution. The E-field distributions are calculated using the ANSYS program with 8000 elements and over 10000 nodes. The results in Fig. 3.4-3.7 were obtained with the dry zone located at the ground end. Fig.3.4 shows E-field contours of bushing models with different lengths of dry zones. The normalized E-fields at shed tips and those in air close to the bushing surface are shown in Figs.3.5 and 3.6 respectively. Fig. 3.7 shows the influence of the length of the dry zone on the electric field. 


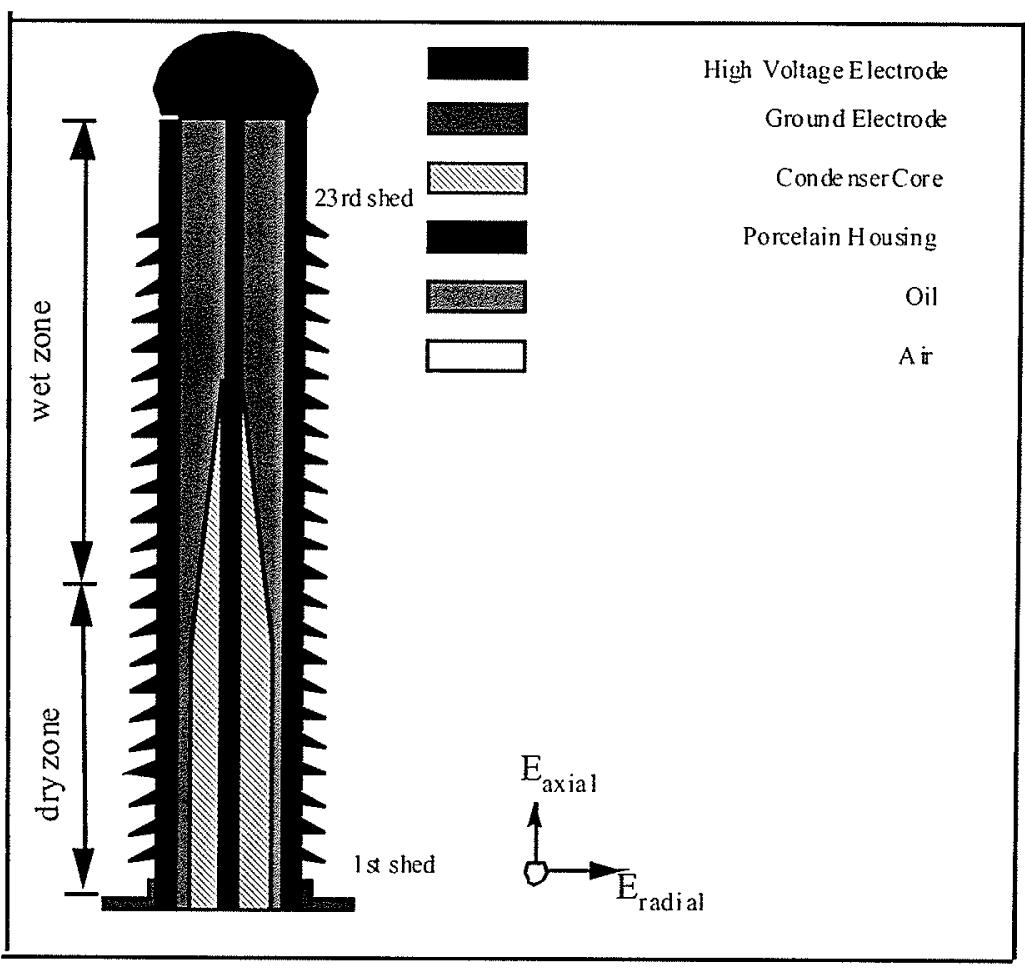

Fig. 3.3 E-freld computation model for a $11 \mathrm{kV}$ wall bushing

Table 3.2 Key Dimensions of the $110 \mathrm{kV}$ Bushing Model

\begin{tabular}{|c|c|}
\hline Number of Shed Pairs & 22 \\
\hline Shed Overhand/spacing & $45 / 50 \mathrm{~mm}$ \\
\hline Inner Diameter of the Porcelain Housing & $200 \mathrm{~mm}$ \\
\hline Outer Diameter of the Porcelain Housing & $260 \mathrm{~mm}$ \\
\hline
\end{tabular}




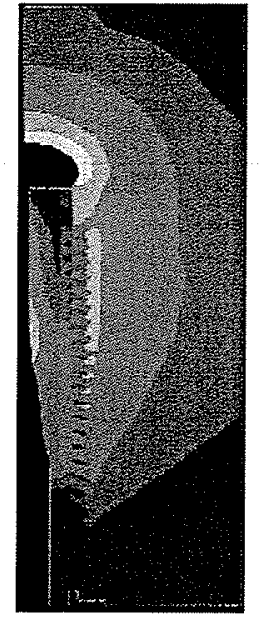

(a) dry bushing

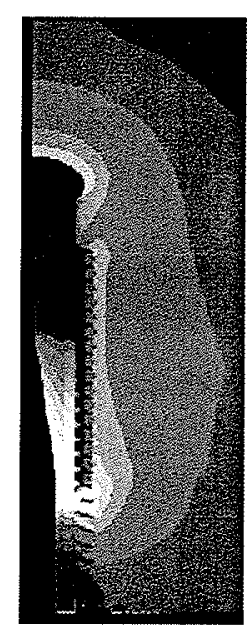

(c) $30 \%$ dry zone
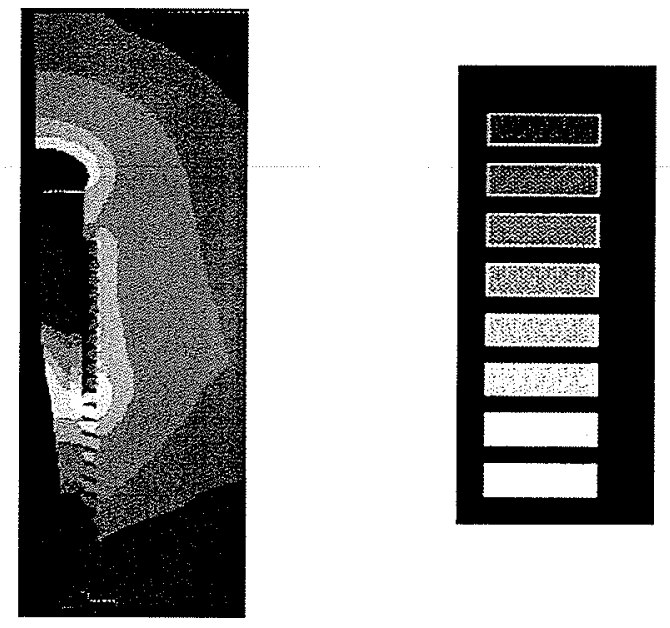

2E-05

0.005

0.010

0.025

0.040

0.060

0.080

0.100

1.000 (b) $50 \%$ dry zone

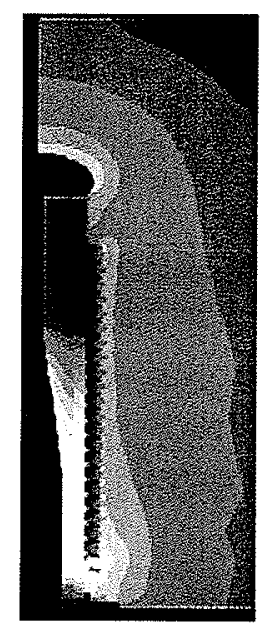

(d) $10 \%$ dry zone

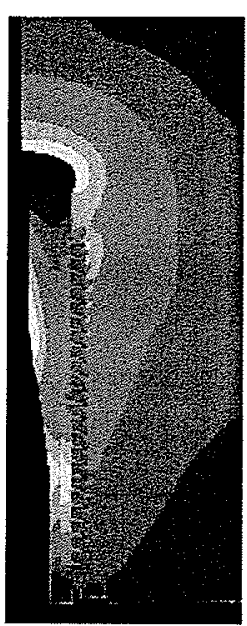

(e) wet bushing

Fig. 3.4 Impact of dry zone length on E-field contours [TaRa95] 


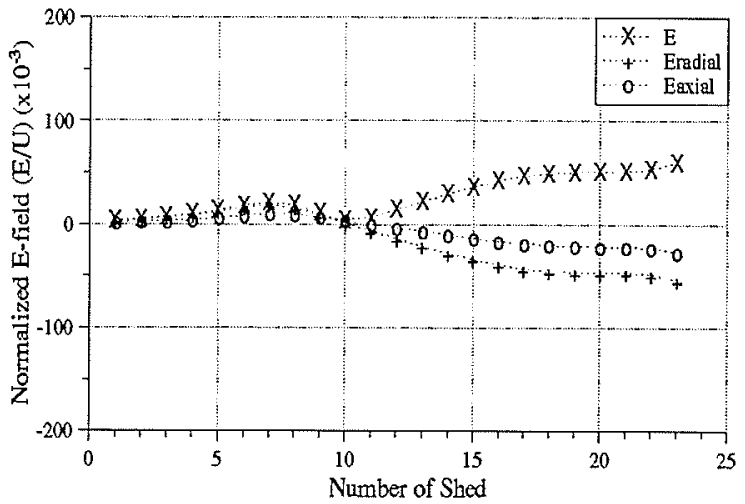

(a) Completely dry surface

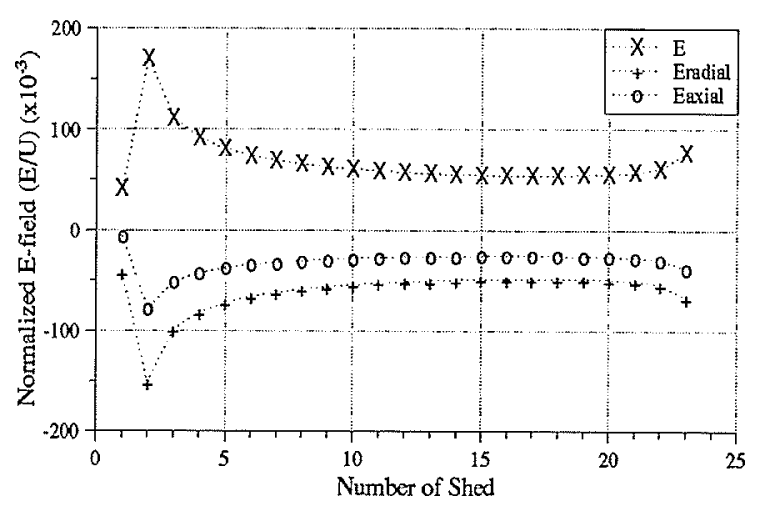

(c) $10 \%$ lengtb of dry zone

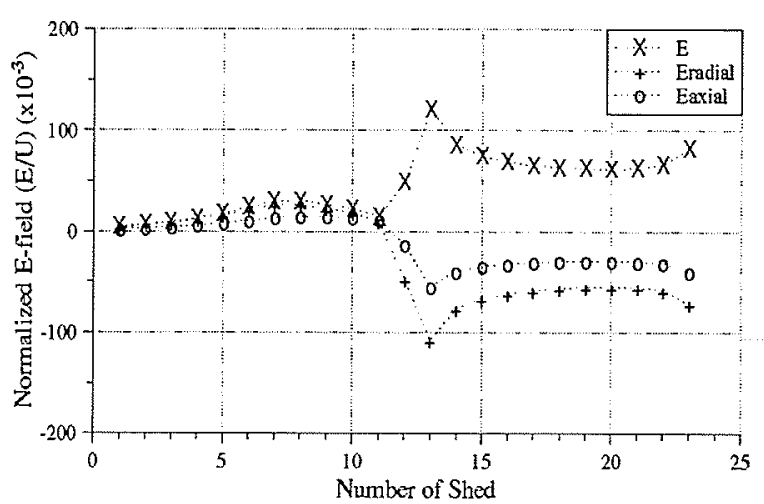

(b) $50 \%$ length of dry zone

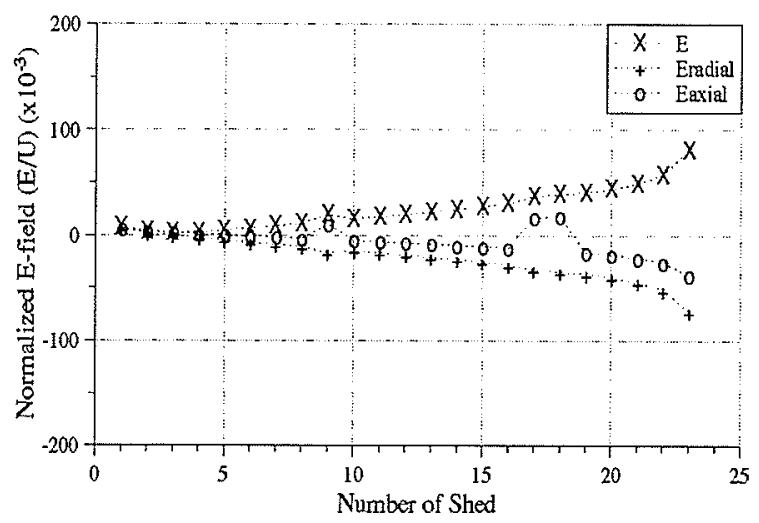

(d) Completely wet surface

Fig. 3.5 E-field intensity at shed tips under -ve unit voltage [TaRa95]

(Sheds are numbered from the ground end) 


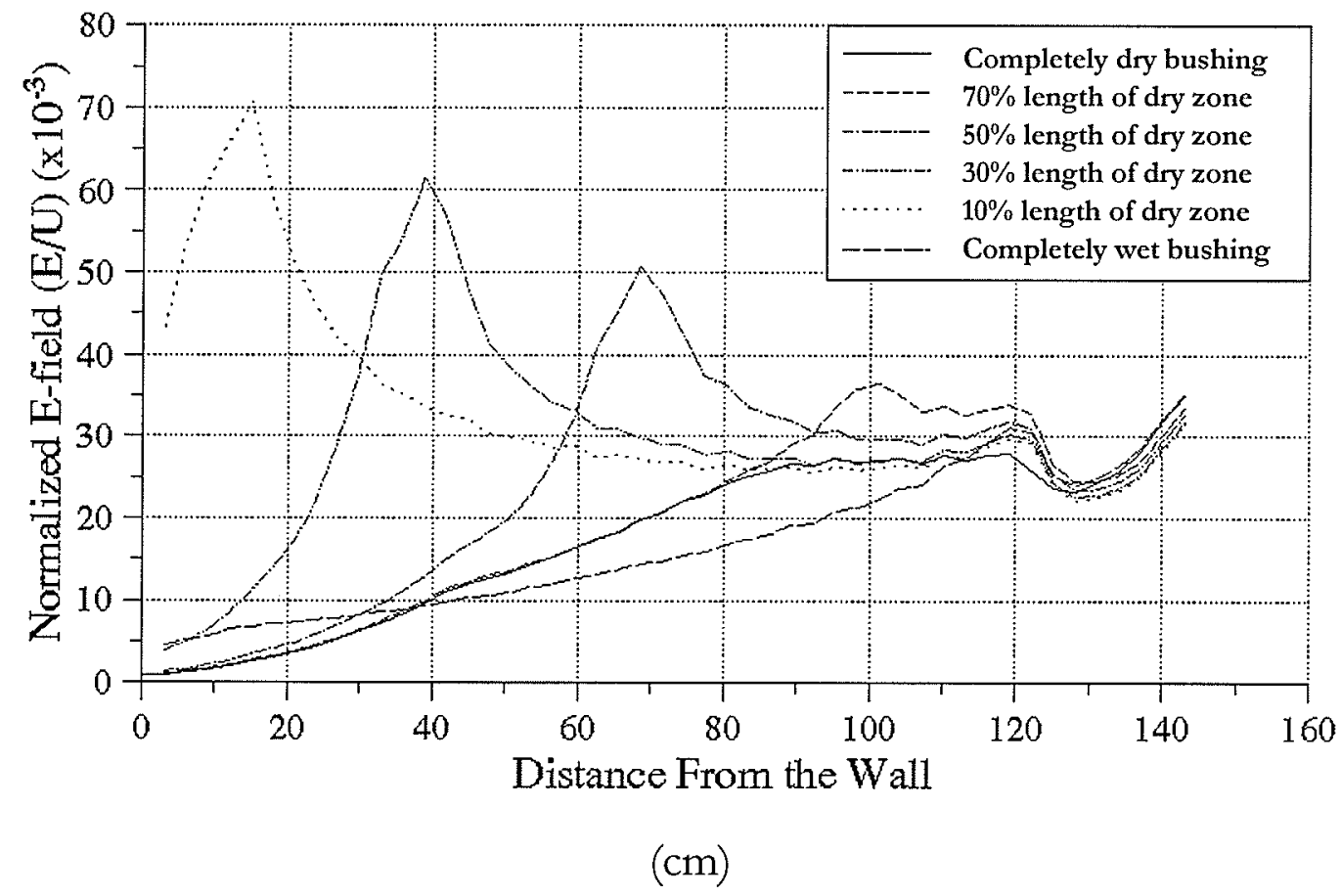

Fig. 3.6 E-field intensity in the air close to the bushing surface [TaRa95] (along a line $2.5 \mathrm{~cm}$ from shed tips) 


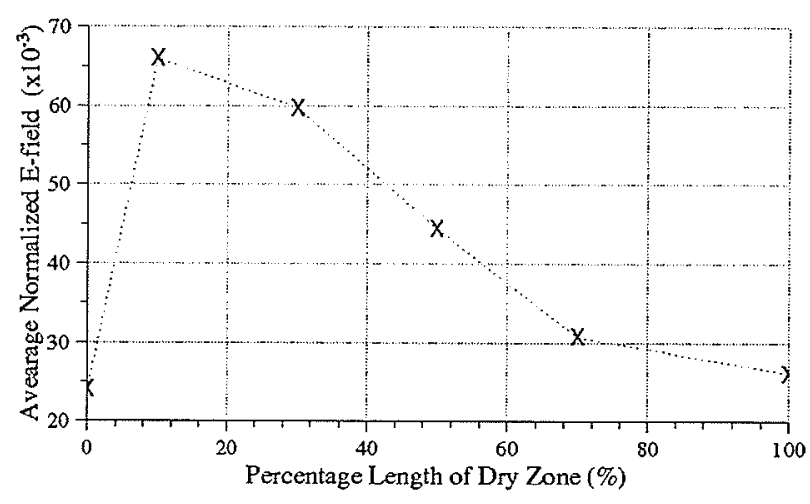

(a) Eav at sbed tips

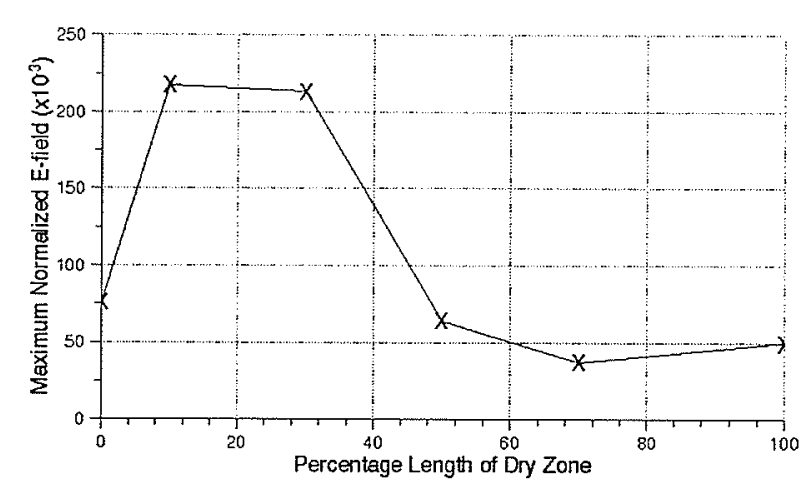

(c) Emax in oil

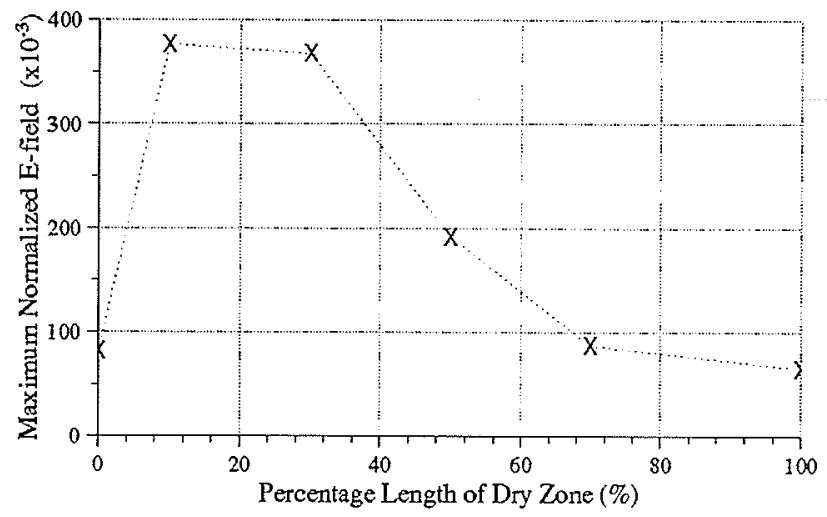

(b) Emax on external surface

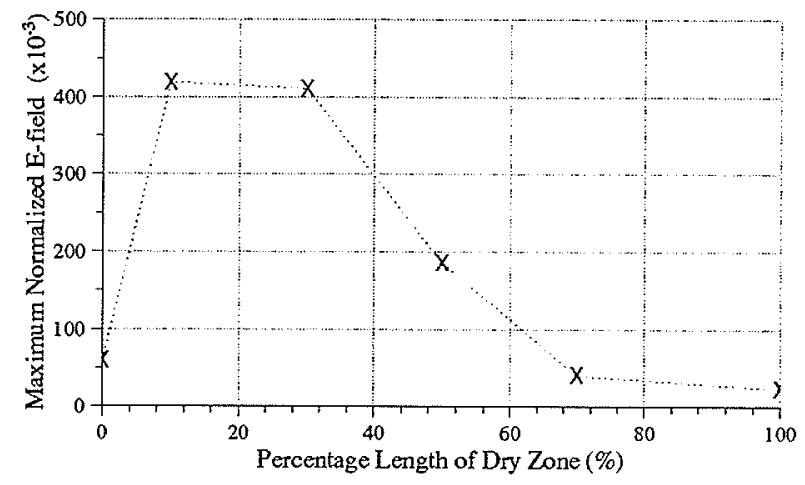

(d) Emax in porcelain bousing

Fig. 3.7 Influence of the dry zone length on E-field intensity [TaRa95] 
For a dry bushing, the highest electric field region is around the top cap of the bushing, while the electric field along the external surface, such as electric field at shed tips or in air close to the bushing surface are relatively low. Therefore, the chance of external flashover for a dry bushing is low, although corona may occur at the bushing top.

As the dry zone length decreases, it is noticed that both the internal and external electric fields increase significantly, especially when the dry zone length is $30 \%$ or less. The location of the maximum electric field in oil shifts from the final HV-end foil of the condenser core to the oil gap between the earth-end foil of the condenser core and porcelain housing, while the maximum electric fields in porcelain and on the external surface move to the region near the first dry shed which is closest to the wet zone. Evidently, the E-field distribution of a dc wall bushing is very sensitive to external surface condition. With a length of $10 \%$ dry zone, the maximum value of E-field in oil is as high as $4 \sim 5$ times that of a dry bushing and the maximum value of E-field in porcelain is 10 times that of a dry bushing. However, since the electric strength in air is comparatively low, the effect of drastically increased E-fields along the external surface is more predominant. Relatively high electric field regions near the bushing surface are observed which cover more of the bushing surface as the dry zone length decreases as shown in Fig.3.4. An external flashover can be triggered if the local E-field is sufficiently high and the high field region is large enough to sustain streamer growth and form a spark. Therefore, uneven wetting can cause extremely severe operating conditions for external and internal insulation. External flashover, tadial puncture of the porcelain housing and discharges in the oil can occur even at operating voltage. External flashover, presence of acetylene dissolved in oil up to the level of 200 700 $\mathrm{ppm}$ and erosion of the inner surface of porcelain housing have been reported [RaMc89-2]. 
Interestingly, the external electric field improves dramatically with decrease of the dry zone length to zero (i.e. a completely wetted bushing). The reason is that the completely wetted external surface provides a relatively uniform voltage distribution along the bushing surface, thus linearizing the external E-field distribution, however at the expense of increasing the internal electric field.

The impact of uneven wetting pattern on E-field distribution can be summarized as following.

1. Uneven wetting can cause a redistribution of the electric field in both internal and external insulation. With the dry zone length in a critical range, insulation integrity can be compromised significantly in both internal and external insulation.

2. External coatings, especially RTV coatings, result in some improvement in the electric field distribution. Therefore, the performance of a coated bushing is superior to that of an uncoated one.

3. The configuration of a wall bushing has an influence on both the internal and external electric field distributions; hollow shells exhibit relative low electric field, while a complete bushing has relative high electric field and high radial component of electric field.

4. To understand the mechanism of flashover initiation, E-field simulation prior to flashover is essential and important.

\subsubsection{Role of Raindrops in the Flashover Process}

When a water drop is present in an ambient electric field, interaction occurs between the electric field and the drop. A drop will be polarized, and then in turn the bound charges due to the polarization will distort the nearby electric field. For a spherical raindrop with radius of a, Fig. 3.8, the ambient electric field $\mathrm{E}_{\mathrm{o}}$ is distorted and becomes [Xieg62], 


$$
\begin{aligned}
& E_{r}=\left[1+\frac{2 a^{3}}{r^{3}} \cdot\left(\frac{\varepsilon_{2}-\varepsilon_{1}}{\varepsilon_{2}+2 \varepsilon_{1}}\right)\right] E_{o} \cdot \cos \theta \\
& E_{\theta}=\left[1-\frac{a^{3}}{r^{3}} \cdot\left(\frac{\varepsilon_{2}-\varepsilon_{1}}{\varepsilon_{2}+2 \varepsilon_{1}}\right)\right] E_{o} \cdot \sin \theta
\end{aligned}
$$

Which, in turn, yields the maximum electric field near the raindrop,

$$
E_{\max }=\left[1+\frac{2 a^{3}}{a^{3}} \cdot\left(\frac{81-1}{81+2}\right)\right] E_{o} \approx 3 \cdot E_{o}
$$

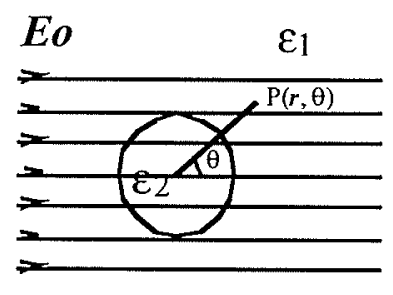

(a) Ambient electric field

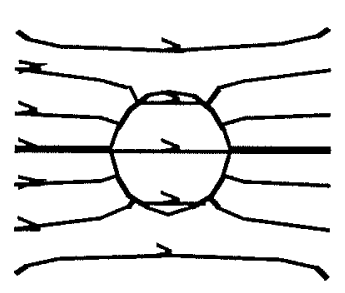

(b) Resultant electric fiela

Fig. 3.8 Electric field distortion due to the presence of a water drop

Therefore, the local electric fields close to water drops are significantly enhanced. Considering the elongating effect of water drops, further increase of the local electric field may be expected.

Due to the interaction between the electric field and water drops, following additional dominating mechanisms are responsible for the initiation of discharges.

\section{Discharges Due to the Disintegration of Raindrop}

When raindrops fall into high electric field regions, they get polarized, and elongate in the direction of electric field. If the electric field is sufficiently divergent, they will experience a force directed towards the region of highest field. 
The total potential energy, $W_{\text {total }}$, of a raindrop mainly consists of the surface tension energy, $\mathrm{W}_{\mathrm{s}}$, and the electrostatic potential energy, $\mathrm{W}_{\mathrm{c}}$.

$$
\begin{aligned}
& W_{s}=s \cdot \sigma \approx 4 \pi \sigma r^{2} \\
& W_{e}=\frac{1}{2}\left(\varepsilon-\varepsilon_{I}\right) \int_{v}\left(E_{I} E_{o}\right) d V \approx-\frac{2}{3} \pi \cdot\left(\varepsilon-\varepsilon_{I}\right) \varepsilon_{I} E_{o}^{2} r^{3} \\
& W_{\text {total }}=W_{s}+W_{e}=f\left(\varepsilon, \sigma, E_{o}, r\right)
\end{aligned}
$$

where: $W_{s}, W_{c}$, and $W_{\text {total }}$ are energies for surface tension, electrostatic potential and the total potential;

$S$ is the surface area, roughly equals to $4 \pi r^{2}$, while $r$ is the radius of a raindrop; $\sigma$ is the surface tension (for water in air: $\sigma=0.0728 \mathrm{~N} / \mathrm{m}$ );

$\varepsilon$ and $\varepsilon_{\mathrm{I}}$ are permittivity of air and a raindrop respectively, in $\mathrm{F} / \mathrm{m}$;

$E_{1}$ and $E_{o}$ are the electric fields inside a raindrop and the ambient electric field respectively;

$\mathrm{v}$ is the volume of a raindrop.

During the process of raindrop deformation, the electrostatic force causes the elongation of a drop, while the surface tension prevents its elongation and tries to keep the surface area as small as possible. As a result, it is expected that there is a local minimal point for the total potential energy, at which the equilibrium condition is no longer satisfied and the electrostatic force becomes greater than the surface tension of a drop and leads to instability of a raindrop. Namely, a water drop starts to be mechanically unstable and ejects water flaments from its tips or coalesces with other drops. 
The elongation of a water drop increases exponentially with the electric field. The degree of elongation and the point of instability are dependent on the drop size and the electric field. The critical ambient electric field, which causes the disintegration of a water drop, in free space as well as on a hydrophobic surface, can be found at the local minimal of total potential energy. Hence,

$$
\left.\frac{d W_{\text {total }}}{d E_{0}}\right|_{E o=E c r}=0
$$

Which, together with equations (3.6)-(3.8), yield following formula.

$$
E_{c r}=C \cdot \sqrt{\frac{\sigma}{r \cdot \varepsilon}}
$$

Where C can be derived either experimentally or theoretically, and is usually in the range of 0.4-0.5 [Tayl64], [Sher88]]. At a critical electric field value the drop becomes unstable and small droplets are ejected from the drop tip. As shown in Fig.3.9, it is expected that a raindrop with $1 \mathrm{~mm}$ tadius will be disintegrated under an electric field of $14.3 \mathrm{kV} / \mathrm{cm}$, while a field of $10.1 \mathrm{kV} / \mathrm{cm}$ is required to cause disintegration of a raindrop with $2 \mathrm{~mm}$ radius and only about $5.1 \mathrm{kV} / \mathrm{cm}$ for a $8 \mathrm{~mm}$ drop. However, further increase in the size of raindrops does not necessarily result in a significantly decrease in the critical electric field value which causes its disintegration. 


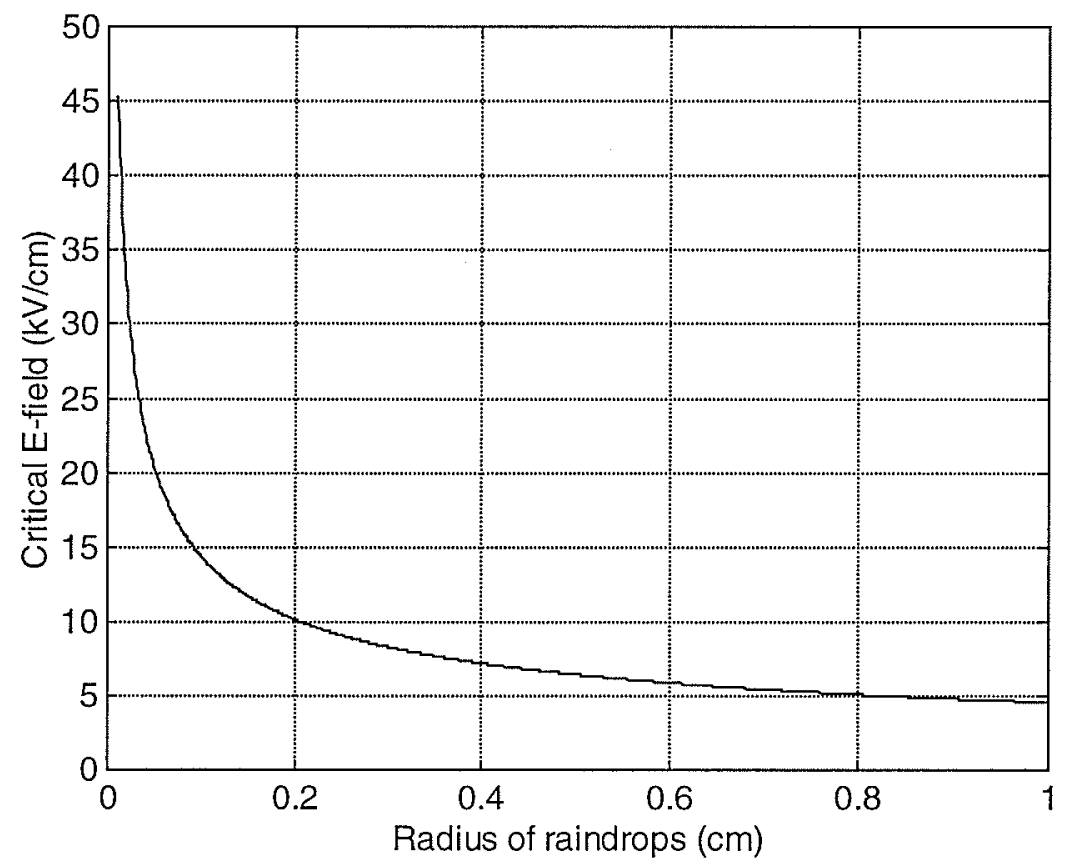

Fig. 3.9 Critical E-field for the disintegration of a raindrops (as per Eqn. 3.10 with $C=0.5$ )

For charged drops, Eqn (3.10) can be modified to

$$
E_{c r}=C \cdot\left(1-\frac{Q}{Q_{R}}\right) \sqrt{\frac{\sigma}{r \cdot \varepsilon}}
$$

Where $Q$ is the charge on a drop, and $Q_{R}$ is the Rayleigh charge limit, which is the maximum charge on a water drop without becoming unstable [Rayl82]. 


$$
Q_{R}=8 \pi \sqrt{\sigma \varepsilon \cdot r^{3}}
$$

The naturally accumulated charge on most raindrops is of the order of $10^{-12} \mathrm{C}$ [Chal57], which normally has a negligible influence on values of $E_{\mathrm{cr}}$. However, there are a few drops with charges up to $10^{-10} \mathrm{C}$, which could lead to a $15 \%$ reduction of $\mathrm{E}_{\mathrm{cr}}$ for a drop with diameter of $2 \mathrm{~mm}$. Moreover, consideration of the charging process as a raindrop approaches an energized insulator, may result in a further reduction of the $\mathrm{E}_{\mathrm{cr}}$.

The disintegration of water drops may result in the onset of a streamer due to the ejected fine droplets causing a sudden increase in electric field nearby, thus triggering discharges along the surface. By considering the behavior of a single water drop on an insulating surface in a dc field, it has been reported [WiSL93], [SuSN95] that such unstable conditions can induce flashover at voltages lower than that obtained under dry conditions.

For HVDC wall bushing uneven wetting flashover, the above instability criterion is a one of the most important mechanisms for initiation of discharges. As indicated in [LaWJ91], the first detectable discharges took place on large drops leaving the low part of larger sheds, when a $600 \mathrm{kV}$ wall bushing was under the uneven wetting tests.

\section{Corona Discharges in the Vicinity of Raindrops}

According to Eqn (3.5), the electric stress in the vicinity of water drops can be as high as 3 times the ambient electric field. Such an enhancement can cause a significant increase in the ionization of air surrounding the raindrops, thus leading to the initiation of corona discharges. Previous studies [Eng148] have revealed that corona onset is dependent on the radius of the raindrop, air pressure, temperature and relatively humidity. With a sufficient reduction in air pressure this mechanism could become dominant in the initiation of discharges. 


\section{Other Factors}

Water drops on a hydrophobic surface may move under the influence of electric field. Hence, the motion of a fine filament of water could trigger sparks.

Other process such as photo emission, field emission, release of charged ions and charge neutralization due to recombination of ambient ions of opposite sign may result in a charged drop losing its charge to the surrounding air, and thus may also contribute to initiation of discharges. Relatively high ionization and attachment coefficients are also expected compared with dry conditions.

\subsubsection{Propagation of Discharges in Uneven Wetting Caused Flashover}

The propagation of a streamer is mainly determined by the local electric field, a resultant field due to the external dc field and space charges. However, in the case of an unevenly wetted bushing, the presence of a wetted surface causes some peculiarities. As shown in Fig. 3.10(a) for a -ve HVDC wall bushing, +ve streamer growth originates from the ground end and heads towards the HV end; while under +ve polarity voltage, Fig. $3.10(\mathrm{~b})$, the polarity of such a streamer is -ve. Besides the large difference between the propagating properties of +ve and -ve streamers, the following peculiarities also have an influence. For a HVDC wall bushing under -ve polarity, the head of the secondary avalanche experiences forces which tend to repel it from the bushing surface and attract it to the propagating streamer and finally to the ground electrode, hence in favor of advancement of streamer and surmount the blocking effect of sheds. Also, electrons emitted from a wetted surface render a favorable condition for the formation of secondary avalanche. Thus the electric field for streamer propagation is lower. Under +ve polarity, the propagating streamer is a negative streamer. The electrons of the secondary avalanche are attracted by the surface and repelled by the streamer. In addition, the 
wetted surface behaves like a sink for electrons. As a result the -ve streamer is easier to be contained, and terminated, which in turn leads to a higher flashover voltage for HVDC wall bushing under tre polarity.

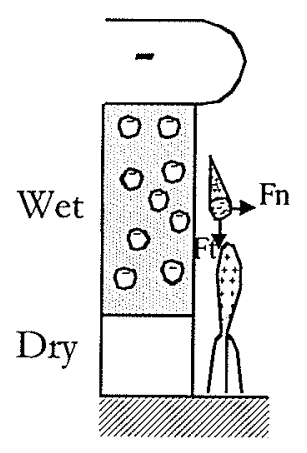

(a) -ve polarity

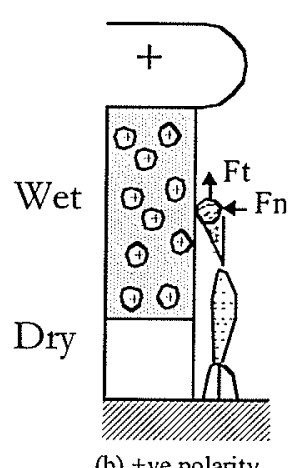

(b) +ve polarity

Fig. 3.10 Discharge propagation with different polarity

\subsubsection{Discharge Propagation on an Electrolytic Surface}

The presence of an electrolytic layer on the surface of a wall bushing can cause considerable amount of conductive current, thus leading to flashover. As long as the discharges can draw sufficient energy from this conductive current, it is expected that discharges will sustain, advance, and eventually spark over a gap.

A schematic illustration of a representative model is shown in Fig. 3.11. The representative equations are given as following, 


$$
V_{s}=V_{d}+V_{r}
$$

Where: $V_{s}$ is the source voltage;

$\mathrm{V}_{\mathrm{d}}$ is the potential across the discharge;

$\mathrm{V}_{\mathrm{r}}$ is the voltage drop across the remaining electrolytic surface;

$$
V_{d}=A \cdot I^{-n} x
$$

Where: I is the arc current;

$\mathrm{x}$ is the length of a propagating discharge;

$A, n$ are the characteristic constant of discharge, (for $\mathrm{dc} A=138, \mathrm{n}=-0.69$ [GuZh90])

$$
V_{r}=R I=\rho \cdot \frac{(L-x)}{\pi D}
$$

Where: $L$ is the total length of the electrolytic surface;

$\mathrm{R}$ is the surface resistance on the electrolytic surface;

$\mathrm{D}$ is the diameter of a bushing;

$\rho_{\mathrm{s}}$ is the surface resistivity of the electrolytic surface.

As shown in Fig. 3.11 (obtained from equations 3.13 to 3.15), when dashed line (actual voltage across discharges) and solid line (voltage to sustain dischatge) intersect, discharges are able to draw a sufficient current, thus can sustain and propagate. However, with progress of discharge, there is a critical point at which the discharges may be extinguished when the length of discharges exceeds $x_{c}$, since the current is no longer sufficient to sustain the discharge as required in Eqn. 3.14. Hence the propagation of discharges will be terminated. For a given configuration, surface resistivity and source voltage, the maximum propagating distance is $x_{c}$ 
and can be estimated. It is also possible to determine the minimum source voltage for sparkover for a given configuration.
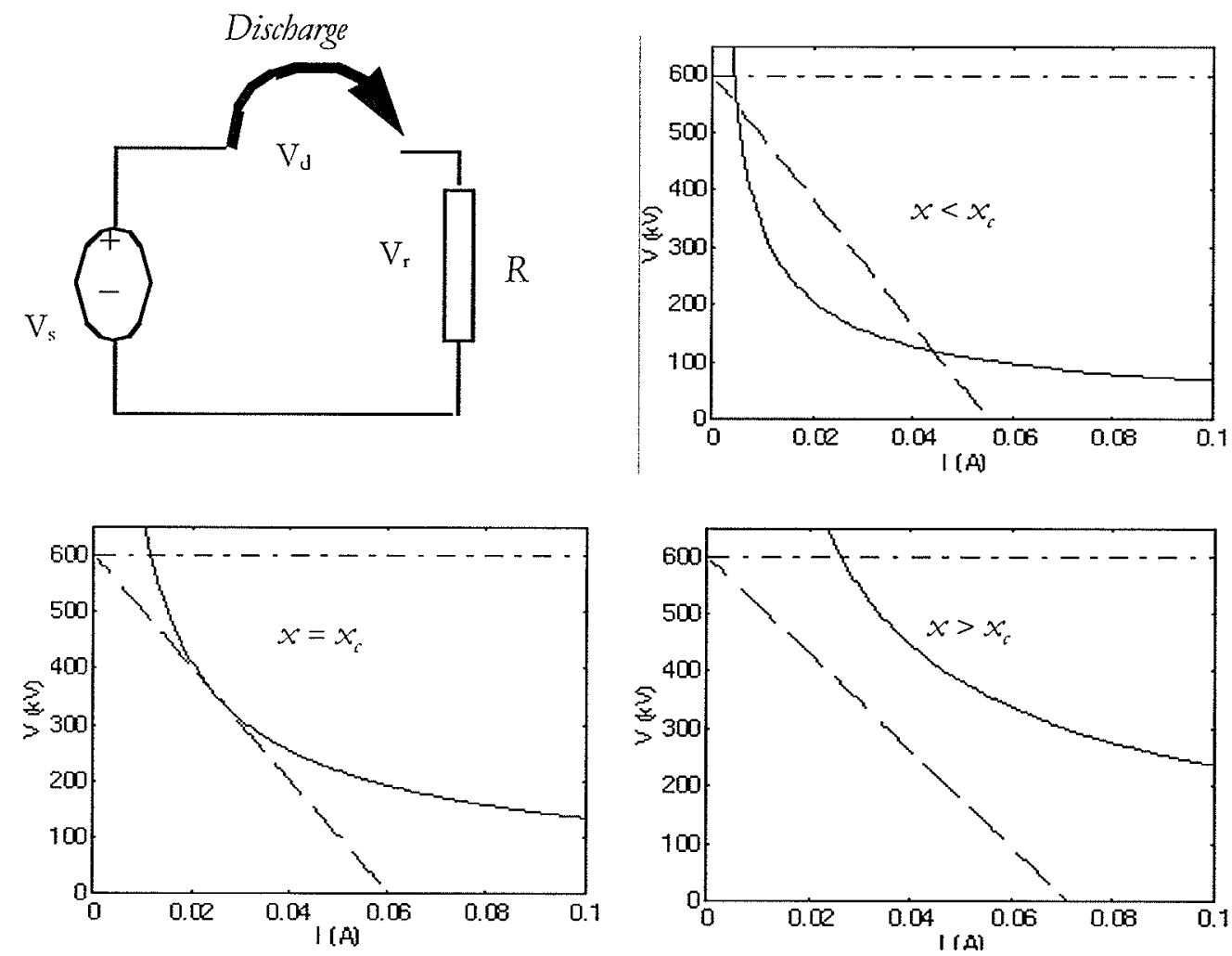

Fig.3.11 Illustration of propagation of discharges on an electrolytic surface

Fig. 3.12 is obtained by changing the arc length and finding the minimum voltage required for propagation of the arc across an electrolytic surface. Part of a bushing with average diameter $64 \mathrm{~cm}$ and creepage length $800 \mathrm{~cm}$ is considered, which corresponds to the case of a bushing with $30 \%$ length of dry zone. With a $0.01 \mathrm{~cm}$ thick water film, low rain conductivity of $10 \mu \mathrm{S} / \mathrm{cm}$ and $\mathrm{k}_{1}=3.6$, (equivalent to a surface resistivity of $3.6 \times 10^{7} \Omega$ ), the minimum voltage for driving an arc across the wetted surface is $2050 \mathrm{kV}$. This value is too high to be responsible 
for flashover under an operating voltage. Howerer, with an increase in rain conductivity, or a decrease in surface resistivity, the minimum voltage for propagation across an electrolytic surface decreases significantly. With a rain conductivity of $500 \mu \mathrm{S} / \mathrm{cm}$, the minimum voltage is only $420 \mathrm{kV}$. This implies that discharge propagation on an electrolytic surface may become a predominant process. The mechanism of discharge propagation along the electrolytic surface could become a competing mechanism for flashover when the rain conductivity is high enough when a thick layer of rain is deposited. The above calculations are consistent with experimental observations [LaW]91].

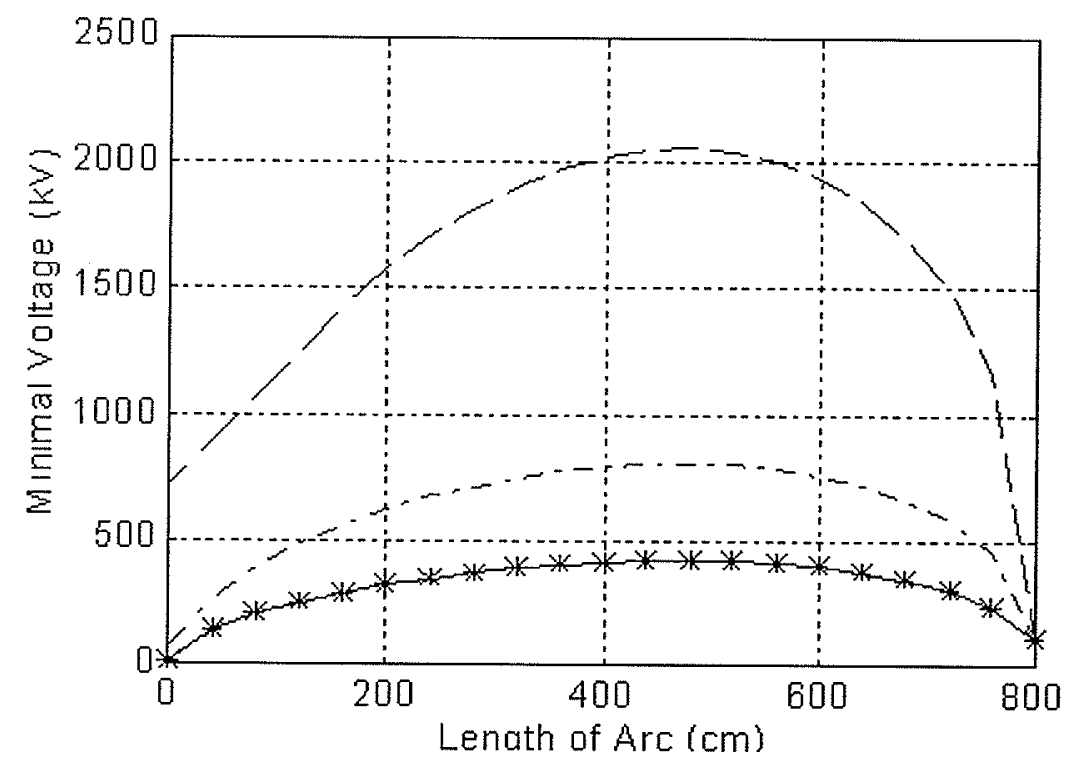

Fig. 3.12 Minimum voltage for arc propagation along wetted surface with respect to the arc length (with $64 \mathrm{~cm}$ in average diameter and $800 \mathrm{~cm}$ in creepage length)

-*_** surface resistivity of $7.2 \times 10^{5} \Omega$

-.-.-. surface resistivity of $3.6 \times 10^{6} \Omega$

--- surface resistivity of $3.6 \times 10^{7} \Omega$ 
The suggested model can be used for prediction of flashorer voltage, when a HVDC wall bushing is impacted by conductive rain or when rain occurs in combination with heavy contamination.

\subsubsection{Sequence of Events for Uneven Wetting Flashover of HVDC Wall Bushing}

Based on the above discussed mechanisms and processes, the following sequence of events is suggested as being representative of the whole process of HVDC wall bushing flashover due to uneven wetting,

Uneven Wetting: $\quad$ In a rain with wind as shown in Fig. 3.2, a "dry" zone (with relative high resistance) is created at the ground end due to shielding effects of a wall.

Enhancement of E-field: Electric fields, particularly those around the region where the dry and wet zones meet, are greatly increased, due to the fact that the steady state dc distribution is determined by the prevailing resistivity. Uneven wetting leads to a HVDC wall bushing operating under a severe condition.

Initiation of Discharges: Discharges are initiated due to the abnormal enhancement of electric field. The critical volume is around the region between the dry and wetted zone with high electric fields. Effects of disintegration of raindrops, E-field distortion due to raindrops further account for the inception of discharges. A lower inception voltage of discharge initiation can be expected. 
Propagation of Discharge: Discharges propagate across the whole bushing, if enough energy is available from the gap, space charges, or leakage current on the electrolytic surface.

Sparkover:

Once discharges approach the high voltage electrode, external flashover will be established.

\subsection{E-field Based Numerical Model for Prediction of HVDC Wall Bushing Flashover due to Uneven Wetting}

A numerical model, based on the E-field distribution, is proposed to predict the flashover voltage of an unevenly wetted HVDC wall bushing. The conditions for streamer initiation and propagation discussed in the previous sections are incorporated into the model as the criteria for flashover.

\subsubsection{Mathematical Description of E-field}

For a HVDC wall bushing, the E-field distribution is governed by the following equation,

$$
\begin{aligned}
& \left(\varepsilon(x, y \cdot z) \frac{\partial}{\partial t}+\gamma(x, y, z)\right)\left(\frac{\partial^{2} \varphi}{\partial x^{2}}+\frac{\partial^{2} \varphi}{\partial y^{2}}+\frac{\partial^{2} \varphi}{\partial z^{2}}\right)=\rho(x, y, z) \\
& \left.\varphi\right|_{c}=\varphi_{c}(t) \text { Boundary condition } \\
& \left.\varphi\right|_{t=0}=\varphi(0) \text { Initial condition }
\end{aligned}
$$

Where, $\varphi(x, y, z)$ is the electrical potential;

$\varepsilon(x, y, z)$ is the permittivity of the material involved;

$\gamma(x, y, z)$ is the conductivity of the material involved;

$\rho(x, y, z)$ is the volume charge density. 
Prior to flashover and ignoring the influence of space charges, Eqn. 3.16 reduces to the Laplacian equation, satisfies boundary conditions at interfaces of different materials, and yields the steady-state dc E-field distribution. This simplification is supported by the results of Efield measurements in the laboratory. Thus, the E-field distribution pattern of a HVDC wall bushing prior to flashover is mainly determined by the conductivity of the different materials and geometry.

\subsubsection{Electric Field Modelling for HVDC Wall Bushing}

To model the dc E-field distribution of a wall bushing under different surface conditions, several assumptions were made as following,

1. Considering the rotational symmetrical characteristics of wall bushing prior to a flashover, a 2-dimensional axial symmetric model was used.

2. Different materials (bushing oil, porcelain, water film and air) were assigned conductivities shown in Table 3.2 to simulate typical operating conditions.

3. To simulate the surface condition of an unevenly wetted wall bushing, a thin layer of water film with various conductivities were used.

4. Since the bushing grading system was optimised in design and the relatively large conductance between two adjacent grading foils ensures the potential distribution along the grading core to be unaffected by stray leakage outside the core, the edge of the grading core can be treated as known boundary with a linear potential distribution.

The electric field distributions of a HVDC wall bushing under different wetting conditions were investigated with the assistance of ANSYS finite element analysis software. 


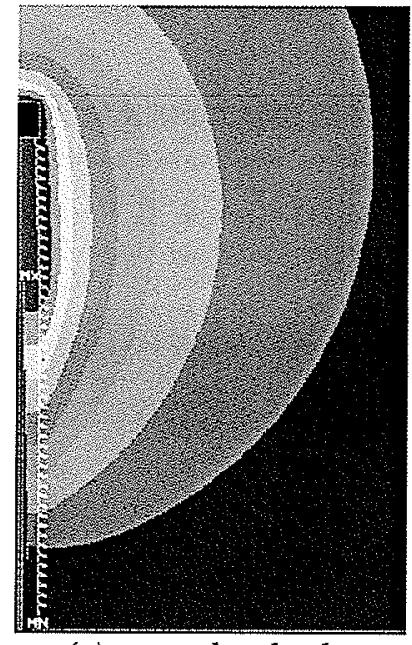

(a) completely dry

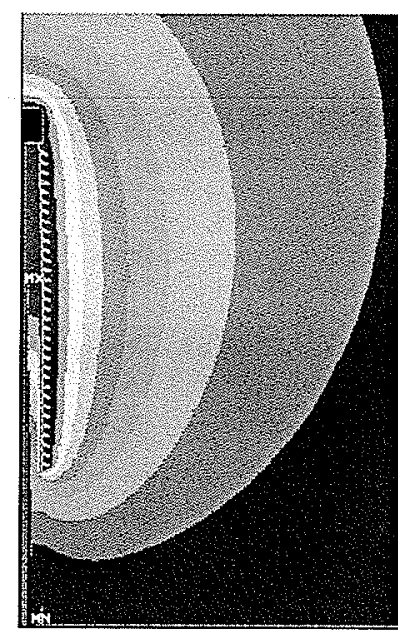

(b) with $30 \%$ length dry zone

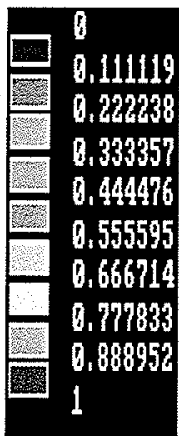

Fig.3.13 Potential contours for a $600 \mathrm{kV}$ HVDC wall bushing

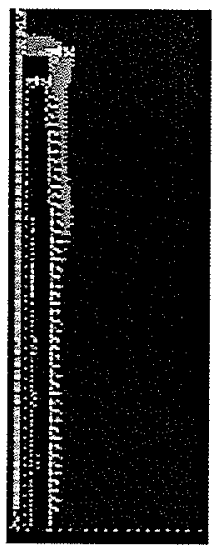

(a) completely drv
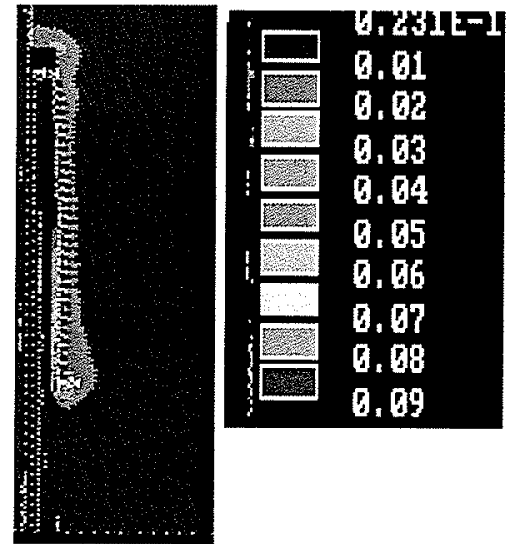

Fig.3.14 E-field contours for a 600kV HVDC wall bushing 
The investigation of the electric field distribution was conducted with a $600 \mathrm{kV}$ HVDC wall bushing using the ANSYS finite element analysis progtam with 8000 elements and 10000 nodes. Figures 3.13 and 3.14 illustrate potential and electric field contours respectively under a completely dry surface and an unevenly wetted surface with $30 \%$ length of dry zone located at ground end. A typical electric field distribution along the shed tips is shown in Fig. 3.15. This distribution was obtained with $30 \%$ dry zone length and rain conductivity of $100 \mu \mathrm{S} / \mathrm{cm}$. The E-field analysis shows that uneven wetting causes a redistribution of the electric field, and hence causes a severe operating condition for a HVDC wall bushing.

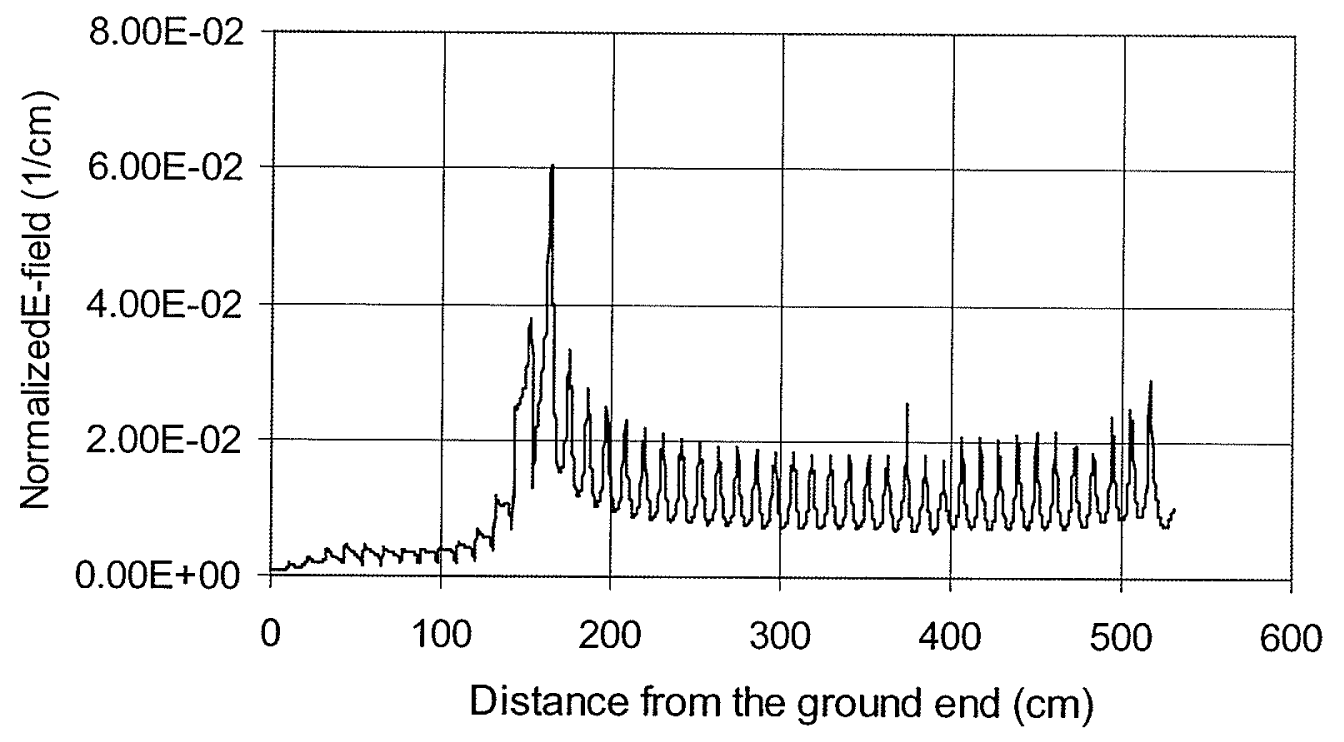

Fig. 3.15 Electric field distribution along the critical line that links tips of sheds for a $600 \mathrm{kV}$ HVDC wall bushing 
Table 3.3 Conductivity of Different Materials [ScLu91], [Hart94]

\begin{tabular}{|c|c|c|c|c|c|}
\hline \multirow{2}{*}{ Material } & \multirow{2}{*}{ Oil } & \multirow{2}{*}{ Porcelain } & \multicolumn{2}{|c|}{ Surface Film } & \multirow{2}{*}{ Air } \\
\cline { 4 - 6 } & & & Wet & Dry & \\
\hline$\gamma(\mathrm{S} / \mathrm{m})$ & $10^{-11}$ & $3 \times 10^{-13}$ & $10^{-2}$ & $10^{-12}$ & $2 \times 10^{-14}$ \\
\hline
\end{tabular}

\subsubsection{HVDC Wall Bushing Uneven Wetting Flashover Criterion}

Most HVDC wall bushings operate under very lightly contaminated conditions, low conductivity rain, or both. The streamer process is therefore primarily responsible for flashover. In the case of negative polarity wall bushings, it is essential that positive streamers be initiated near the ground end and propagate towards the high voltage terminal. The following model is proposed to determine the critical flashover voltage of an unevenly wetted wall bushing.

Experimental observations have confirmed that the flashover paths for a majority of uneven wetting caused flashovers are more or less directed along shed tips rather than completely along and close to the bushing surface [NaMI89]. Hence, in this model, the critical line is defined as the shortest line that links all shed tips and both HV and ground electrodes. For flashover to occur, the following three conditions must be satisfied.

Condition for streamer initiation: To facilitate a streamer, either the secondary avalanche due to photo-ionisation or disintegration of water drop has to occur. In case of secondary avalanche, the number of electrons in the active region must reach a critical level. In other words, the integration of the effective ionisation coefficient in the active region along the critical line is required to reach a certain level, usually 9.15-11.5 [PeZa95]. This leads to a transition of the primary avalanche to a secondary avalanche. On other hand if streamer 
initiation is due to disintegration of water drops, the maximum electric field along the critical line has to be greater than $\mathrm{E}_{\mathrm{cr}}$, where $\mathrm{E}_{\mathrm{cr}}$ is defined in Eqn. 3.10.

The production of free electrons by ionisation processes is related to the un-ionised electric field through the primary net ionisation coefficient, governed by following equation [PeZa95],

$$
\frac{\alpha-\eta}{p}=C \cdot\left[\frac{E}{p}-\left(\frac{E}{p}\right)_{M}\right]^{2}-A
$$

Where: $\alpha=$ ionization coefficient;

$\eta=$ attachment coefficient;

$\mathrm{p}=$ air pressure $[\mathrm{bar}]$

$\mathrm{C}\left[\mathrm{bar} \cdot \mathrm{mm} / \mathrm{kV}^{2}\right], A[1 /(\mathrm{mm} \cdot \mathrm{bar})]$ and $(\mathrm{E} / \mathrm{p})_{M}[\mathrm{kV} /(\mathrm{mm} \cdot \mathrm{bar})]$ are constants, which are determined by the type of gas.

For synthetic air $\left(\mathrm{O}_{2} 20 \%, \mathrm{~N}_{2} 80 \%\right), \mathrm{C}=1.6053, \mathrm{~A}=0.2873,(\mathrm{E} / \mathrm{p})_{\mathrm{M}}=2.165$. Hence, at the critical value $(\mathrm{E} / \mathrm{p})_{\mathrm{cr}}$ of $2.588 \mathrm{kV} /(\mathrm{mm} . \mathrm{bar})$, the effective ionisation coefficient is zero. The integtation of the effective ionisation coefficient in the active region along the critical line can be estimated by using following formula.

$$
K=\int_{0}^{X c}(\alpha-\eta) d x
$$

Condition for streamer propagation: The average electric field along the gap has to be greater than the gradient for streamer propagation, namely $4.55 \mathrm{kV} / \mathrm{cm}$ for + ve streamers and $11.5 \mathrm{kV} / \mathrm{cm}$ for -ve streamers as discussed in the section 3.1 .

Condition for streamer sustenance: The minimum electric field in the expected flashover path must be larger than $600 \mathrm{~V} / \mathrm{cm}$ as discussed in section the 3.1 . 
The above criteria relate the electric field to the flashover via various constants, thus enabling the critical flashover voltage to be estimated.

\subsubsection{Prediction of the Critical Flashover Voltage under -ve Polarity}

To determine the critical flashover voltage for a HVDC Wall Bushing, the following procedure is proposed.

1. A normalized electric field distribution along the critical line, i.e. along the expected flashover path bridging shed tips, is obtained by E-field computation.

2. An initial voltage value is selected, and the electric fields throughout the calculation region are obtained by multiplication of the normalized electric field values by the selected voltage value for the initial iteration.

3. The active region is determined where the effective ionisation coefficient is larger than zero according to Eqn. 3.17, or where (E/p) is larger than $2.588 \mathrm{kV} /(\mathrm{mm}$.bar).

4. The number of electrons in the active region is estimated by using Eqn. 3.17 and Eqn. 3.18 .

5. The maximum, minimum and average electric fields along the critical line are estimated.

6. The electron number and the minimum \& average electric fields in the gap are compared with the flashover criterion. If the criteria are satisfied, a flashover may be expected along the shed tips and the selected applied voltage is the critical flashover voltage. If the criteria are not satisfied the selected voltage is increased by a suitable amount and the procedure is repeated starting from step 2 until the critical flashover voltage is determined.

Fig. 3.16 shows the flow chart of a typical procedure to predict the critical flashover voltage of an unevenly wetted HVDC wall bushing. 


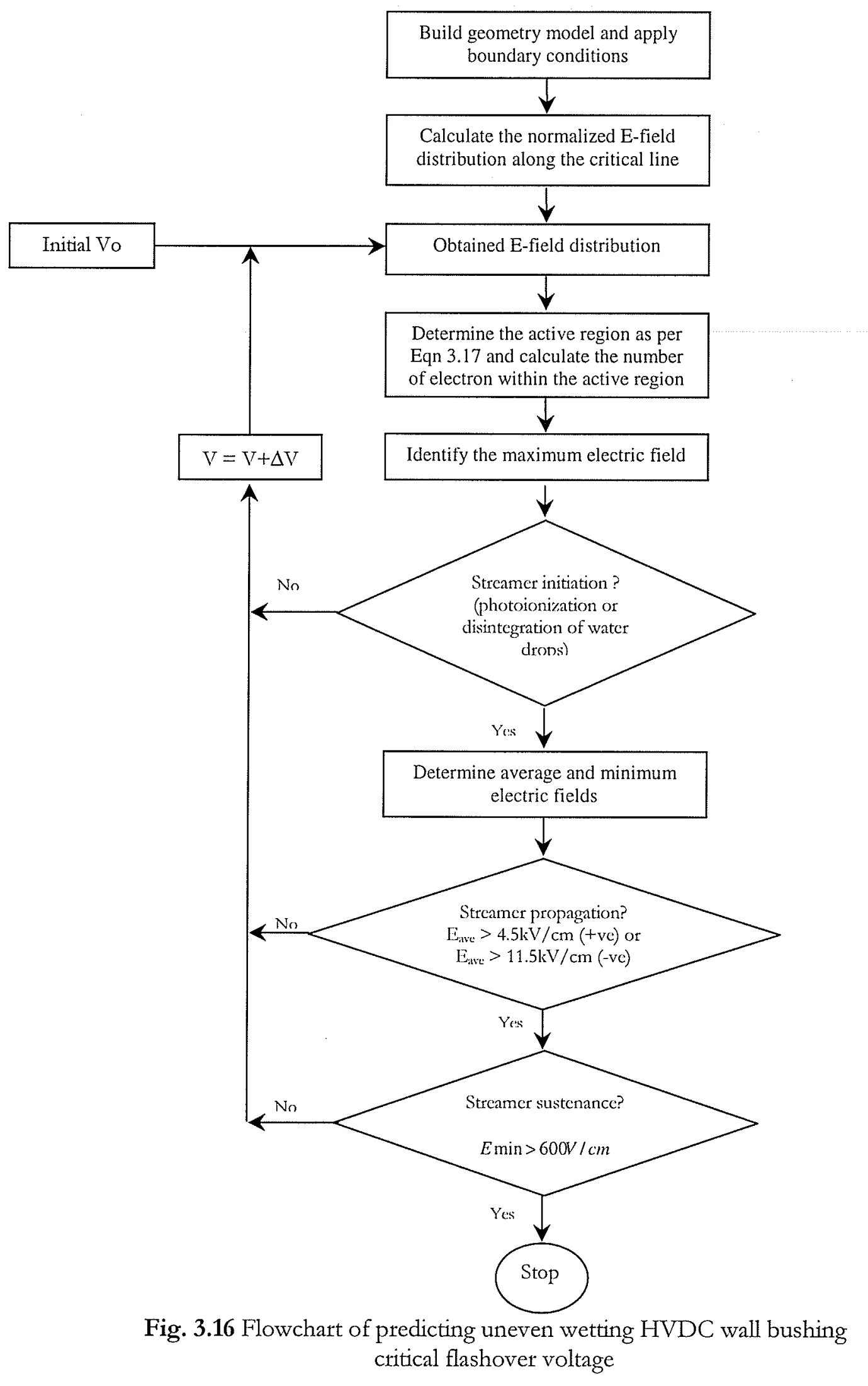

1 The flowchart for CFO prediction is essentially identical for HVDC wall bushings under +ve polarity and -ve polarity with exception that -ve streamer propagation is considered for busing under +ve polarity 
Table 3.4 shows the breakdown voltage, using the above procedure, of a $50 \mathrm{~cm}$ diameter spheres with various spacing in the range $5-25 \mathrm{~cm}$. The efficacy of the model is confirmed by the results.

Table 3.4 Comparison of Predicted Breakdown Voltage and Standard Data for a $50 \mathrm{~cm}$ Sphere Gap (under room temperature at $1.01325 \mathrm{bar}$ )

\begin{tabular}{|c|c|c|c|}
\hline \multirow{2}{*}{ Spacing(cm) } & \multicolumn{3}{|c|}{ - ve polarity Flashover Voltage (kV) } \\
\cline { 2 - 4 } & Predicted & IEC values[KuZa84] & Deviation (\%) \\
\hline 5.0 & 136.7 & 138 & -0.9 \\
\hline 7.5 & 200.2 & 202 & -0.9 \\
\hline 10.0 & 259.4 & 263 & -1.4 \\
\hline 12.5 & 314.9 & 320 & -1.6 \\
\hline 15.0 & 366.9 & 373 & -1.6 \\
\hline 17.5 & 415.7 & 420 & -1.0 \\
\hline 20.0 & 461.5 & 460 & 0.3 \\
\hline 25.0 & 544.8 & 530 & 2.8 \\
\hline
\end{tabular}

\subsubsection{Modification in Procedure to Determine the Critical Flashover Voltage of a HVDC Wall Bushing Operating under +ve Polarity}

Although the electric field distribution for an unevenly wetted bushing under different polatities are essentially the same, the flashover processes involved under +ve polarity is different from that of a HVDC wall bushing under -ve polarity. In the latter case, positive 
streamers are initiated at the ground end where the electric field is higher and propagate towards the HV end. For a wall bushing under +ve polarity, -ve streamers start from the ground end and if electric fields around the HV electrode are sufficiently high, positive streamers may also launch from the HV terminal towards the negative streamer. Therefore, modifications in the model are necessary to account for the physics involved in +ve polarity. Following is the modified procedure for a +ve HVDC wall bushing.

1. A normalized electric field distribution along the critical line, namely along the expected flashover path bridging the shed tips, is obtained by accurate E-field computation. An initial voltage value is selected that equals either (a) $p \cdot \frac{\left(\frac{E}{p}\right)_{c r}}{E \max (\text { normalised) }}$ or (b) $\frac{E_{c r}}{E \max (\text { normalised })}$ for triggering a discharge due to water droplets, whichever is smaller.

2. The electric field is scaled accordingly.

3. The active region, where facilitates negative streamer growth, is determined. In other words, a region is identified where the effective ionisation coefficient is larger than zero according to Eqn. 3.17, or where $(\mathrm{E} / \mathrm{p})$ is larger than $2.588 \mathrm{kV} /(\mathrm{mm}$.bar).

4. The factor $\mathrm{K}$ is estimated in the active region for negative streamers by using Eqn (3.17)

5. The maximum, average and minimum values of electric field along the critical line are obtained.

6. It is also determined whether or not an active region is present immediately close to the HV terminal along the critical line; this is the region in which a positive streamer growth is facilitated. $\mathrm{K}$ is estimated in this region, if there is one. 
7. If active regions along the critical line are absent or the values of $K$ in both active regions are less than 9.15, the applied voltage is incremented and the procedure repeated from step 2.

8. If $K$ in the active region for negative streamer is greater than 9.15 , average electric field is larger than $11.5 \mathrm{kV} / \mathrm{cm}$, and the minimum electric field along the critical line is no less than $600 \mathrm{~V} / \mathrm{cm}$, then a flashover due to complete negative streamers occurs. The applied voltage is the critical flashover voltage and iterations are stopped. If not, the procedure continues as described below.

9. If $K$ in the active region for positive streamer is greater than 9.15 , and the average electric field is larger than $4.55 \mathrm{kV} / \mathrm{cm}$, and the minimal electric field along the critical line is no less than $600 \mathrm{~V} / \mathrm{cm}$, then a flashover due to tve streamers occurs. The applied voltage is the critical flashover voltage and iterations are stopped.

10. If $K$ in the active region for positive streamer is greater than 9.15 , and the average electric field over $2 / 3$ of the critical line is larger than $11.5 \mathrm{kV} / \mathrm{cm}$, and the minimal electric field along the critical line is no less than $600 \mathrm{~V} / \mathrm{cm}$, and $\mathrm{K}$ in the active region for positive is also greater than 9.15 then a flashover due to both -ve and +ve streamers occurs. The applied voltage is the critical flashover voltage and iterations are stopped.

11. The applied voltage is incremented and the procedure repeated starting with step 2 until the critical flashover voltage is determined.

\subsection{Summary}

In this chapter, fundamental processes that occur in uneven wetting caused flashover are discussed in detail, which suggests that: 
The uneven wetting flashover of HVDC wall bushing is a streamer-discharge predominant process. Initiation and progress of streamer discharges under uneven wetting condition for a bushing type configuration is of particular interest to understand the phenomena.

Initiation of discharges is due to several competing mechanisms. The enhancement of local electric field due to uneven wetting of a bushing, corona due to raindrops and disintegration of raindrops play important roles in this stage.

A numerical model is proposed to assess the performance of HVDC wall bushings and predict the critical flashover voltage. The model utilizes the physics of discharges and accurate numerical evaluation of electric fields. 


\section{SIMULATION AND DISCUSSION}

In the previous chapter the E-field distribution of a wall bushing has been computed under various conditions and a model developed to predict the flashover voltage of an unevenly wetted HVDC wall bushing. This model includes conditions for streamer initiation and propagation as the criteria for flashover. Furthermore, various processes behind the phenomena have been taken into consideration fully.

In this chapter, the developed model is used to investigate various aspects associated with flashover of an unevenly wetted bushing. Among the factors considered are (1) dry zone length; (2) dry zone location; (3) water drop size; (4) rain conductivity; (5) altitude; (6) bushing configuration; (7) polarity. The efficacy of RTV coating and booster sheds to improve the performance of HVDC wall bushing has been verified through simulations. All the results of simulation reported in this chapter were obtained with the negatively energized bushing, unless otherwise mentioned.

It is shown that the numerical model offers an effective tool to assess the unevenly wetted HVDC wall bushings.

\subsection{Description of Modelled HVDC Wall Bushing}

The $600 \mathrm{kV}$ HVDC wall bushing shown in Fig. 4.1 is investigated in the simulation. The bushing is of the conventional condenser type with 77 foils. The earth end foil extends $355 \mathrm{~mm}$ beyond the earth flange, and the final HV foil ends $1555 \mathrm{~mm}$ from the HV end. The main 
dimensions of the wall bushing are shown in Table 4.1. The actual profile of bushing sheds, as well as the condenser core, is taken into consideration in the simulation.

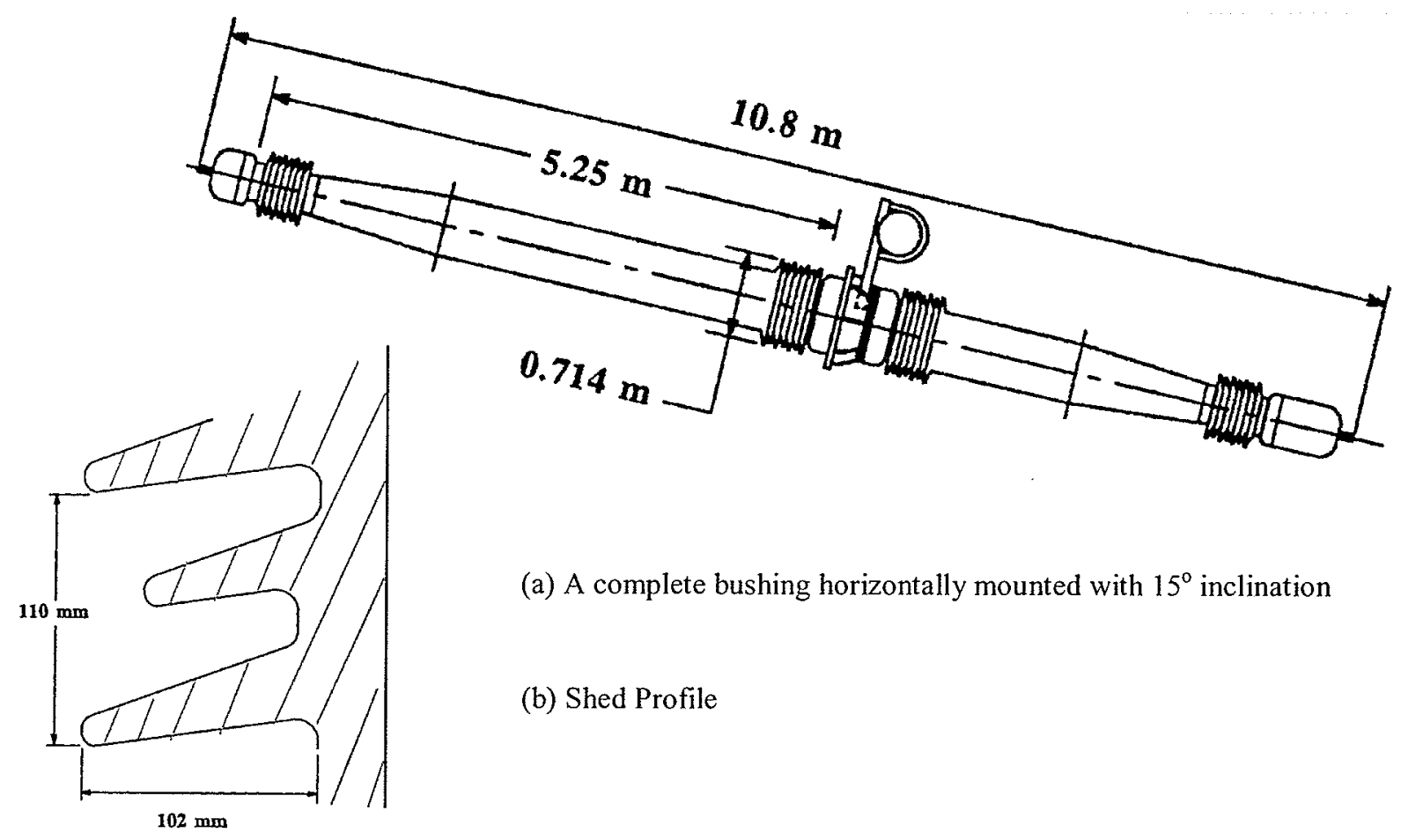

Fig. 4.1 Schematic drawing of a $600 \mathrm{kV}$ wall bushing

Table 4.1 Critical Dimensions of the 600kV HVDC Wall Bushing [LaBK96]

\begin{tabular}{|c|c|c|c|}
\hline Insulation Length, $\mathbf{m}$ & Mean Diameter, $\mathbf{m m}$ & Creepage Length, $\mathbf{m}$ & $\begin{array}{c}\text { Overhang/spacing } \\
\text { shed pairs, } \mathbf{m m}\end{array}$ \\
\hline 5.25 & 635 & 19.8 & $102 / \mathbf{1 1 0}$ \\
\hline
\end{tabular}




\subsection{Effect of Dry Zone Length, Its Location and Critical Dry Zone Length}

The influence of uneven wetting, particularly the length of dry zone was investigated using the suggested model. The critical flashover voltages for the $600 \mathrm{kV}$ HVDC wall bushing with various dry zone lengths located at the ground end were predicted and are shown in Table 4.2. Typical rain conductivity, $100 \mu \mathrm{S} / \mathrm{cm}$ is used in the simulations.

\section{Table 4.2 Predicted Flashover Voltages for the $600 \mathrm{kV}$ Wall Bushing with Various Dry Zone Lengths}

\begin{tabular}{|c|c|c|c|c|c|c|}
\hline Dry Zone Length (\%) & 0 & 20 & 30 & 50 & 70 & 100 \\
\hline CFO w/o Raindrops (kV) & 946.2 & 342.4 & 507.7 & 737.3 & 936.0 & 1423.2 \\
\hline CFO with Raindrops(kV) & 536.8 & 342.4 & 375.8 & 432.1 & 442.5 & 1423.2 \\
\hline
\end{tabular}

The results are presented in Fig. 4.2 which illustrates the influence of dry zone length on the flashover stress which is defined as the critical flashover voltage divided by the striking distance. The solid curve represents the results obtained when the effect of waterdrops are not considered; the dotted curve represents the results obtained by consideration of waterdrops. For comparison purposes, experimental tesults from literature [Lamb89], [ScHN91] are also presented. As shown in Fig.4.2, all the experimental points fall within the range defined by the solid and dotted curves. The model, in essence, predicts that all flashovers lie within the region enclosed by the solid and dotted curves. The four anomalous experimental points, which lie outside the range, correspond to cases where a flashover was not observed i.e. withstand voltage. This finding reinforces the validity of the proposed model. Furthermore, it is seen that simulation including the effect of water drops yields a better prediction in the majority of cases. Hence, it is suggested that disintegration of water drops is an important process in modelling the uneven wetting flashover problem. 


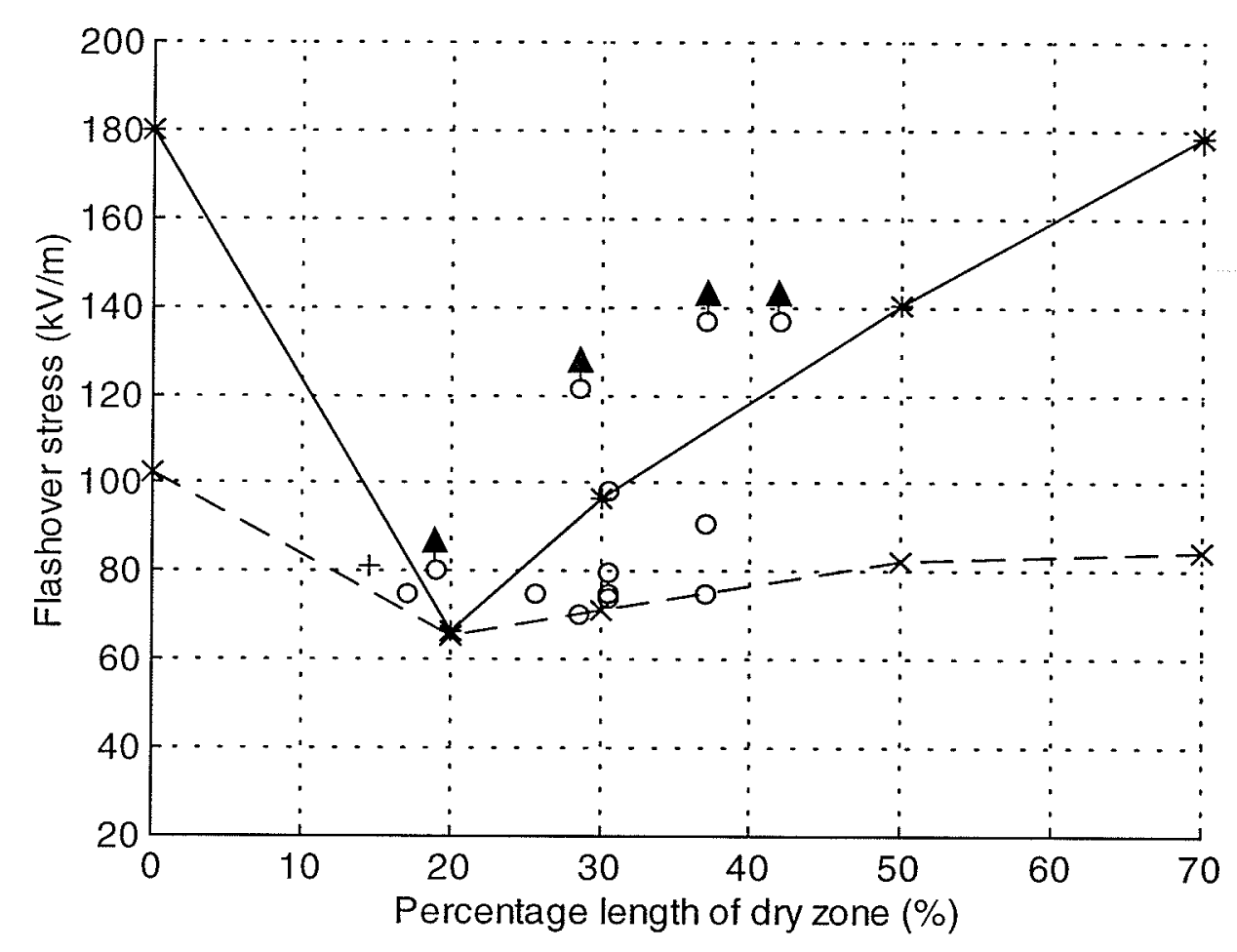

Fig. 4.2 Influence of dry zone length on flashover stress for a $600 \mathrm{kV}$ HVDC wall bushing (-ve) Water conductivity: $100 \mu \mathrm{S} / \mathrm{cm}$; Radius: $2 \mathrm{~mm}$ simulation results without considering waterdrops;

----- simulation results including effect of waterdrops;

o experimental results from [Lamb89],

+ experimental result from [ScHN91].

of withstand voltage;

Table 4.3 Critical Flashover Stress vs. Critical Dry Zone Length (-ve polarity)

\begin{tabular}{|l|c|c|c|c|}
\hline CFO stress (kV/m) & 65 & 68 & 63 & 75 \\
\hline $\begin{array}{l}\text { Critical Dry Zone } \\
(\%)\end{array}$ & 20 & $17 \sim 30$ & 10 & 18 \\
\hline Reference & $\begin{array}{c}\text { Results obtained } \\
\text { from the } \\
\text { proposed model }\end{array}$ & $\begin{array}{c}\text { Experimental } \\
\text { data }^{2} \text { Lamb90] }\end{array}$ & $\begin{array}{c}\text { Experimental } \\
\text { data [Schn91] }\end{array}$ & $\begin{array}{c}\text { Experimental } \\
\text { data Lamp88] }\end{array}$ \\
\hline
\end{tabular}

${ }^{2}$ Bushing used by [Lamb90] is identical to that considered in the simulation in this thesis. 
The unique U-shaped characteristics of the curve of flashover stress versus dry zone length is also reproduced by the simulation. As shown in Fig. 4.2, a critical range of $10 \%$ to $40 \%$ can be found in dry zone length, where flashover stresses fall below $80 \mathrm{kV} / \mathrm{m}$. This confirms the existence of a critical dry zone length.

The critical flashover stress for the model was found to be $65 \mathrm{kV} / \mathrm{m}$ when $20 \%$ of the dry zone length is located at the ground end. This value is substantially lower compared to typical operating stresses of HVDC wall bushing as shown in Table 1.1. A high stress level adversely affects the performance of wall bushings. To ultimately improve the HVDC wall bushing performance, one has to either reduce the operating stress to an acceptable level or increase the critical flashover stress well above the operating stress.

Table 4.3 compares the estimated critical flashover stress and critical dry zone length with those obtained from experimental investigations. The results agree with each other to within reasonable engineering accuracy. The deviations are likely caused by the differences in the definition of dry zone length and by the fact that the shed profiles in each case are different.

The influence of dry zone location on the critical flashover voltage was also investigated. The estimated critical flashover voltage is found to be $418 \mathrm{kV}$ when a dry zone of $30 \%$ length is located at the HV end. This is equivalent to the flashover stress of $80 \mathrm{kV} / \mathrm{m}, 11 \%$ higher than that obtained when a dry zone of the same length is located at the ground end and $22.5 \%$ higher than the CFO of a HVDC with dry zone located at the ground end. A dry zone at the ground end is more critical than that at the HV end under the negative polatity. 


\subsection{Effect of Voltage Polarity}

Uneven wetting flashover voltage for a (+ve) $600 \mathrm{kV}$ bushing was estimated using the modified model. For comparison purposes, simulation was done with $30 \%$ dry zone located at the ground end. The estimated flashover stress is $92 \mathrm{kV} / \mathrm{m}$, which is about $28 \%$ higher than that of the negatively energized bushing. The result agtees well with the fact that a positively energized HVDC wall bushing has superior performance.

As pointed out earlier, in chapter 1, field experience indicates that less than $30 \%$ of the total reported wall bushing flashovers occur under +ve polarity.

\subsection{Influence of Raindrops}

The influence of raindrops was investigated in more detail for a $600 \mathrm{kV}$ wall-bushing model under $30 \%$ length of dry zone located at the ground end.

\subsubsection{Raindrop Size}

Fig.4.3 shows the dependence of the estimated flashover voltages of a $600 \mathrm{kV}$ wall bushing on the size of raindrops. In general, the critical flashover voltage decreases with increase in raindrop size, particularly in the range of $\mathrm{r}=0.25 \mathrm{~mm} \sim 0.4 \mathrm{~mm}$ for the considered configuration. Under rain with radius of drops $0.25 \mathrm{~mm}$ or less, flashover is probably initiated due to photo-ionization process, while flashovers are more likely caused by disintegration of raindrops under rain with larger size raindrops. A further increase in drop size beyond $0.4 \mathrm{~mm}$ in radius does not result in a decrease in the flashover voltage, since the critical flashover voltages are mainly limited by the propagation field, although a much severer corona may be observed. The pattern of Fig. 4.3 is configuration dependent.

From Fig.4.3, it is evident that the critical flashover voltage has a significant dependence on the size of raindrops. This observation is consistent with current experimental knowledge. Practically, since there is a wide range of raindrop sizes, the critical flashover voltage may be more likely to be determined by the 
large sized raindrops. Hence the influence of raindrop size may not as pronounced as in Fig.4.3, particularly in terms of rain intensity.

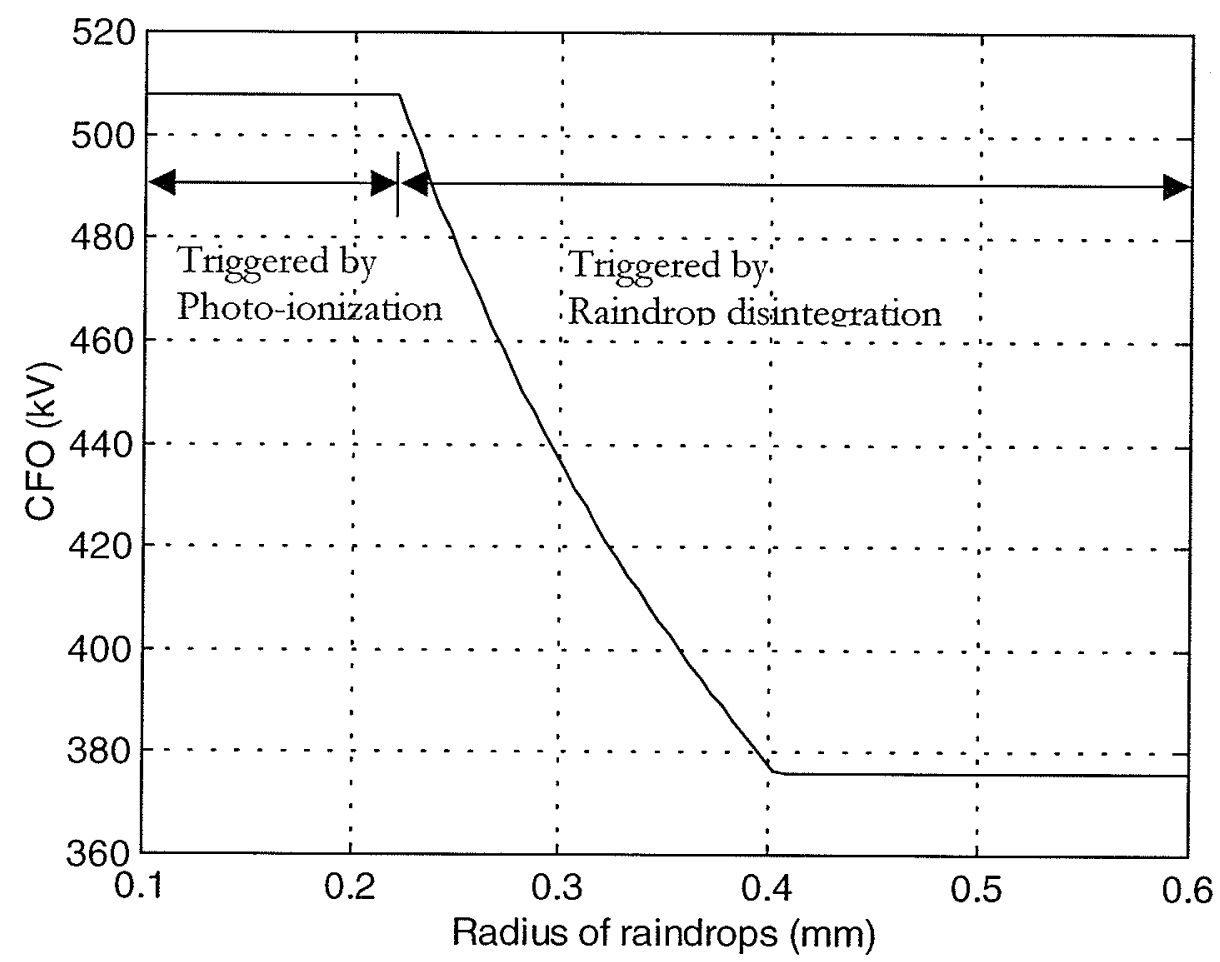

Fig. 4.3 Critical flashover voltage versus the size of raindrops for a $600 \mathrm{kV}$ HVDC wall bushing with $30 \%$ length of dry zone located at the ground end Rain conductivity: $100 \mu \mathrm{S} / \mathrm{cm}$

\subsubsection{Raindrop Conductivity}

Fig. 4.4 reveals the effect of rain conductivity on the critical flashover voltage. In Fig.4.4, data points corresponding to the upper bound were obtained without consideration of raindrops. The data points corresponding to the lower bound were obtained by consideration of raindrops of size $4 \mathrm{~mm}$ in diameter. It is found that rain conductivity in the range of $1 \mu \mathrm{S} / \mathrm{cm}$ to $30 \mu \mathrm{S} / \mathrm{cm}$ has a limited influence for the $600 \mathrm{kV}$ wall bushing with $30 \%$ length of dry zone at the ground end. The lower the rain conductivity, the higher the critical flashover voltage (CFO) will be. The critical flashover voltage is related to rain conductivity by a power law with exponent of -0.122 as 
estimated from Fig.4.4. i.e. $\mathrm{CFO}(\mathrm{kV}) \propto \mathrm{\kappa}^{-0.122}$. This result is comparable to experimental data [Lamb89], in which the exponent is -0.11 .

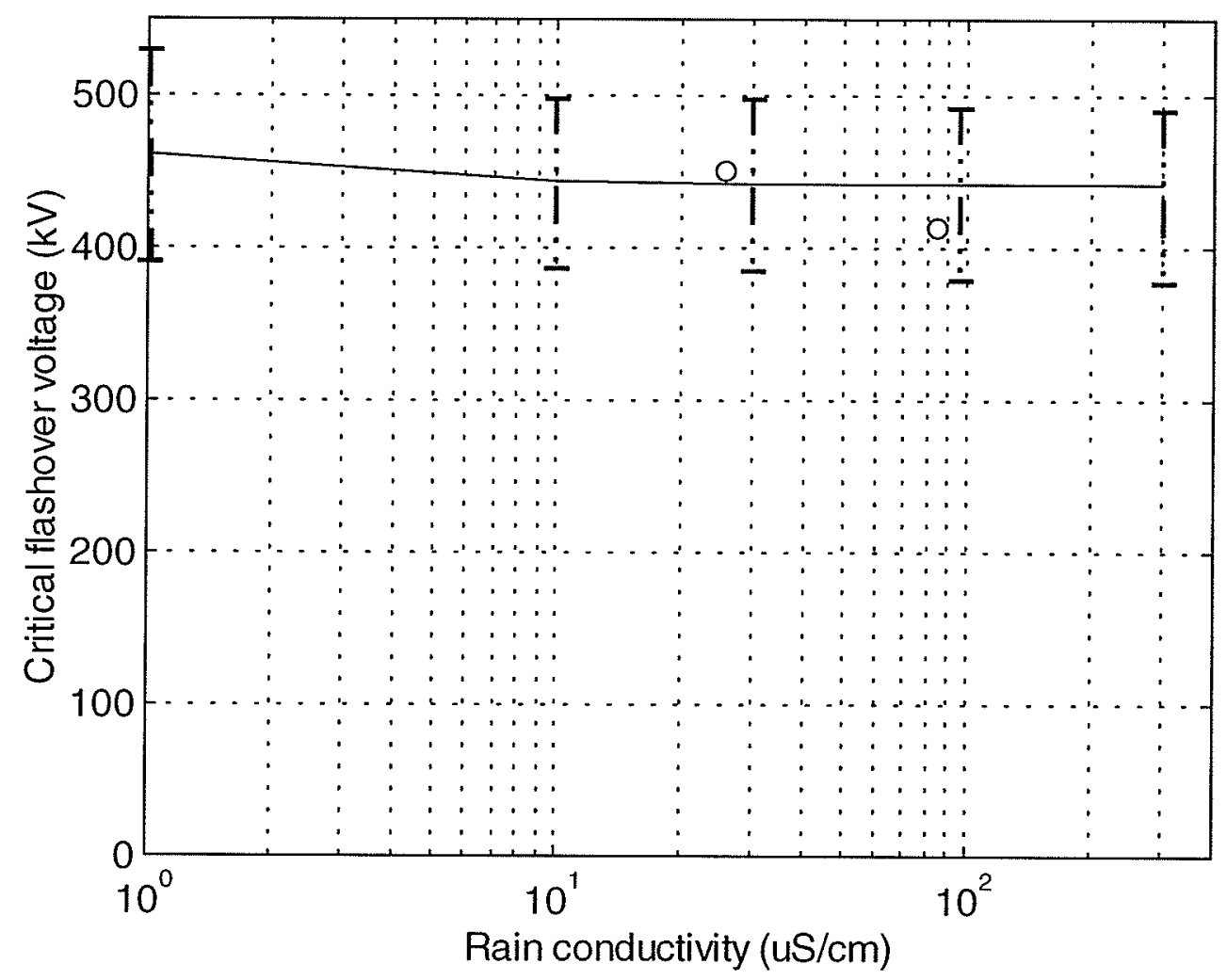

Fig. 4.4 Influence of rain conductivity on the critical flashover voltage for a $600 \mathrm{kV} \mathrm{HVDC}$ wall bushing with $30 \%$ length of dry zone

Further increase in the rain conductivity does not necessarily decrease the critical flashover voltage until the flashover propagation mechanism is dominated by electrolytic discharge as discussed in the previous chapter. Fig. 4.5 shows the transition from uneven wetting flashover to an electrolytic discharge mechanism, once the water conductivity reaches a certain value. As shown in the figure, the transition point is at $500 \mu \mathrm{S} / \mathrm{cm}$, and electrolytic discharges becomes a leading mechanism once the water conductivity is beyond $1000 \mu \mathrm{S} / \mathrm{cm}$. This is very close to what was found in experimental investigations [Lamp88], [LaW]91]. 


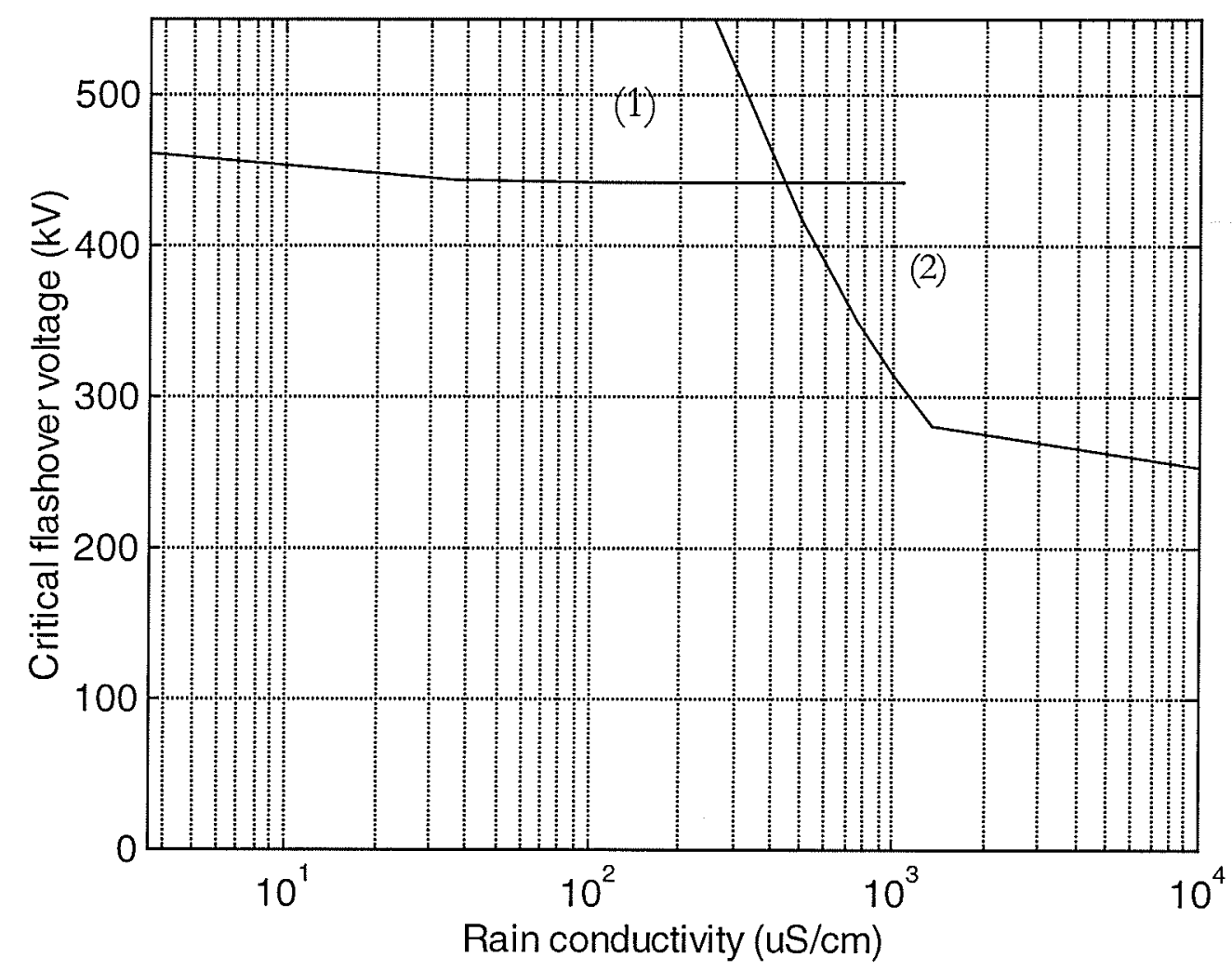

(1) Streamer discharge based criteria; (2) Electrolytic discharge based criteria

Fig. 4.5 CFO vs. water conductivity for a $600 \mathrm{kV} \mathrm{HVDC}$ wall bushing with $30 \%$ length of dry zone

\subsection{Influence of Air Pressure and Altitude}

The air pressure at sea level is about $101.3 \mathrm{kPa}$. As altitude increases the air pressure decreases at the rate of approximately $1 \mathrm{kPa} / 100 \mathrm{~m}$. From field experience it is known that the reduction of the strength of external insulation in transmission systems at high altitudes is of concern. The influence of altitude on the streamer inception voltage due to ionisation processes for a $600 \mathrm{kV}$ HVDC wall bushing with $30 \%$ length of dry zone located at the ground end is shown in Fig.4.6. As altitude increases the streamer inception voltage due to photo-ionization 
decreases. Therefore at higher altitude the flashover of a wall bushing is less dependent on raindrop disintegration. In contrast, at sea level where the streamer inception voltage is high, raindrop disintegration plays a vital role in causing flashover.

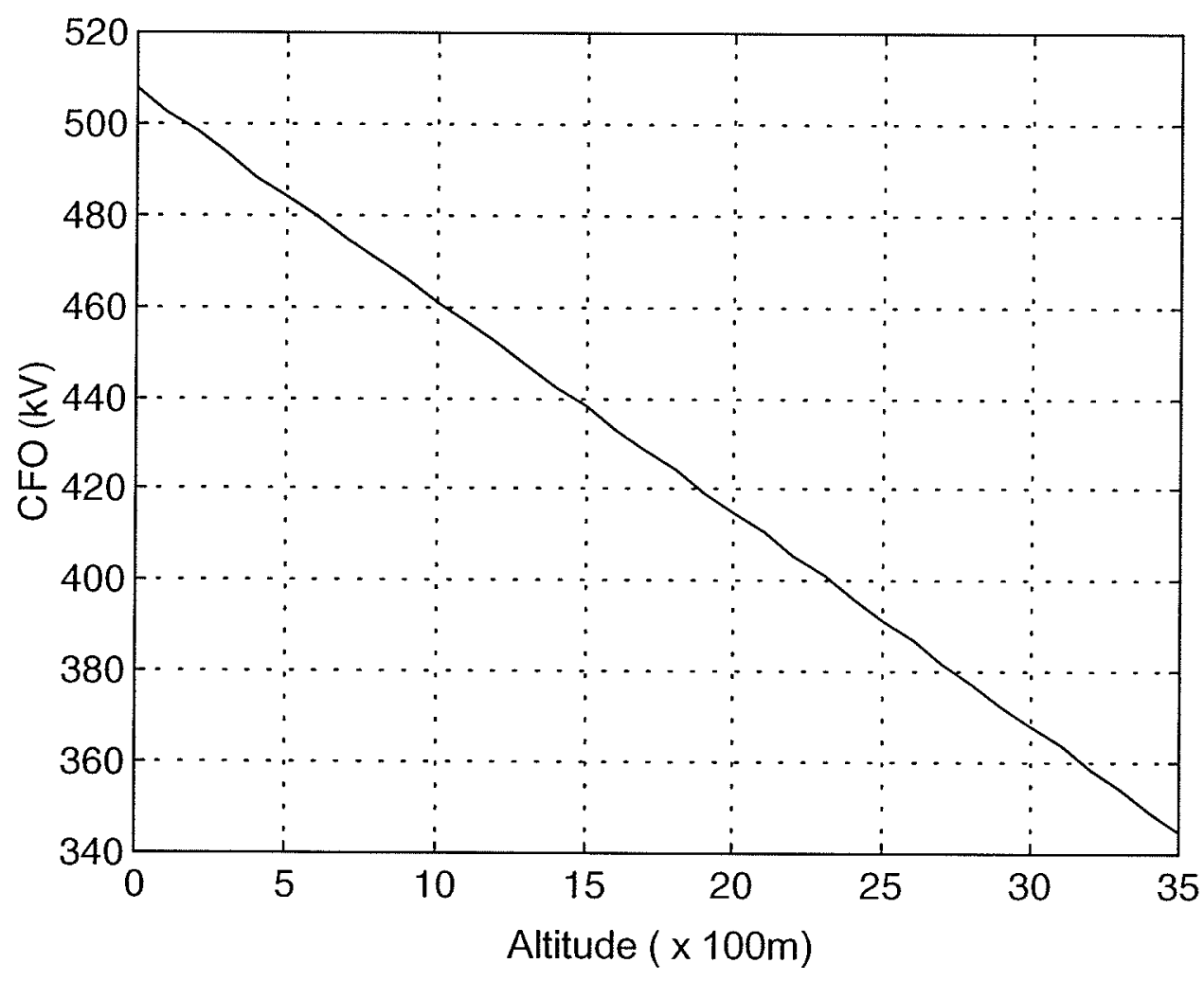

Fig. 4.6 Streamer inception voltage due to photo-ionization for a $600 \mathrm{kV}$ HVDC wall bushing with $30 \%$ length of dry zone under various altitudes Rain conductivity: $100 \mu \mathrm{S} / \mathrm{cm}$; radius of raindrop: $2 \mathrm{~mm}$

Fig.4.7 shows the effects of air pressure and raindrop size on the CFOV. With increase in altitude the critical flashover voltage more or less decreases for small sizes of raindrops. The critical size for transition from a photo-ionization triggered process to a raindrop disintegration triggered process is shifted to the right. The influence of raindrop size diminishes with increase in altitude. 


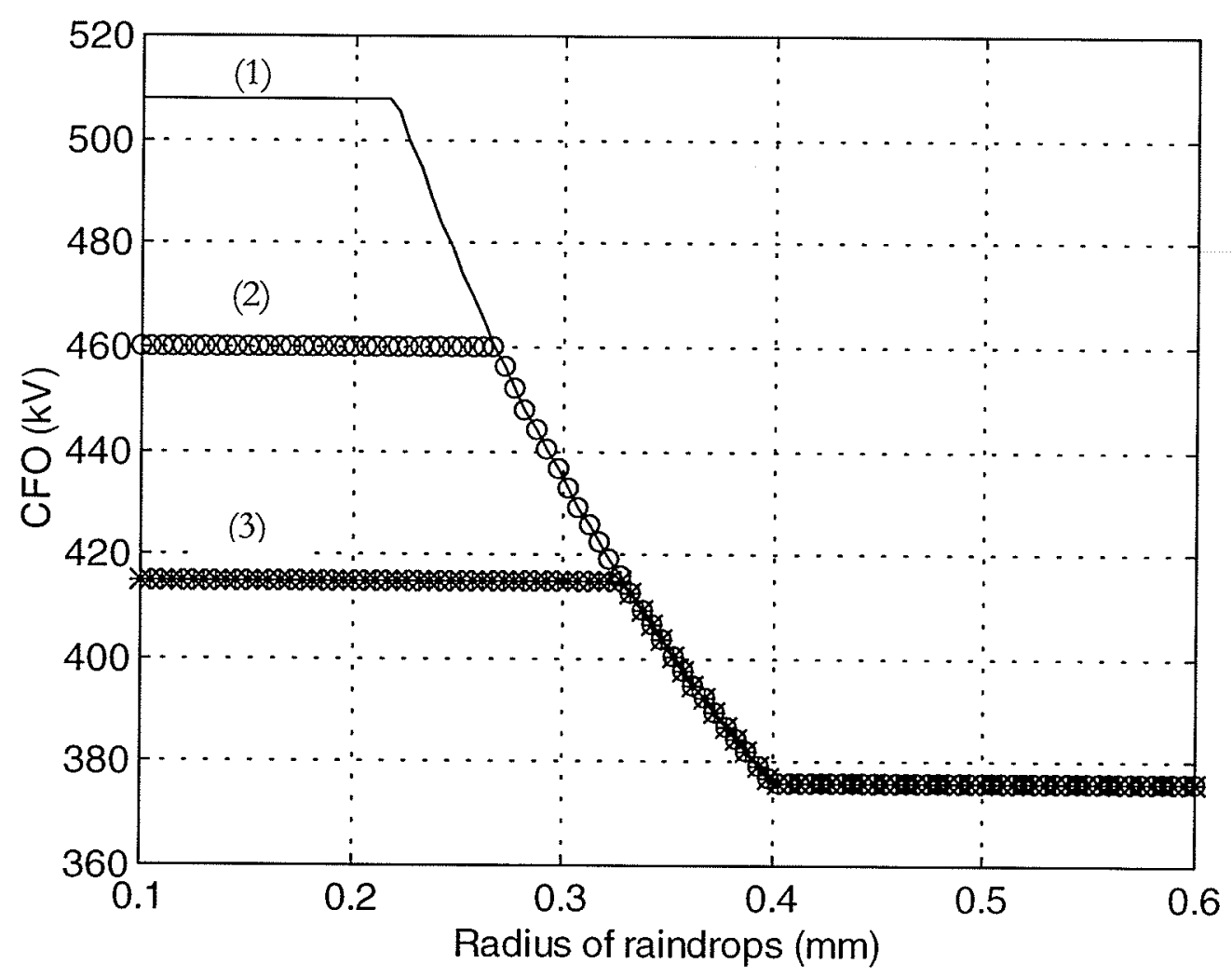

Fig. 4.7 Influence of altitude on the relation between $\mathrm{CFO}$ and raindrop size Rain conductivity: $100 \mathrm{mS} / \mathrm{cm}$ curve (1): sea level or air pressure $=101.3 \mathrm{kPa}$ curve (2): $1000 \mathrm{~m}$ altitude or air pressure $=91.3 \mathrm{kPa}$ curve (3): $2000 \mathrm{~m}$ altitude or air pressure $=81.3 \mathrm{kPa}$

\subsection{Effect of Bushing Configuration}

\subsubsection{Impact of Condenser Core}

Simulation of electric fields of a $110 \mathrm{kV}$ hollow bushing was conducted. Fig. 4.8 shows E-field contours and E-field at the shed tips. It is found that the E-field distribution is quite different from that of complete bushings. Generally speaking, the distribution of E-field of a hollow shell is characterised by a relatively low radial E-field. A complete bushing, on the other hand, has relatively high radial E-field and the voltage distribution at the surface of the porcelain shell is influenced by the grading system. As shown in Fig. 4.8, the E-field of a hollow shell is comparatively uniform and low. The normalized average E-field at shed tips for a $110 \mathrm{kV}$ 
hollow shell with $30 \%$ length of dry zone is about $78 \%$ of that for a complete bushing with the same length of dry zone.

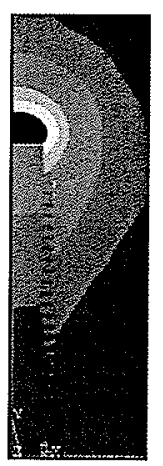

(a) for dry hollow shell

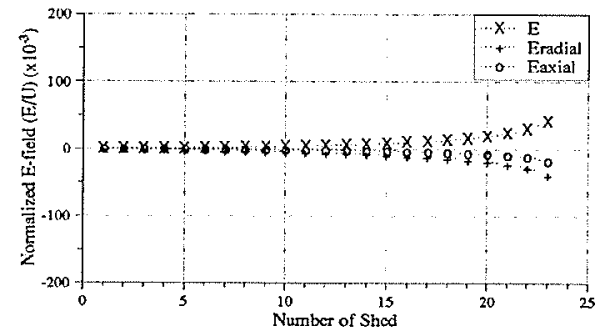

(c) for dry hollow shell
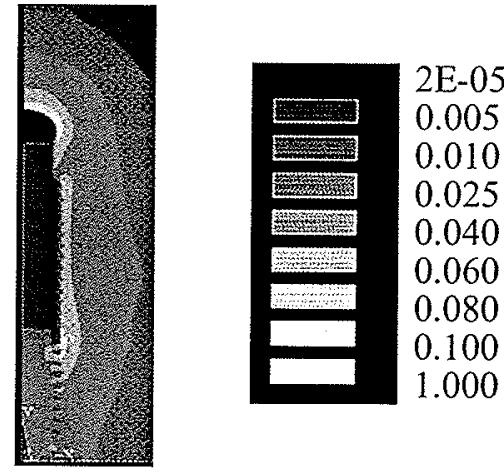

(b) for a hollow shell with $30 \%$ length of dry zone

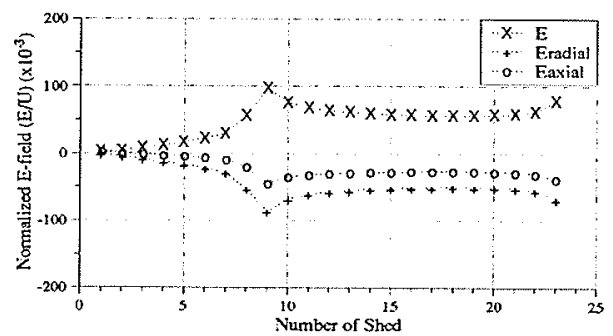

(d) for a hollow shell with $30 \%$ length of dry zone

Fig. 4.8 E-field contours and E-fields at shed tips for housing shells (Sheds are numbered from the ground end)

The critical flashover voltage for a $600 \mathrm{kV}$ bushing shell with $30 \%$ dry zone located at the ground end was predicted using the proposed model. In the simulation, all parameters were remained the same, but the condenser core was removed from the model. The estimated minimal CFO is $572 \mathrm{kV}$. The value is about $52 \%$ higher than $376 \mathrm{kV}$, the CFO of a full HVDC wall bushing with same dimensions. 
It has been experimentally confirmed that a hollow shell has a superior performance compared to a complete bushing. The performance of hollow shells does not represent that of a complete bushing. Therefore, one should use a complete bushing in experimental or simulation studies.

\subsubsection{Impact of Specific Length}

For the $600 \mathrm{kV}$ wall bushing model with specific length of $3.3 \mathrm{~cm} / \mathrm{kV}$, the model predicts a critical flashover voltage of $65 \mathrm{kV} / \mathrm{m}$. To confurm the effect of shed shape and creepage length on the CFO, the shed shape was modified from alternate-type to underrib-type sheds. As a result, the specific length is increased to $4.3 \mathrm{~cm} / \mathrm{kV}$, which is a $31 \%$ increase in creepage length. As shown in Table 4.6, the critical flashover stress is essentially the same. Further increase in the specific length up to $6.1 \mathrm{~cm} / \mathrm{kV}$ by increasing the overhang distance, results in only a marginal increase in the predicted critical flashover stress. With $6.1 \mathrm{~cm} / \mathrm{cm}$ specific length, the bushing is still likely to experience uneven wetting flashovers well below 400kVunder the worst case scenario.

The above observation is consistent with field experience in several HVDC schemes. In the Pacific Intertie Upgrade project, the specific length was increased from $2.5 \mathrm{~cm} / \mathrm{kV}$ to $4.0 \mathrm{~cm} / \mathrm{kV}$ when the operating voltage was increased from $400 \mathrm{kV}$ to $500 \mathrm{kV}$. In the Nelson River HVDC Line project, the specific length was increased from $3.29 \mathrm{~cm} / \mathrm{kV}$ to $4.36 \mathrm{~cm} / \mathrm{kV}$ when the $2^{\text {nd }}$ bi-pole $(500 \mathrm{kV})$ was commissioned. However, flashovers were reported in both stations when HVDC wall bushings were subjected to rain, particularly under uneven wetting conditions.

It is clear that high specific length by itself only offers limited improvement in the critical flashover voltage under uneven wetting conditions, although it may help to substantially 
improve, temporarily, the contamination flashover hold-off capability under heavy ESDD environments. Higher specific length alone does not solve the abnormal flashover problem of a HVDC wall bushing.

Table 4.4 Predicted Critical Flashover Stress vs. Specific Lengths ( $20 \%$ dry zone length located at the ground end)

\begin{tabular}{|l|c|c|c|}
\hline Specific length $(\mathrm{cm} / \mathrm{kV})$ & 3.3 & 4.3 & 6.1 \\
\hline $\begin{array}{l}\text { Critical flashover stress } \\
(\mathrm{kV} / \mathrm{m})\end{array}$ & 65 & 66 & 69 \\
\hline
\end{tabular}

By altering the profile it may be possible to create additional dry area in the wet zone next to the large sheds as shown Fig. 4.9. To study this effect in the simulation, a small dry strip (15 $\mathrm{mm}$ in width) was introduced in each of 10 wet zone sheds located next to the dry zone. Simulation with the configuration of $6.1 \mathrm{~cm} / \mathrm{kV}$ specific length was re-evaluated. Interestingly the critical flashover stress increases by almost $20 \%$, up to $82 \mathrm{kV} / \mathrm{m}$. It implies that the insulator shed profile may potentially have some impact on the $\mathrm{CFO}$ of a unevenly wetted HVDC wall bushing. Certain types of shed profiles may inherently create dry strips next to large sheds or underribs due to the shadow effect. Based on the simulation results, this may help to improve the performance significantly. 


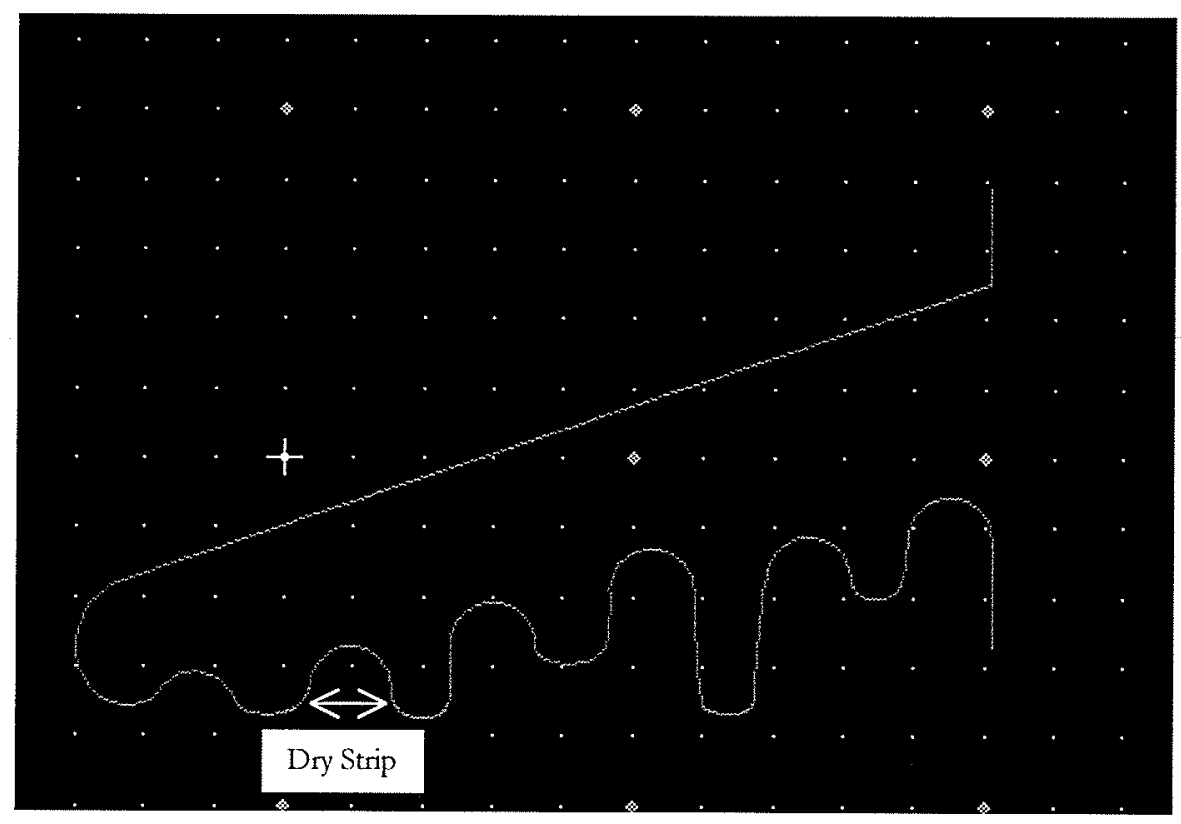

Fig. 4.9 Profile of underrib-type shed and dry strip

\subsection{Effect of Booster Sheds}

Booster sheds were originally developed in England to prevent the flashover of vertically mounted ac substation insulator under heavy rain [ElLL78]. The sheds are usually made of silicone rubber material. However, Manitoba Hydro has found that booster sheds can be fabricated from NEMA GPO-3 sheet material to which a RTV coating can be applied, if desired. This is a less expensive alternative to silicone rubber [ $\mathrm{McDe} 02]$. The effectiveness of booster sheds is due to a combination of water shedding, discharge inhibition and arc suppression. For a horizontally mounted HVDC wall bushing, the water shedding effect may not be that dominant. However, as may be seen from Fig.3.11, booster sheds not only provide a significant improvement in the electric field distribution along the critical line that links shed tips but also substantially extend its length. For a $600 \mathrm{kV}$ bushing with 12 booster sheds, the flashover path along the critical line can be increased by more than $60 \%$ due to additional 
$250 \mathrm{~mm}$ overhang. These effects are unfavourable for inception and propagation of discharges, and therefore ultimately lead to an increase in the critical flashover voltage.
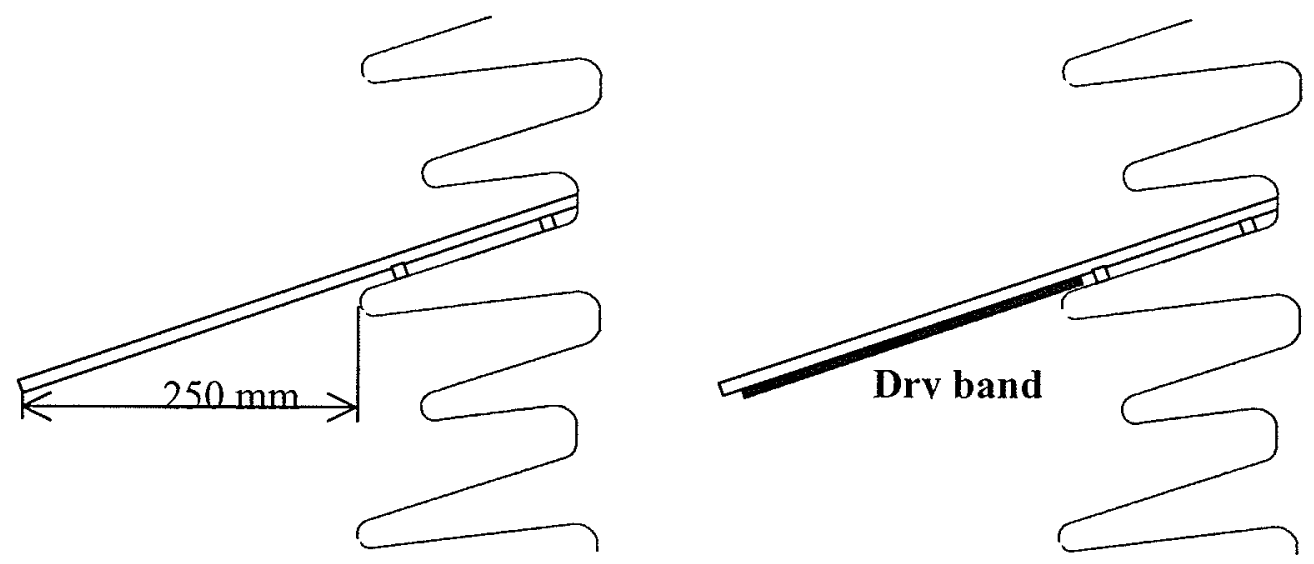

Fig. 4.10 Booster shed profile and dry band illustration

For a $600 \mathrm{kV}$ wall bushing with 12 booster sheds, the model predicts the critical flashover voltage to be $854 \mathrm{kV}$ when the dry zone is $30 \%$ in length and located at the ground end and shadow effect of booster shed is considered. The shadow effect was taken into account in the simulation by creating additional dry stripes underneath the booster sheds as shown in Fig.4.11. As a result, the flashover stress is increased from $72 \mathrm{kV} / \mathrm{m}$ to $163 \mathrm{kV} / \mathrm{m}$. Without considering the shadow effect, the estimated flashover stress value drops to $124 \mathrm{kV} / \mathrm{m}$. This value is still sufficiently high to avoid the occurrence of flashover during operation according to Table 1.1. The result is consistent with operational experience in Manitoba Hydro and other utilities. 

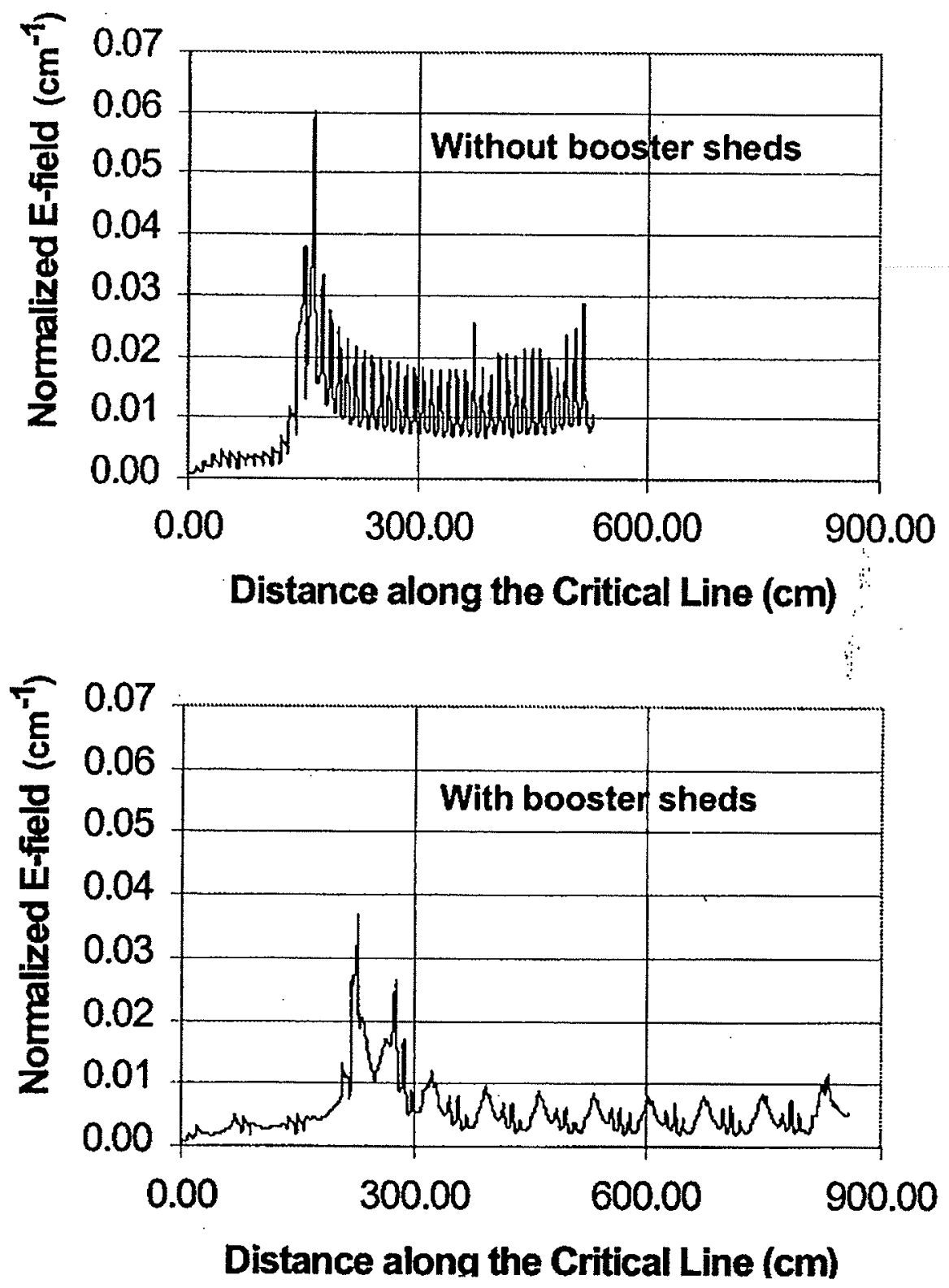

Fig. 4.11 E-field distribution along the critical line for a $600 \mathrm{kV}$ HVDC wall bushing with and without booster sheds ( $30 \%$ length of dry zone located at the ground end)

\subsection{Effect of RTV and Other Surface Coatings}

\subsubsection{Influence of Surface Conditions on E-field Distribution}

To improve the performance of HVDC wall bushings, periodic greasing or RTV coating is usually used. The use of a resistive glaze on a bushing surface to improve the surface voltage distribution has also been proposed. The influence of surface treatment on the E-field 
distribution can be investigated by either increasing the conductivity of the wet film or decreasing the conductivity of the dry surface. The values of conductivity for the different coatings are selected as shown in Table 4.4. Results of E-field simulation on a $110 \mathrm{kV}$ model are shown in Figs. 4.12 and 4.13.

As shown in Figs 4.12 and 4.13, it is evident that with a coated surface, generally, the E-field improves. It appears that bushings with coatings are less sensitive to uneven wetting. Thus, the risk of external flashover can be reduced with different degrees of success.

Fig. 4.14 shows the normalized electric field distribution along the critical line for the $600 \mathrm{kV}$ wall bushing model, with and without RTV coating when a $30 \%$ length of dry zone is located at the ground. It is seen that the RTV coating significantly reduces the surface electric fields, which leads to a better operating condition even under the worst case scenario of non-uniform wetting.

The maximum electric fields both inside and outside a $600 \mathrm{kV}$ HVDC bushing with $30 \%$ dry zone located at the ground end were evaluated and presented in Table 4.6.

Table 4.5 Conductivities for Surface Film with Different Coatings [ScLu91], [HaKu91]

\begin{tabular}{|c|c|c|c|c|}
\hline & RTV & Greasing & Glaze 1 & Glaze 2 \\
\hline$\gamma_{\text {wet }}(\mathrm{S} / \mathrm{m})$ & $5 \times 10^{-10}$ & $10^{-9}$ & $5 \times 10^{-4}$ & $5 \times 10^{-4}$ \\
\hline$\gamma_{\text {dry }}(\mathrm{S} / \mathrm{m})$ & $10^{-12}$ & $10^{-12}$ & $10^{-10}$ & $10^{-6}$ \\
\hline
\end{tabular}




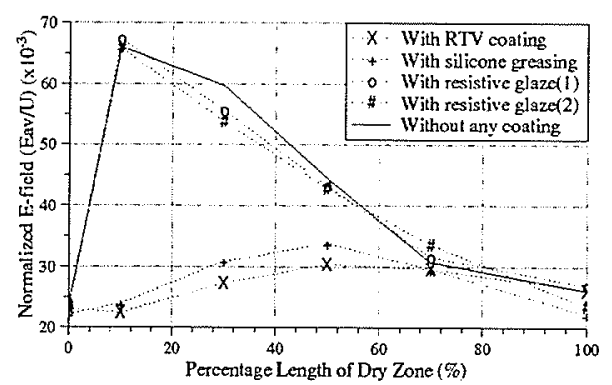

(a) Eav at shed tips

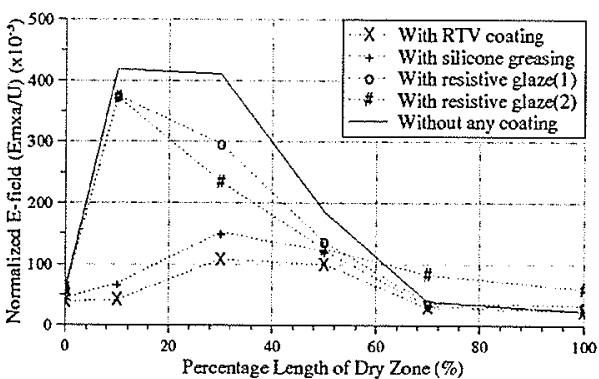

(c) Emax in porcelain housing

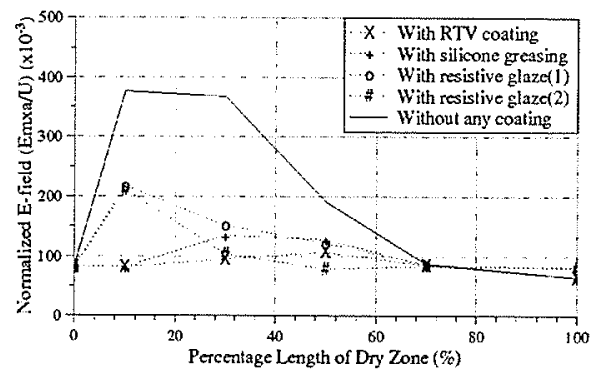

(b) Emax on extemal surface

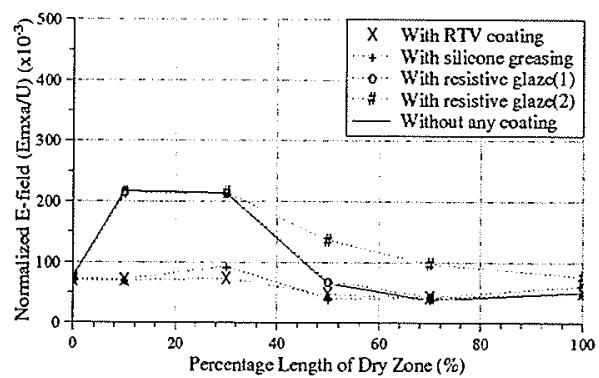

(d) Emax in oil

Fig. 4.12 Dependence of E-field intensity on the length of dry zone for a $110 \mathrm{kV}$ bushing with various surface conditions

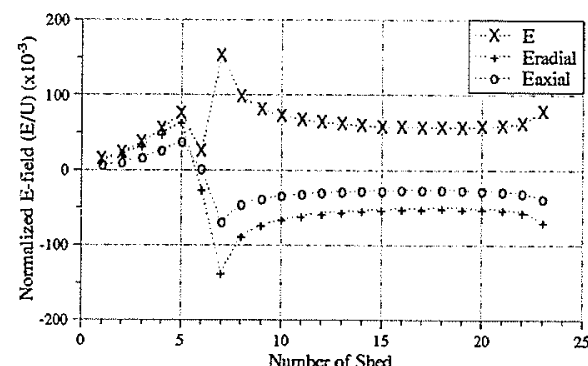

(a) without coating

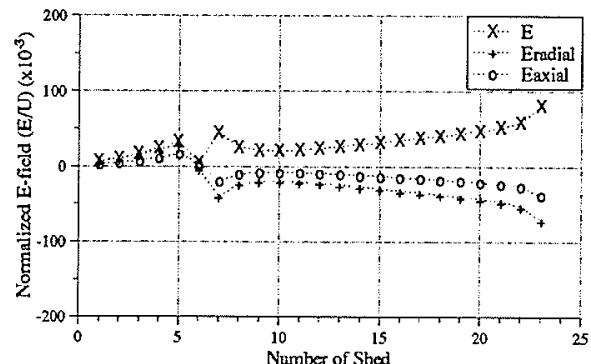

(c) with grease coating

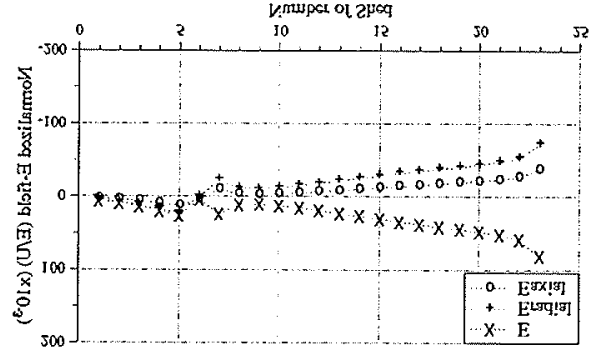

(b) with RTV coating

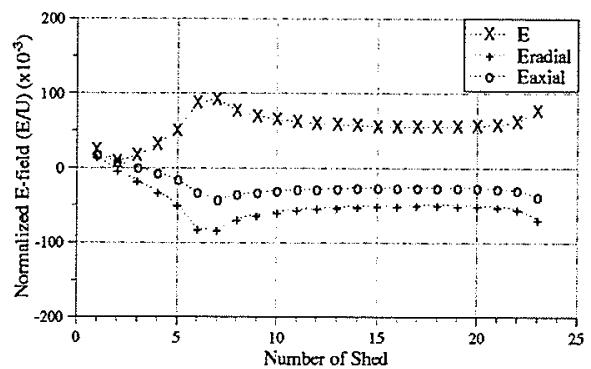

(d) with resistive glaze21

Fig. 4.13 E-field intensity at shed tips for a $110 \mathrm{kV}$ bushing with various coatings (30\% length of dry zone, sheds are numbered from the ground end) 


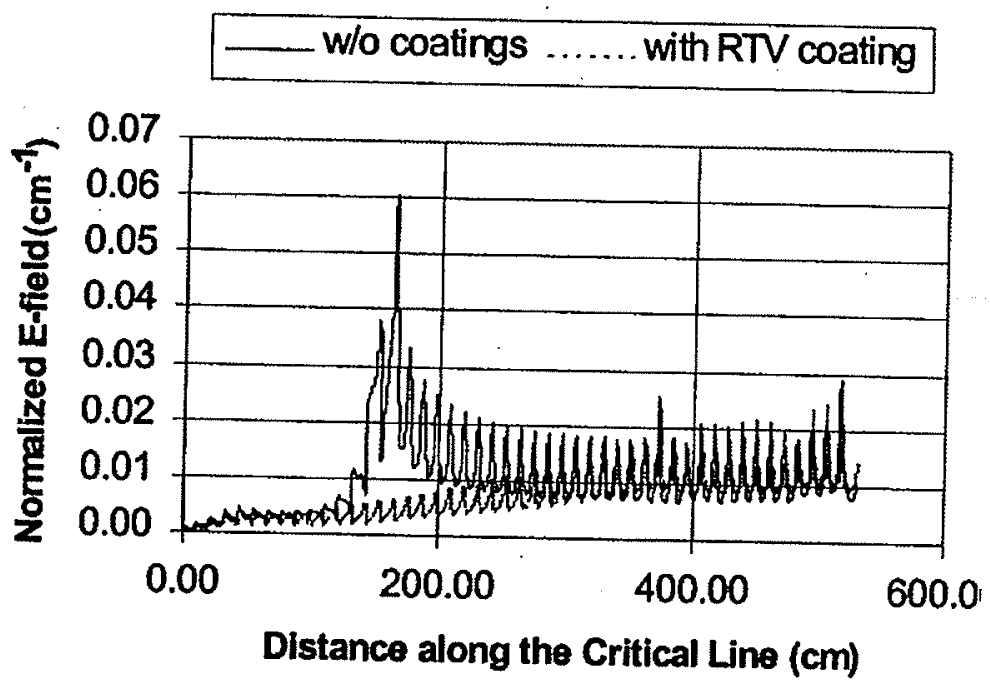

Fig. 4.14 Comparison of E-field distributions along the critical line with and without RTV coating (30\% dry zone located at the ground end)

Table 4.6 Maximal Normalized E-fields in Different Locations $\left(\mathrm{cm}^{-1}\right)$

\begin{tabular}{|l|c|c|c|}
\hline & Oil & Porcelain & External Air \\
\hline W/o coating & .006782 & .133144 & .102640 \\
\hline RTV & .004719 & .004932 & .031422 \\
\hline Glaze 1 & .005801 & .097294 & .075265 \\
\hline Glaze 2 & .005906 & .087121 & .044256 \\
\hline
\end{tabular}

As shown in Table 4.6, the maximal E-field in the ceramic under worst case of scenario is well above the typical ceramic dielectric strength of $12 \mathrm{kV} / \mathrm{mm}$. As a result of substantial local discharges, ceramic puncture is likely possible. Field failures due to ceramic puncture have been reported in [LaBK97].

Among these, the RTV coating provides the best improvement in E-field distribution, since both internal and external electric fields are relatively low. Although a resistive glaze does provide a relatively uniform voltage distribution along the external surface, it might also 
increase the electric field in the oil. Prolonged operation under these conditions may prove to be a concern for internal insulation.

\subsubsection{Impact of RTV Coatings on Uneven Wetting Flashover Voltage}

As discussed above, the RTV coating significantly reduces the surface electric fields, which leads to a better operating condition even under the worst case scenario of non-uniform wetting. Further, simulation results show that a RTV coated $600 \mathrm{kV}$ wall bushing with $30 \%$ length of dry zone at the ground end has a flashover voltage in excess of $1000 \mathrm{kV}$. On the other hand, the flashover voltage can be only between $376 \mathrm{kV}$ and $508 \mathrm{kV}$ when the coating is absent.

Fig. 4.15 compares the estimated critical flashover voltages for a $600 \mathrm{kV}$ HVDC wall bushing with and without RTV coating under different dry zone lengths. With RTV coating, the dry zone length is no longer critical to CFO. In other words, uneven wetting is no longer a prominent factor in facilitating a flashover. As a result, RTV coating is very successful in desensitizing the impact of uneven wetting and eliminating flashovers of HVDC wall bushing due to uneven wetting.

As observed from both field experience and laboratory tests, surface conductivity of RTV coating can be compromised due to ageing, which may only exhibit several times of resistivity compared to the uncoated one. Surface conductivity of wetted RTV coating was increased 100 times to reflect the aged RTV surface in the simulation. The predicted critical flashover voltage decreases to $680 \mathrm{kV}$, reflecting the influence of ageing. 


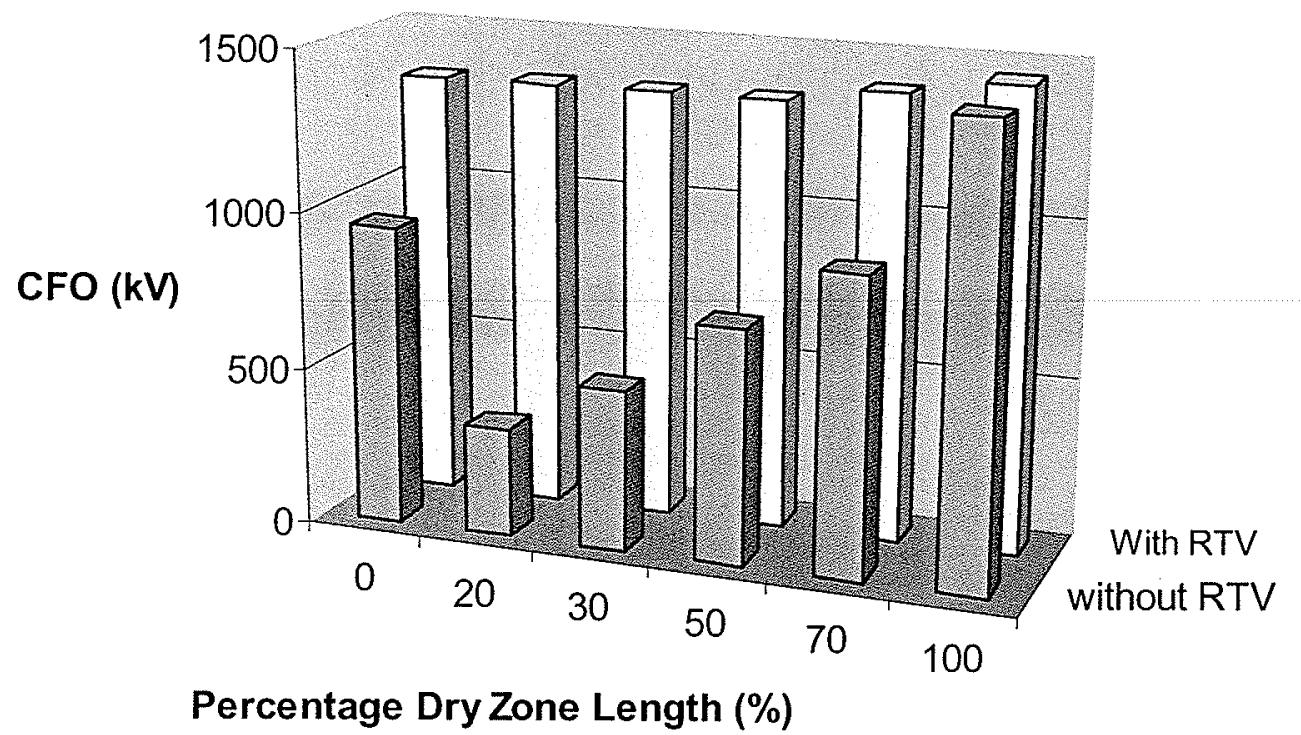

Fig. 4.15 CFOs versus dry zone length for a $600 \mathrm{kV}$ HVDC wall bushing with and without RTV coating

The critical flashover voltages for a $600 \mathrm{kV}$ HVDC wall bushing with resistive glazed coatings are also investigated through simulation. The results are presented in Fig. 4.16. In general, it appears that bushings with coatings are less sensitive to uneven wetting. Thus, the risk of external flashover can be reduced with different degrees of success.

The coatings may degrade over the time. As a result, the efficacy of the eliminating flashover may be compromised and the critical flashover voltage with an aged coating may be lower compared to the simulation results. 


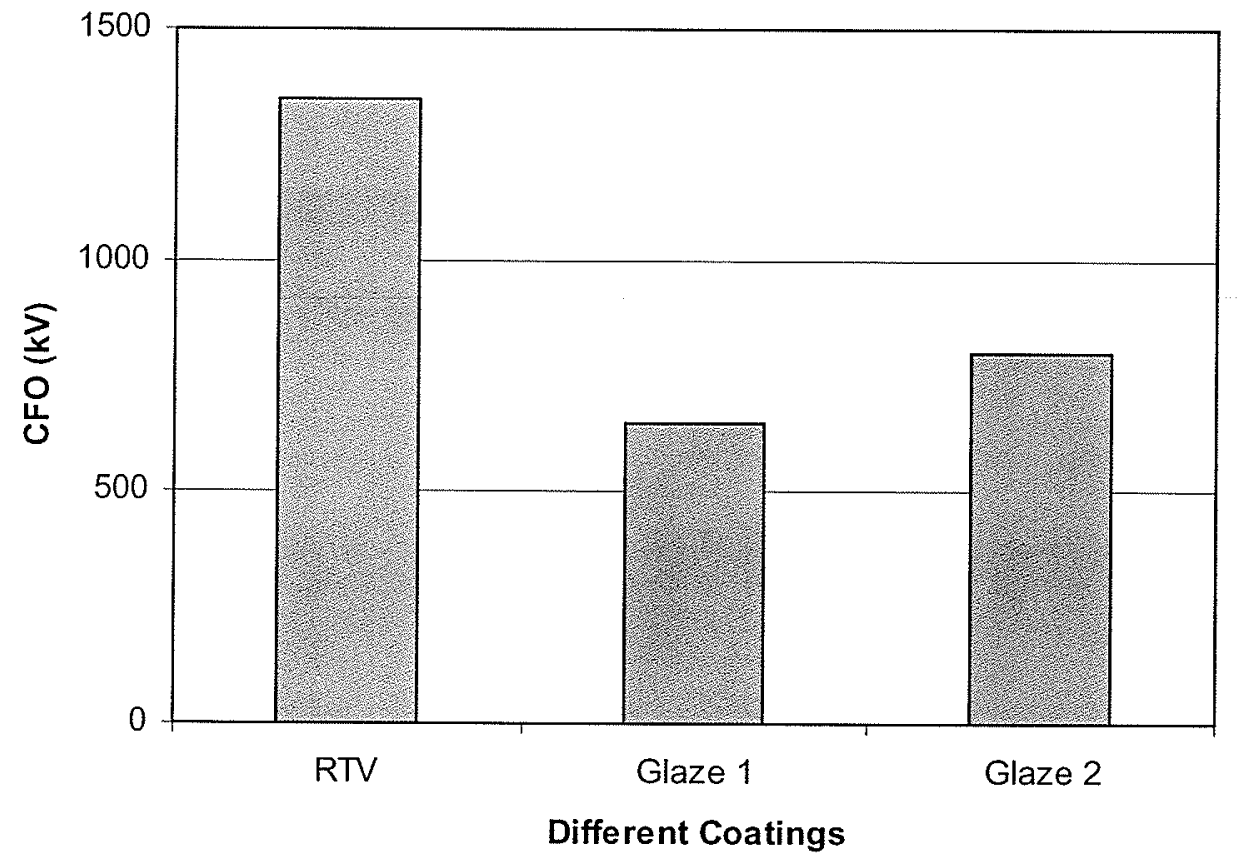

Fig. 4.16 CFOs for a $600 \mathrm{kV} \mathrm{HVDC}$ wall bushing with different coatings (30\% length of dry zone located at the ground end)

\subsection{Comparison of Results from Proposed Model with Experimental Results Published in Literature}

Such comparisons have been made in Fig. 4.2 and Table 4.3. Figure 4.2 shows that the flashover stresses lie in-between the model-predicted values obtained by neglect and inclusion of the effect of raindrops. The experimental results in Table 4.3 (column 3) and in Fig. 4.2 (indicated by blank circles) were obtained using a bushing identical to that considered in this work.

Table 4.7 shows predicted values of CFO stresses obtained by using the proposed and IREQ models. Also shown are experimental results published by Schneider [ScHN91]. It must be pointed out that the bushings used in the present simulation and that in [RiKa91] and [ScHN91] are all different. Comparison can therefore be only made with reference to the CFO 
stresses. Table 4.7 shows that under -ve polarity, all the results are close while under +ve polarity the proposed model yields results much close to experimental results.

Table 4.7 Comparison of CFO Stresses between the Proposed and IREQ Model

\begin{tabular}{|l|c|c|}
\hline & -ve & + ve \\
\hline Proposed model & $65 \mathrm{kV} / \mathrm{m}$ & $28 \%$ increase \\
\hline IREQ model [RiKa91] & $68 \mathrm{kV} / \mathrm{m}$ & $10 \%$ increase \\
\hline $\begin{array}{l}\text { Experimental data } \\
\text { [ScHN91] }\end{array}$ & $63 \mathrm{kV} / \mathrm{m}$ & $>30 \%$ increase \\
\hline
\end{tabular}

\subsection{Summary}

The proposed model has been used to evaluate the performance of HVDC wall bushings. By consideration of the mechanisms responsible for both initiation and propagation of streamers, the simulation yields encouraging tesults in terms of values and trend of results.

The model has been used to account for the following effects or interesting aspects of experimental and field observations for HVDC wall bushing flashovers.

- CFO vs. dry zone length, location, and critical range of dry zone length

- Polarity effect 
- $\mathrm{CFO}$ vs. taindrop size and conductivities

- $\mathrm{CFO}$ vs. air pressure and altitude

- Impact of condenser core and specific length

- Efficacy of booster shed

- Effects of RTV and other coatings

Since the proposed model yields results of acceptable engineering accuracy, it offers an attractive alternative to time consuming and expensive full scale field-testing. 


\section{Chapter 5}

\section{SUMMARY AND CONCLUSIONS}

The problem of HVDC wall bushing flashover due to uneven wetting is introduced and reviewed, with emphasis on recent progress in understanding the phenomena.

The physics of discharges, particularly for flashover of an unevenly wetted HVDC wall bushing, is discussed and various processes and mechanisms responsible for discharge initiation and propagation are clarified and discussed in detail. The uneven wetting flashover phenomenon of HVDC wall bushings is discussed, from fundamental concepts to mechanisms responsible for various processes in each stage. The influence of uneven wetting patterns on E-field and flashover voltage are verified.

A numerical model is developed in order to predict flashover voltages for a wall bushing, based on the results of electric field computation carried out on a bushing prior to initiation of flashovers. This analysis is carried out under a variety of practical conditions. By considering the mechanisms responsible for both initiation and propagation of discharges, the simulation yields encouraging results in terms of numerical values and trends.

The following conclusions are derived from the simulation results using a $600 \mathrm{kV}$ wall bushing with condenser core. The obtained results may be considered to be typical for porcelain clad HVDC wall bushings. The main conclusions are: 


\section{General Remarks}

Uneven wetting is verified as one of most severe operational conditions for a HVDC wall bushing. The non-uniform pattern of E-field distribution caused by uneven wetting results in a significant reduction in flashover stress. Model prediction shows the critical flashover stress can be as low as $65 \mathrm{kV} / \mathrm{m}$ under negative polarity, substantially lower than a typical operational design limit of $100 \mathrm{kV} / \mathrm{m}$.

The unique U-shaped characteristic of the curve of flashover stress versus dry zone length is reproduced by the numerical simulation. It is verified that the flashover voltage becomes the most critical when there is a $20 \%$ dry zone length located at the ground end for the -ve $600 \mathrm{kV}$ HVDC wall bushing considered in this study. The predicted critical flashover stress is very close to experimental data, i.e. $63 \mathrm{kV} / \mathrm{m} \sim 75 \mathrm{kV} / \mathrm{m}$.

\section{Effect of Configuration}

Wall bushing flashover under uneven wetting conditions is very susceptible to type of configuration. For example, the predicted CFO of the $600 \mathrm{kV}$ wall bushing shell is about $52 \%$ higher than that of the same bushing with a condenser core when $30 \%$ dry zone length is located at the ground end.

\section{Effect of Polarity}

(a) It is verified that the dry zone location also plays a role in the critical flashover. Dry zone at HV terminal seems to be more benign. For a given bushing model, the predicted CFO is $11 \%$ higher when the $30 \%$ length of dry zone located next to the HV terminal for a negatively energized HVDC wall bushing.

(b) Critical flashover voltage of the +ve HVDC wall bushing is predicted to be approximately $92 \mathrm{kV} / \mathrm{cm}$, when $30 \%$ length of dry zone located at the ground end. This is a $28 \%$ increase 
compared to the value obtained with the same bushing under negative polarity. This explains well why more than $70 \%$ of all reported HVDC wall bushing flashovers occur under negative polarity.

\section{Effect of Rain Drop Size and Rain Conductivity}

(a) The predicted range of CFO is between $376 \mathrm{kV}$ and $508 \mathrm{kV}$ for the negatively energized $600 \mathrm{kV}$ HVDC wall bushing with $30 \%$ dry zone length located at ground end. The lower limit is obtained when the influence of water drops is taken into account. This value is closer to the experimental results. It is evident that the critical flashover voltage has a strong dependence on the size of raindrops.

(b) Correlation between the $\mathrm{CFO}$ vs. rain conductivity is verified. Again there is a close agreement between the predicted values, trends and experimental results.

\section{Effect of Air Pressure and Altitude}

Air pressure and altitude have a second order impact on the critical flashover voltage. With increase in altitude, the critical flashover voltage caused by disintegration of small size raindrop decreases. The impact of rain size starts to diminish when a certain altitude is reached.

\section{Effect of Specific Length and Shed Profile}

(a) It is also shown that the specific length will not offer any significant improvement in uneven wetting flashover. In the simulation, the increase in the critical stress is marginal, from $65 \mathrm{kV} / \mathrm{m}$ to $69 \mathrm{kV} / \mathrm{m}$, when the specific length is almost doubled from $3.3 \mathrm{~cm} / \mathrm{kV}$ to $6.1 \mathrm{~cm} / \mathrm{kV}$. 
(b) The simulation shows relative dry strips created by shedding effect help to improve the flashover voltage. It is possible to improve the critical flashover stress by $20 \%$ by just selecting more wetting-friendly insulator profiles. Since the critical flashover voltage is shed profile dependent, it is important to review the details of the tested bushings when comparing simulation and experimental results.

\section{Effect of Booster Sheds}

Uneven wetting flashovers can be substantially improved by using booster sheds. For a $600 \mathrm{kV}$ HVDC wall bushing with $30 \%$ length of dry zone located at the ground end, the flashover stress can be increased from $72 \mathrm{kV} / \mathrm{m}$ to $124 \mathrm{kV} / \mathrm{m}$. When the shedding effect is considered the estimated flashover stress can be as high as $163 \mathrm{kV} / \mathrm{m}$.

\section{Effect of Coatings}

(a) RTV coating significantly reduces the surface electric frelds. With RTV coating, uneven wetting pattern is no longer critical to the HV performance. Simulation results show that a RTV coated $600 \mathrm{kV}$-wall bushing, with $30 \%$ length of dry zone located at the ground end, has a flashover voltage in excess of $1000 \mathrm{kV}$. On the other hand the flashover lies between $376 \mathrm{kV}$ and $508 \mathrm{kV}$ when the coating is absent. However, for aged RTV coating, the above flashover voltage can be compromised to $680 \mathrm{kV}$ as per the simulation.

(b) Other coatings can also offer some electric field relief on the HVDC wall bushing surface, and therefore improve the HV performance under uneven wetting conditions. However, among all coatings, the RTV coating provides the best improvement in E-field distribution, since both internal and external E-fields are comparably lower. Although a resistive glaze can also render a relative uniform voltage distribution along the external 
surface, it will also increase the electric fields in oil inside housing. Prolonged operation under these conditions may prove to be a concern for internal insulation.

The proposed numeric model has been validated through comprehensive simulations and their comparison to the experimental results available in literature. The simulation results are in good agreement with experimental data and, in general, explain very well many aspects of uneven wetting flashover. The simulation results provide insight not only to the vulnerability of wall bushings to different weather conditions, but also attempt to give at least some insight as to whether certain insulator profiles are more vulnerable than others, and other factors which affect performance. The simulation has also enabled the assessment of the effectiveness of different profiles for improving the HV performance of wall bushings.

The results of this research, particularly the proposed models are important supplements to large-scale experiments, which are costly and time consuming. The use of such a model will be very helpful in selecting and designing HVDC wall bushings for future HVDC transmission schemes and to improve the performance of wall bushings in the existing HVDC transmission schemes. 


\section{References}

\section{BOOKS}

[Cha157] J. Alan Chalmers, Atmospheric Electricity, Pergamon Press, New York, 1957

[FiBe93] Donald G. Fink, H. Wayne Beaty, Standard Handbook for Electrical Engineers, Thirteen Edition, McGRAW-HILL INC, 1993

[KiKä85] Dieter Kind, Hermann Kätner, High-Voltage Insulation Technology, Braunschweig/ Wiesbaden; Friedr. Vieweg \& Sohn, 1985

[KuZa84] E. Kuffel, W. S. Zaengl, High Voltage Engineering - Fundamentals. Pergamon Press, 1984

[Loeb55] L. Loeb, Basic Process of Gaseous Electronics, University of California Press, 1955

[MeCr53] J. M. Meek, J. D. Craggs, Electrical Breakdown of Gases, Oxford University Press, 1953

[Raga80] Klaus Ragaller, Surges in High-Voltage Networks, Plenum Press, 1980

[Rees73] J. A. Rees, Electrical Breakdown in Gases, the Macmillan Press Limited, 1973

[XieG62] G. Xie, Static Field for High Voltage Engineering, Shanghai Science and Technology Press, 1962 (Chinese)

[Yang83] J. Yang, Gaseous Discharges, Science Press, 1983 (Chinese) 


\section{PAPERS}

[AlBL93] N. L. Allen, M. Boutlendj, H. A. Lightfoot, "Dielectric Breakdown in Nonuniform Field Air Gaps", IEEE Transactions on Electrical Insulation, Vol. 28 No. 2, pp 183 191, April 1993

[AlBo88] N. L. Allen, M. Boutlendj, "The Threshold for Streamer Propagation in Air", IX International Conference on Gas Discharges and Their Application, pp159 162, Venezia, September, 1988

[AlGh93] N. L. Allen and A. Ghaffar, "Temperature and Density Effects on Streamer Propagation in Air", 8th International Symposium on the High Voltage Engineering, Vol.2, pp.5 8, Yokohama, Japan, August 1993

[AlSh93] N. Alame, S.Shihab, "On the Effects of Internal Insulation Systems of High Voltage Current Transformers and Bushings on Their Surface Flashovers under Pollution", 8th International Symposium on the High Voltage Engineering, Vol.2 pp.129 132, Yokohama, Japan, August 1993

[Brau70] A. Braunstein, "Lightning Strokes to Power Transmission Lines and the Shielding Effect of Ground Wires”, IEEE Trans. PAS-89, No.8, pp1900 1910, 1970

[Cai96] Chenliang Cai, "Investigation on the Equivalent Salt Deposit Density Values for the HVDC Converter Station in Three Gorge Project", Hubei Electric Testing and Research Institute, China, Report, June, 1996

[CaTh76] G. Carrara, L. Thione, "Switching Surge Strength of Large Air Gapa: A Physical Approach", IEEE Trans. PAS-95, No.2 (March/April), 1976

[CEA95] CEA 203 T 787, "A Survey of the Service Performance of HVDC Wall Bushings and Other Outdoor Converter Station Insulators", Volume II, June 1995

[EPRI90] Electric Power Research Institute, “HVDC Wall Bushing Studies”, EPRI EL-6923, Project 3039-1, Final Report, July 1990

[Eng148] W. N. English, "Corona from a Water Drop", Phys. Rew., 74. 2, pp179 189, 1948 
[ElLL78] C. H. A. Ely, P. J. Lambeth, J. S. T. Looms, "The Booster Shed: Prevention of Flashover of Polluted Substation Insulators in Heavy Wetting", IEEE Trans. PAS-97, No.6, pp2187, 1978

[FeHu88] K. Feser and R. C. Hughes, "Measurement of Direct Voltage by Rod-Rod Gap", Electra, No117, pp23 34, 1988

[Forr88] J. A. C. Forrest, "Monitoring the Flashover of a $-450 \mathrm{kV}$ dc Wall Bushing", Minutes of BPA's 3rd Workshop Meeting on HVDC Insulation, Vancouver, Washington, July 1988

[Gall72] I. Gallimberti, "A Computer Model for Streamer propagation”, J. Phys. D. 5 , pp2179 2189, 1972

[Gall79] I. Gallimberti, "The Mechanism of the Long Spark Formation", Journal De Physique, Colloque C7, supplement au no 7, Tome 40, Juillet pp c7-193 250, 1979

[GaMa91] Ivo Gallimberti, Gabriele Marchesi, "Streamer Corona at an Insulator Surface", 7th International Symposium on the High Voltage Engineering, Vol.4, pp.47 50, Dresden, August 1991

[GäMa72] Berthold E. Gänger, E. G. Maier, "Studies of Spark Formation at High Switching Voltages of Positive Polarity", IEEE Trans. PAS-91, No.5, pp2427 2435 1972

[GuZh90] Zhicheng Guan and Renyu Zhang, "Calculation of dc and ac Flashover Voltage of Polluted Insulators", IEEE Transactions on Electrical Insulation, Vol.25 No.4, pp723 729, August, 1990

[HaKu91] F. Hammer and A. Kuchler, "Insulating System for HVDC Power Apparatus", Proceedings of the 3rd International Conference on Properties and Applications of Dielectric Materials, Tokyo, Japan, July, 1991

[Hart91] Ralf Hartings, "Modern Experimental Techniques to Study the Discharge Phenomena on Outdoor Insulators", 7th International Symposium on the High Voltage Engineering, 72.10, Dresden, Germany, August 1991

[Hart94] Ralf Hartings, "The AC-Behavior of a Hydrophobic Post Insulator during Rain", IEEE Transactions on Power Delivery, Vol. 9, No.3, pp1584 1592, 1994

[Hutz89] B. Hutzler, "Dielectric Properties of Air Gaps", 8th International Symposium on the High Voltage Engineering, 28.01, New Orleans, USA, August 1989 
[HuHu78] B. Hutzler, D. Hutzler-Barre, "Leader Propagation Model for Predetermination of Switching Surge Flashover Voltage of Large Air Gaps", IEEE Trans. PAS-97, No.4, pp1087 1095, 1978

[JoKi89] Alan R. Johnston, Harold Kirkham, "A Miniaturized Space-potential DC Electric Field Meter", IEEE Transactions on Power Delivery, Vol.4, No.2, pp1253 1261, April 1989

[KaSB95] George G. Karady, Minesh Shah, R. L. Brown, "Flashover Mechanism of Silicone Rubber Insulators Used for Outdoor Insulation- Part1 \&Part 2", IEEE Transactions on Power Delivery, Vol.10, No.4, pp1965 1978, October 1995

[KiCH90] S. H. Kim, E. A. Cherney, R. Hackam, "The Loss and Recovery of Hydrophobicity of RTV Silicone Rubber Insulator Coating", IEEE Transactions on Power Delivery, Vol.5, No.3, pp1491 1499, July 1990

[Klin77] L. E. Kline, "Corona Cloud Model Prediction of Switching Surge Flashover Voltage Versus Electrode Geometry”, IEEE Trans. PAS-96, No.2, 1977

[KoVA95] A. R. Koriavin, O. V. Volkova, A. V. Almazov, "Calculation of Electrical Strength of External Insulation for EHV and UHV Bushing", 9th International Symposium on the High Voltage Engineering, 8374, Graz, Austria, August 1995

[Küch95] Andreas Küchler, "Suppression of Surface Discharges and Flashover on Dielectric Surface", 9th International Symposium on the High Voltage Engineering, 8032, Graz, Austria, August 1995

[KuYT95] Mamoru Kubuki, Ryuichi Yoshimoto, Kazuki Tanoue, Masanori Hara, "Breakdown Characteristics in Air Gaps with Artificial Floating Metals under dc Voltage", IEEE Transactions on Dielectrics and Electrical Insulation Vol.2 No.1, pp 155 166, Feb. 1995

[LaA191] W. Lampe, B. Almgren, "External Flashovers in HVDC Stations", CIGRÉ 33.91. (Coll)IWD 4.17, 1991

[Lamb89] P. J. Lambeth, "HVDC Wall Bushing”, CEA Report No. 203 T421, 1989

[Lamb90] P. J. Lambeth, "Laboratory Tests to Evaluate HVDC Wall Bushing Performance in the Wet Weather", IEEE Transactions on Power Delivery, Vol.5, No.4, pp1782 1793, November 1990

[LaBK96] P. J. Lambeth, Y. Beausejour, S. I. Kamel, "Behavior of HVDC Wall Bushings under Rain", 203T787 V0lume I, Canadian Electrical Association, July 1996 
[LaBK97] P. J. Lambeth, Y. Beausejour, S. I. Kamel, "HVDC Wall Bushings: Problems and Solutions", 10th International Symposium on High Voltage Engineering, Montreal, August 1997

[Lamp88] W. Lampe, "Pollution and Rain Flashovers on HVDC Wall Bushings", Proceeding of 2nd International Conference on Properties and Applications of Dielectric Materials, Beijing, September, 1988

[LaWJ91] W. Lampe, D. Wikström, and B. Jacobson, "Field Distribution on An HVDC Wall Bushing During Laboratory Tests", IEEE Transactions on Power Delivery, Vol.6, No.4, pp1531 1540 October 1991

[McDe88] W. McDermid, "HVDC Bushing Flashovers \& Failures", Minutes of BPA's $3^{\text {rd }}$ Workshop on HVDC Insulation, Vancouver, Washington, July 1988

[McDe02] W. McDermid, "Exam Report for Liang' Dissertation”, pp3 and pp7, March 2002

[NaHe74] E. Nasser and M. Heiszler, "Mathematical-physical Model of the Streamer in Nonuniform Field", Journal of Applied Physics, Vol.45, No.8, pp3396 3401, August 1974

[NaMI89] Katsuhiko Natio, Ryosuke Matsuoka, Susumu Ito, and Satoshi Morikawa, "An investigation of the Horizontally Mounted Insulators for HVDC Stations", IEEE Transactions on Power Delivery, Vol.4, No.1, pp653 666, January 1989

[NaSh69] E. Nasser and R. Shah, "Analysis of Streamer Branching in Atmospheric Air", Int. Conf. on Phenomena in Ionized Gases Bucharest Conf. Proc. 9: 271, 1969

[OnCH85] T.L. Ong, T. C. Cheng, and N. G. Hingorani, "Survey of Creepage Distances and Clearances in HVDC Converter Station", IEEE Transactions on Power Apparatus and Systems, Vol. PAS-104, No.8, pp2255 2266, August 1985

[PaCo68] Luigi Paris, Rosario Cortina, "Switching and Lightning Impulse Discharge Characteristics of Large Air Gaps and Long Insulator Strings", IEEE Transactions on Power Apparatus and Systems, Vol. PAS-87, No.4, pp947 957, 1968

[Pari67] Luigi Paris, "Influence of Air Gap Characteristics on Line-to-ground Switching Surge Strength", IEEE Transactions on Power Apparatus and Systems, Vol. PAS-86, No.8, pp936 947, 1967

[Pede89] A. Pedersen, "On the Electrical Breakdown of Gaseous Dielectrics - An Engineering Approach", IEEE Transactions on Electrical Insulation, Vol.24 No.5, October, 1989 
[PePP95] D. Perin, A. Pigini, A. Porrino, I. Visintainer, "Flashover in HVDC Bushings under Nonuniform Rain", 9th International Symposium on High Voltage Engineering, paper 3204, Graz, Austria, August, 1995

[PeZa95] K. Petcharaks and W. S. Zaengl, "Numerical Calculation of Breakdown Voltages of Standard Air Gaps(IEC 52) Based on Streamer Breakdown Criteria", 9th International Symposium on High Voltage Engineering, paper 2173, Graz, Austria, August, 1995

[Rayl82] F. R. S. Lord Rayleigh, "On the Equilibrium of Liquid Conducting Masses Charged with Electricity”, Phil. Mag. 14, pp184 186, 1882

[RaMc89] M. M. Rashwan, W. McDermid, "DC Wall Bushings on the Nelson River HVDC System", IEEE Canadian Review, March 1989

[RaMc89-2]M. M. Rashwan, W. McDermid, "Experience with DC Wall Bushings Associated with the Nelson River System", Proceedings of the Second HVDC Operating Conference, pp117 125, Winnipeg, September 1989

[Rash91] M. M/ Rashwan, Discussion in "Modelling of HVDC Flashover in Nonuniform Rain", IEEE Transactions on Power Delivery, Vol.6, No.4, pp1661, October 1991

[Rena74] The Renardieres Group, "Research on Long Air Gap Discharges at Les Renardieres", Electra No.35, pp49 156, July 1974

[Rena77] The Renardieres Group, "Research on Long Air Gap Discharges at Les Renardieres", Electra No.53, pp, July 1977

[RiKa91] Farouk A. M. Rizk, Sherif I. Kamel, "Modelling of HVDC Flashover in Nonuniform Rain”, IEEE Transactions on Power Delivery, Vol.6, No.4, pp1650 1662, October 1991

[Rizk89] Farouk A. M. Rizk, "A Model for Switching Impulse Leader Inception and Breakdown of Long Air-gaps", IEEE Transactions on Power Delivery, Vol.4, No.1, pp596 604 January, 1989

[Rizk95] Farouk A. M. Rizk, "Effect of Floating Conducting Objects on Critical Switching Impulse Breakdown of Air Insulation", IEEE Transactions on Power Delivery, Vol.10, No.3, July 1995

[SaPS77] M. M. A. Salama, H. Parekh, and K. D. Srivastava, "A Comment on the Methods of Calculation of Corona Onset Voltage”, Applied Physics Letters, Vol.30, No.3, pp139 141, February 1977 
[ScGG91] H. M. Schneider, W. W. Guidi, and J. C. Gleadow, "Clean Fog and Live Washing Performance of Vertical HVDC Bushings", IEEE Transactions on Power Delivery, Vol.6, No.4, pp1812 1818, October 1991

[ScHN91] H. M. Schneider, J. F. Hall, C. L. Nellis, S.S. Low, and D. J. Lorden, "Rain and Contamination Tests on HVDC Wall Bushings With and Without RTV Coatings", IEEE Transactions on Power Delivery, Vol.6, No.3, pp1289 1300, July 1991

[ScLu1] H. M. Schneider, A.E. Lux, "Mechanism of HVDC Wall Bushing Flashover in Nonuniform Rain", IEEE Transactions on Power Delivery, Vol.6, No.1, pp448 455, January 1991

[ShSu95] Takatoshi Shindo, Toshio Suzuki, “A Method of Predicting Anomalous Flashovers", IEEE Transactions on Power Delivery, Vol.10, No.3, pp1371 1377, July 1995

[Sher88] J. D. Sherwood, "Breakup of fluid droplets in electric and magnetic fields, J. Fluid Mech., 188, pp133 146, 1988

[SpLS95] Rapid Evaluation of HVDC Grading Rings by BIE-based Field Caculation", 9th International Symposium on High Voltage Engineering, paper 8339, Graz, Austria, August, 1995

[StTo91] I. A. Stathopulos, F. V. Topalis, "Investigation of the Dielectric Bahavor of Polluted Insulators Using a Stochastic Model”, 7th International Symposium on the High Voltage Engineering, 43.21, Dresden, Germany, August 1991

[SuCL1] Zhaoyin Sun, Xing Chen, and Xiaokang Lai, "Non-uniform Rain Flashovers on HVDC Wall Bushing", Proceeding of 7th International Symposium on High Voltage Engineering, 43.05, Dresden, August 1991

[SuSu99 Zhiyi Su, Zhaoyin Sun, "Dermentioning Rules of External Insulations of Coverter Stations for the Three-Gorges First $\pm 500 \mathrm{kV}$ HVDC Project ", EPRI(China) Report G9620, 1996

[SuSN95] N. Sugawara, K. Sakaguchi, I. Nakajima, and K. Kondo, "Negative DC Surface Discharge Triggered by Water Drops on Hydrophobic Surface of Insulation Materials", 9th International Symposium on High Voltage Engineering, paper 3216, Graz, Austria, August, 1995

[Tayl64] G. I. Taylor, "Disintegration of Water Drops in an Electric Field", Proc. Roy. Soc. London, A280, pp383 397, 1964 
[TaRa95] L. Tang, and M. R. Raghuveer, "E-field Modelling of HVDC Wall Bushing Performance", 9th International Symposium on High Voltage Engineering, paper 8324, Graz, Austria, August, 1995

[TaRT95] L. Tang, M. R. Raghuveer, and N. J. Tarko, "Experimental Investigation of the Influence of Different Wetting Conditions on dc Strength of a Flat Insulating Surface”, 1995 IEEE Conference on Electrical Insulation and Dielectric Phenomena, pp467 470, Virginia Beach, USA, October, 1995

[TaRa96] L. Tang, M. R. Raghuveer, "Numerical Prediction of HVDC Wall Bushing Flashover Caused by Uneven Wetting", 1996 IEEE Conference on Electrical Insulation and Dielectric Phenomena, pp455 458, San Francisco, USA, October, 1996

[TaRa97a] L. Tang, M. R. Raghuveer, "Influence of Waterdrops on the Uneven Wetting Flashover of HVDC Wall Bushings", 10th International Symposium on High Voltage Engineering, paper 3156, Montreal, Canada, August, 1997

[TaRa97b] L. Tang, M. R. Raghuveer, "Simulation of HVDC Wall Bushing Performance under Unevenly Wetted Conditions", IEEE WESCANEX'97 Conference, Winnipeg, Canada, 1997

[TaRa97c] L. Tang, M. R. Raghuveer, "Numerical Evaluation of the Efficacy of Booster Sheds and RTV Coating in Improving the performance of HVDC Wall Bushings", 1997 IEEE Conference on Electrical Insulation and Dielectric Phenomena, pp410 413, Minnesota, USA, October, 1997

[TaRa99] L. Tang, M. R. Raghuveer, "Modelling of HVDC Wall Bushing Flashover Due to Uneven Wetting”, IEEE Transactions on Power Delivery, Vol.14, No.1, pp194 199, January 1999

[Thio79] L. Thione, "The Dielectric Strength of Large Air Insulation", Surges in High Voltage Networks, New York, 1979

[UdWa68] Tatsuo Udo, Yasuo Watanabe, "DC High-Voltage Sparkover Characteristics of Gaps and Insulator Strings", IEEE Transactions on Power Apparatus System, Vol. PAS-87, No.1, pp266 270, 1968

[UlGa91] L. Ullrich and I. Gallimberti, "A Numerical Leader Inception Model in Air", IX Int. Con. on Gas Discharges, pp419 422, Venice, 1988

[Wate81] R. T. Waters, "Breakdown in Nonuniform Fields", IEE Proc. Vol. 128 Pt.A No.4, pp319 325, 1981 
[WaJo64] R. T. Waters and R. E. Jones, "The Impulse Breakdown Voltage and Time-lag Characteristics of Long Gaps in Air", Philosophical Transactions of the Royal Society of London, Series A. No.1069 Vol.256, pp185 234, April 1964

[WiFo93] Dan WikstrÖm and Peter Forsberg, "Flashover Performance of Post Insulators with Different Hetrogeneous Wetting Properties", 8th International Symposium on the High Voltage Engineering, Vol.2 pp.165 168, Yokohama, Japan, August 1993

[WiNP88] N. Wiegart, L.Niemeyer, F. Pinnekamp, W. Boeck, J. Kindsberger, R. Morrow, W. Zaengl, M. Zwicky, I. Gallimberti and S. A. Boggs, "Inhomogeneous Field Breakdown in SF6", Parts 1 3, IEEE Transactions on Power Delivery, Vol.3, No.3, pp923 946, 1988

[WiSL93] Dan Windmar, Viktor Scuka, and Wolfgang Lampe, "Water Drop Triggered Discharges on Hydrophobic Surfaces", 8th International Symposium on the High Voltage Engineering, Vol.2 pp.169 171, Yokohama, Japan, August 1993

[WoMc70] Herbert H. Woodson, Allan J. Mcelroy, "Insulators with Contaminated Surfaces, Part II: Modelling of Discharge Mechanisms", IEEE Transactions on Power Apparatus System, Vol. PAS-89, No.8, pp1858 1867, 1970

[WuHÅ95] D. Wu, R. Hartings, U. ÅstrÖm, "The Performance of Station Post Insulators in Uneven Rain Under dc Voltage", 9th International Symposium on the High Voltage Engineering, Vol.3 3237, Graz, Austria, August 1995

[ZhLi93] Jianchao Zheng, Youwei Liu, "Humidity Effect on Surface Discharges Under Impulse Voltages", 8th International Symposium on the High Voltage Engineering, Vol.2 pp.161 164, Yokohama, Japan, August 1993

[ZhSC91] Jianchao Zheng, Zhaoying Sun, Xing Chen, Xiaokang Lai, and Yifeng Yin, "Studies on the Mechanism of Flashover along An Uneven-wetted Insulating Surface", Proceeding of 7th International Symposium on High Voltage Engineering, 43.05, Dresden, August 1991 
Appendix

\section{EXPERIMENTAL INVESTIGATION OF THE INFLUENCE OF DIFFERENT WETTING CONDITIONS ON A FLAT INSULATING SURFACE}

The purpose of this experimental study is to investigate the influence of an uneven wetting pattern on the electric field distribution and surface discharges. Factors, which may contribute to flashover such as configuration, dry zone length, water conductivity, voltage polarity, and space charges, are studied experimentally.

\section{A.1 Test Arrangement}

In order to ensure that the test data is realistic, it is necessary to use a powerful voltage source of sufficient capacity. In this work, a HV capacitor of $0.1 \mu \mathrm{F}$ was used in parallel with the output of dc source.

To simulate the surface strength of porcelain, a glass plate system, which was made from Neoceram glass, was used. Two basic configurations were considered, i.e. a bushing-type configuration in which both longitudinal and normal electric field components exist and an insulator-type configuration in which the longitudinal component of E-field is dominant. The bushing type configuration was simulated by provision of a third electrode (aluminium foil) used beneath the glass plate as shown in Fig.A.1 


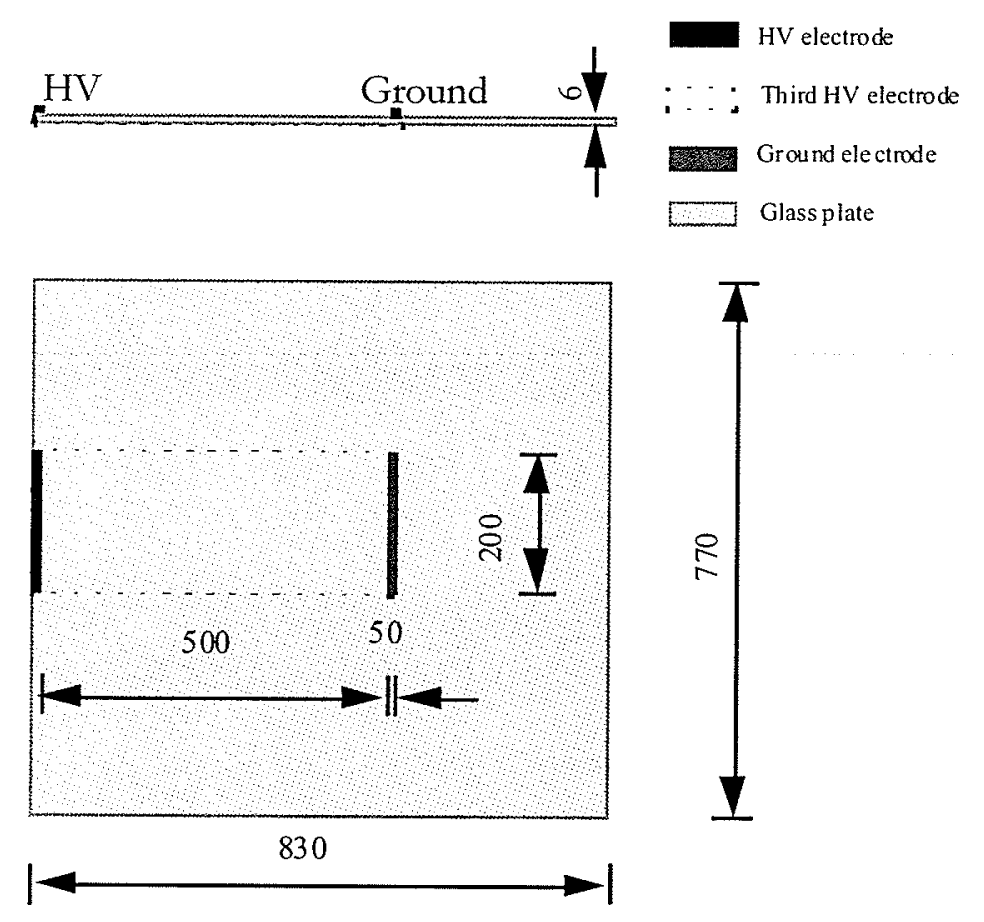

Fig. A.1 Sketch of electrode configurations

\section{A.1.1 Wetting Pattern}

A spray gun was used to spray water on to the glass surface, and an uneven wetting pattern was created by using a plastic sheet to cover a part of glass surface. The nozzle of the spray gun was adjusted to produce fine water droplets in order to create a completely wet condition in the wetted portion of the surface. After each measurement or flashover, the wetting pattern was re-created. Two different types of water were used, i.e. tap water with conductivity of $150 \mu \mathrm{S} / \mathrm{cm}$ and distilled water with conductivity of $2.5 \mu \mathrm{S} / \mathrm{cm}$. Each spray resulted in the depletion of $1 \mathrm{ml}$ of water and a water film with mean thickness of $0.1 \mathrm{~mm}$ was obtained by controlling the total amount of water sprayed onto the surface.

Before wetting, the glass surface was carefully cleaned by methanol alcohol, in order to improve its wettability and temove surface charges created by the previous test. 


\section{A.1.2 Conductivity of Water}

Water conductivity was measured using a conductivity cell in conjunction with a Wheastone bridge.

\section{Conductivity Cell}

The conductivity cell is made with stainless steel cylindrical electrodes of diameter of $31.8 \mathrm{~mm}$ in a perplex cylinder of diameter of $43.8 \mathrm{~mm}$. The cell volume is $200 \mathrm{ml}$ and the distance between electrodes is $50 \mathrm{~mm}$. The dimensions of the cell are shown in Fig.A.2.

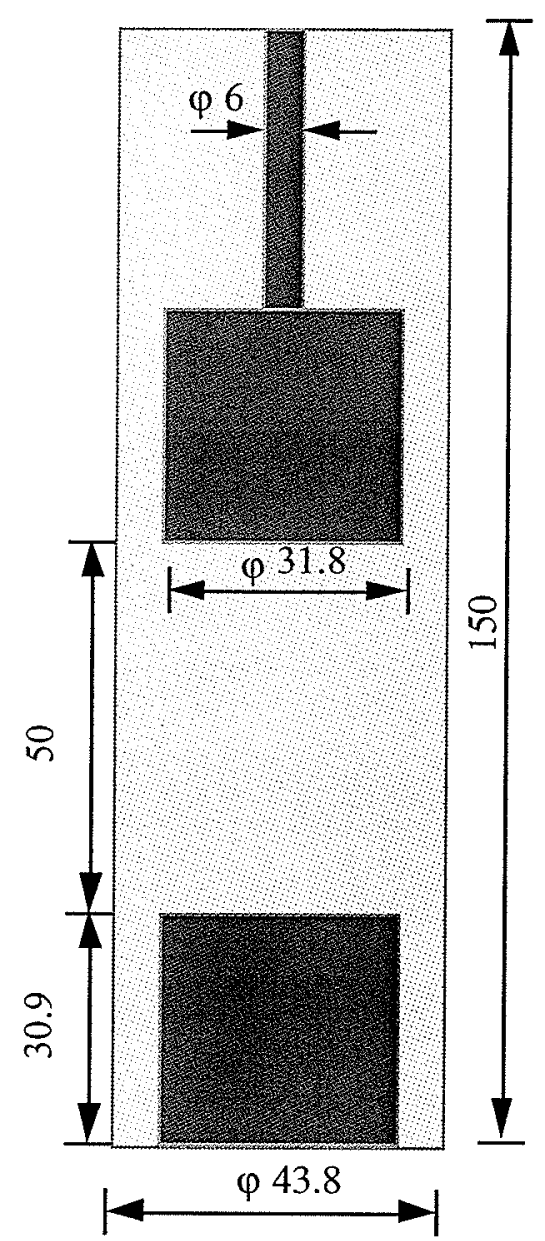

Fig. A.2 Sketch of the conductivity cell 


\section{Wheatstone Bridge}

A Wheatstone bridge circuit was assembled using low inductive, $0.05 \%$ grade shielded decade resistors and a null detector. The bridge was powered through a $3 \mathrm{~V}$-peak $1 \mathrm{kHz}$ sine wave generator. The resistance of the cell $\left(R_{x}\right)$ can be estimated by $R_{x}=\frac{R_{1} \times R_{d}}{R_{2}}$.

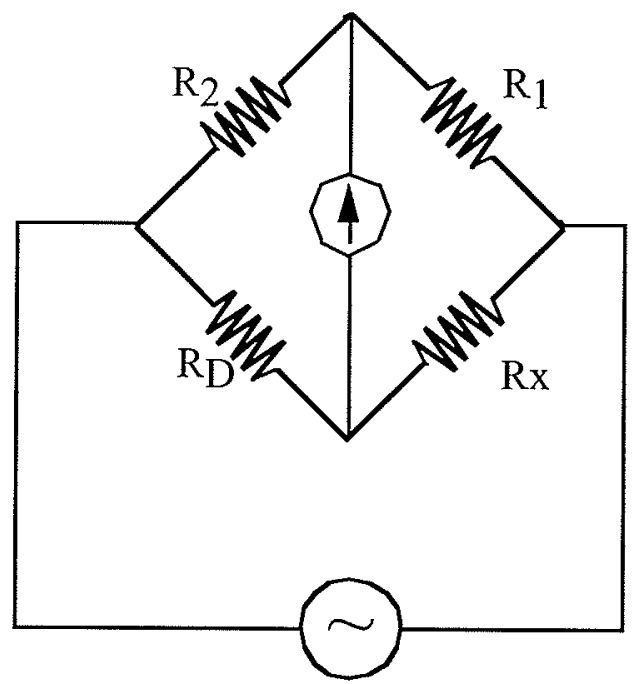

Fig.A.3 Schematic diagram of the Wheatstone bridge

\section{Computation of Water Conductivity}

The E-field and potential distributions inside the cell are shown in Fig. A.4. Based on the Efield computation, the conductivity $(\gamma)$ is determined by following formula.

$$
\gamma=\frac{U}{\left(R_{x} \cdot \oint_{s} E \cdot d S\right)}
$$

Where, $\mathrm{U}$ is the applied voltage;

$\mathbf{E}$ is the electric field;

dS is the surface element on the closed surface. 
For this given configuration, $\frac{U}{\left(\oint_{s}(E \cdot d S)\right)}$ is about $0.4006\left[\mathrm{~cm}^{-1}\right]$. Therefore, EqA.1 becomes

$$
\gamma=\frac{0.4006}{R_{x}}
$$
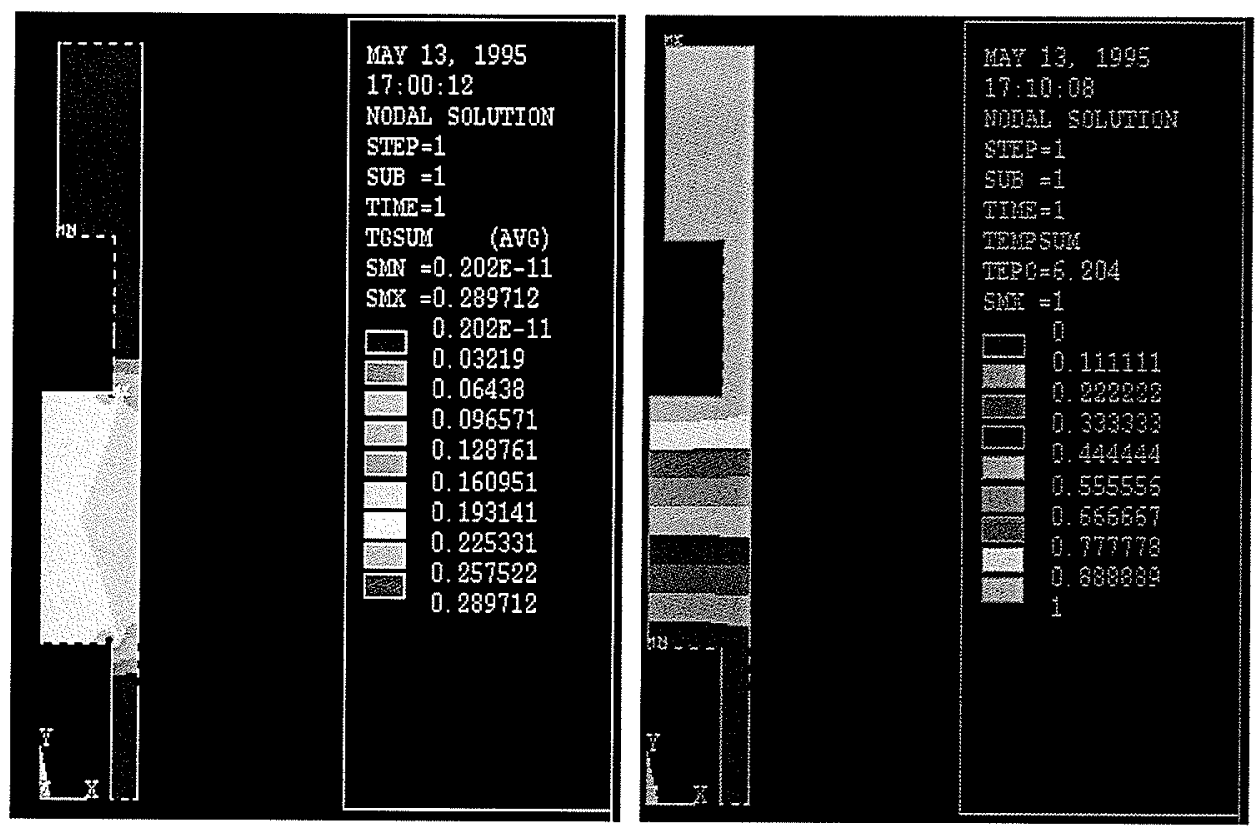

Fig. A.4 E-field and potential distribution inside the conductivity cell

\section{Conductivity of Tap and Distilled water}

Based on above measuring and formula, Conductivities of tap and distilled water were estimated.

Table A.1 Measured Resistance and Conductivity $\left(20^{\circ} \mathrm{C}\right)$

\begin{tabular}{|c|c|c|}
\hline Type of Water & Resistance $(\mathrm{k} \Omega)$ & $\begin{array}{c}\text { Conductivity } \\
(\mu \mathrm{S} / \mathrm{cm})\end{array}$ \\
\hline tap water & 2.5 & 160.3 \\
\hline distilled water & 156.5 & 2.6 \\
\hline
\end{tabular}




\section{A.2 E-field Measurements above Glass Plate under dc Voltage}

A portable miniaturized electric dc field meter was borrowed from the Manitoba HVDC Research Center and used to measure the E-field above the glass surface. The meter measures fields ranging from $30 \mathrm{~V} / \mathrm{m}$ to about $500 \mathrm{kV} / \mathrm{m}$ in space, and is unaffected by the presence of ions [JoKi89]. The meter consists of a rotating probe and a receiver. A rotating probe, at the end of a fibreglass pole, senses the field and communicates recordings of its direction and magnitude to a remote read-out device. Fire Optic cable is used to minimize the field perturbation due to the presence of the miniature field probe.

All E-field data were obtained at locations $5 \mathrm{~cm}$ above the glass plate and 5 minutes after voltage application. The E-field data fluctuated by about $\pm 5 \%$ during the tests, especially in the presence of corona.

\section{A.2.1 Influence of Dry Zone}

The electric field distributions under different lengths of dry zone are shown in Fig.A.5. It is observed that electric fields were redistributed and substantially increased when an uneven wetted pattem is created. With decrease of dry zone length, the overall electric field increases and becomes more non-uniform along the surface. Close to the dry zone the horizontal component is overwhelmingly strong, which is essential to initiate a streamer. The vertical component is dominant close to the wet zone. The measured E-field at a location near the ground electrode with $30 \%$ length of dry zone is twice that for a completely dry surface. 


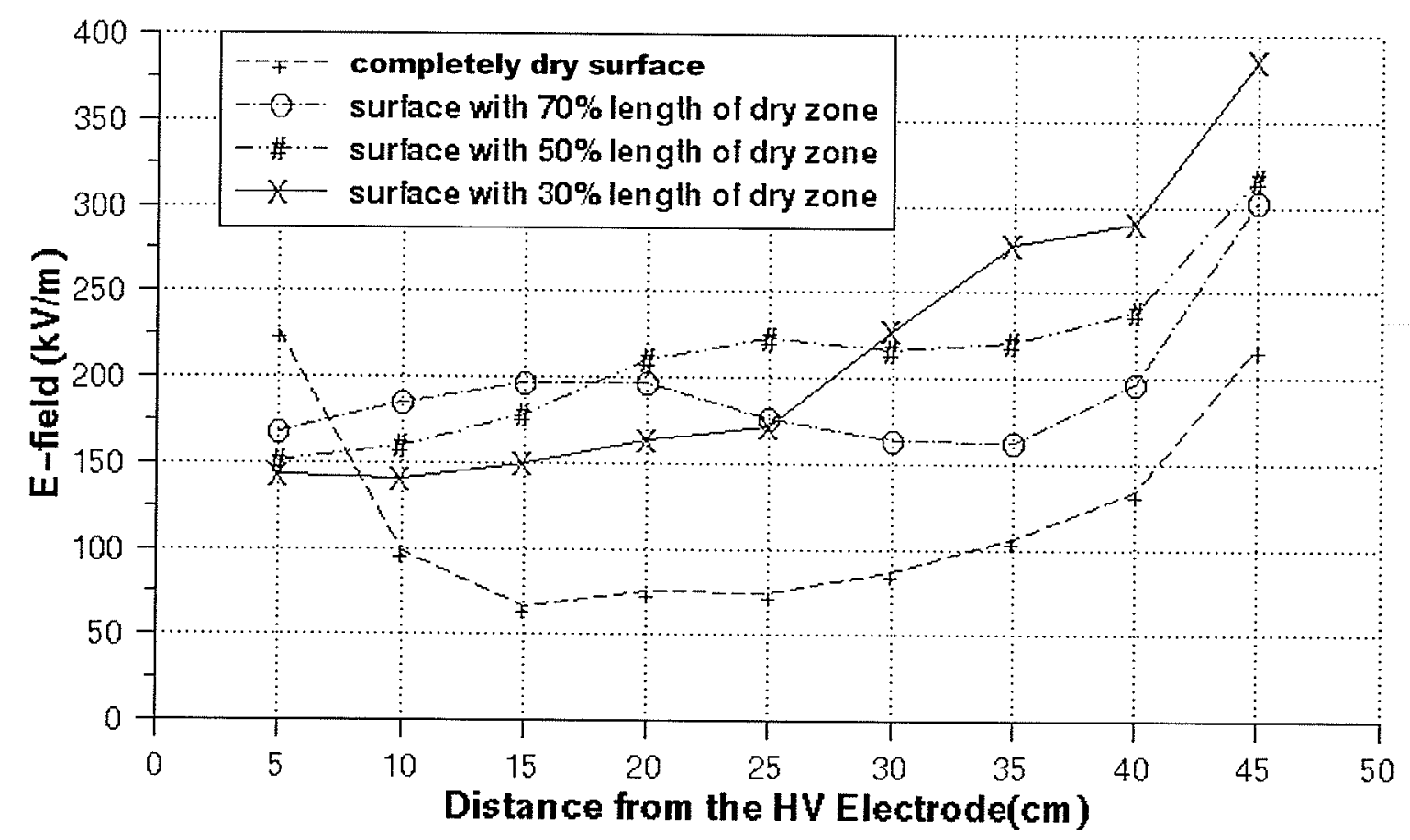

Fig. A.5 E-field distribution under different lengths of dry zone(Insulator type, $-80 \mathrm{kV}$ )

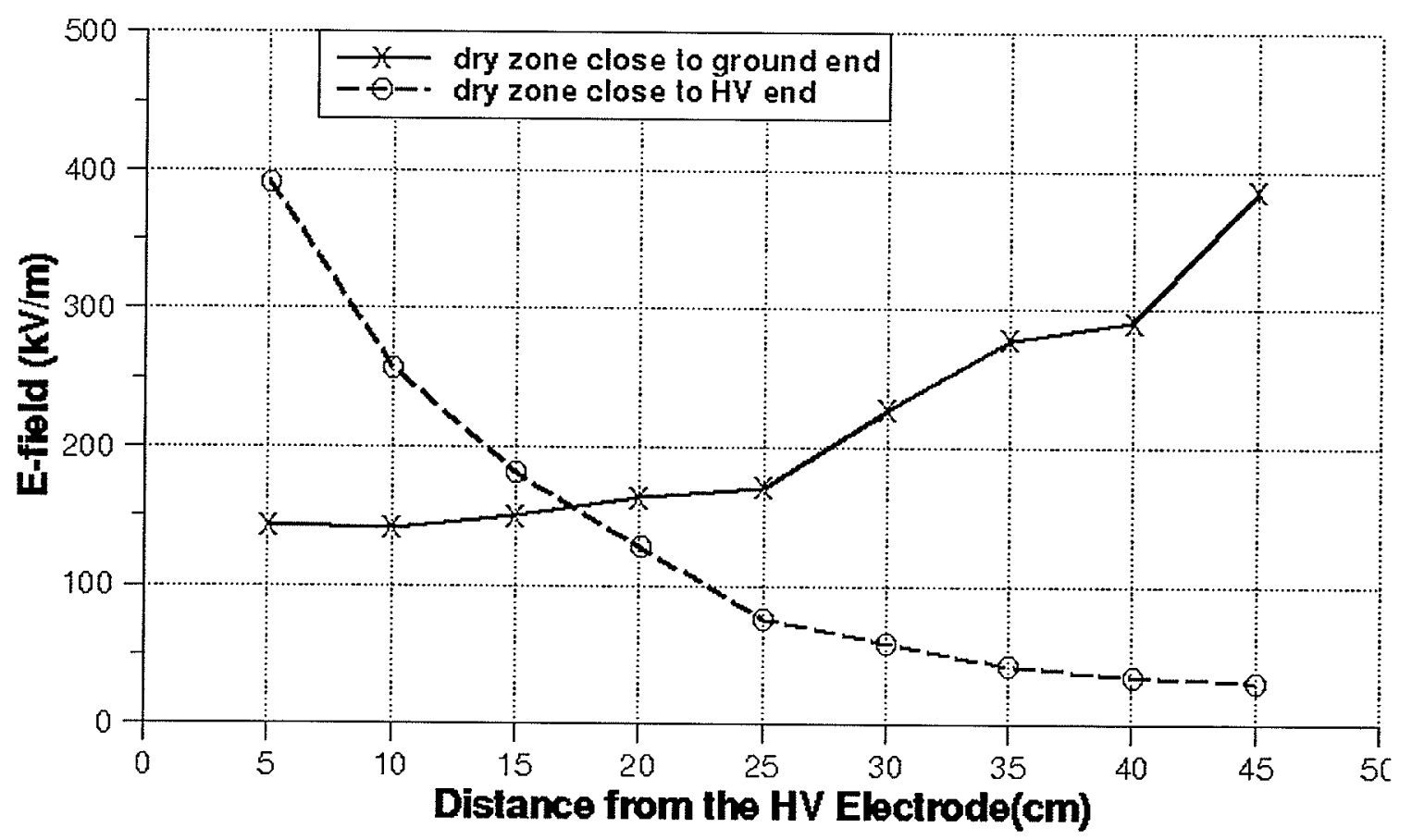

Fig. A.6 Influence of dry zone location on the E-field distribution $(30 \%$ length of dry zone, $-80 \mathrm{kV})$ 
Fig.A.6 shows the effect of position of the dry zone on E-field distribution. For -ve applied voltage, the E-field values are relatively higher when the dry zone is located at the ground end. This shows that the E-field distribution has a strong dependence on the location and length of the dry zone. A dry zone length of $30 \%$ located next to the ground end does produce a favourable condition for flashover.

\section{A.2.2 Influence of Configuration}

The influence of configuration on the E-field distribution is shown in Fig.A.7. Generally the electric field in the insulator-type arrangement is quasi-uniform, while the electric field in the bushing-type arrangement has a much more non-uniform characteristic along or close to the surface. During preliminary flashover tests, no visible discharges were observed with the insulator-type configuration even up to a voltage of $80 \mathrm{kV}$. In contrast, visible streamers are occasionally initiated from the ground electrode at a voltage of $40 \mathrm{kV}$ in the bushing-type configuration due to the extreme local electric field. With additional effects due to uneven wetting, further exaggeration in the non-uniformity of E-field distribution along the surface can be expected with this configuration.

\section{A.2.3 Influence of a Simulated Partial Arc}

A bare wire of diameter $3 \mathrm{~mm}$ and length $50 \mathrm{~mm}$ was placed at the ground end perpendicularly to the electrode to simulate a partial arc. Its influence on the E-field distribution is shown in Fig.A.8. It is evident that the electric field in front of the partial arc is enhanced, and therefore favours its progress. 


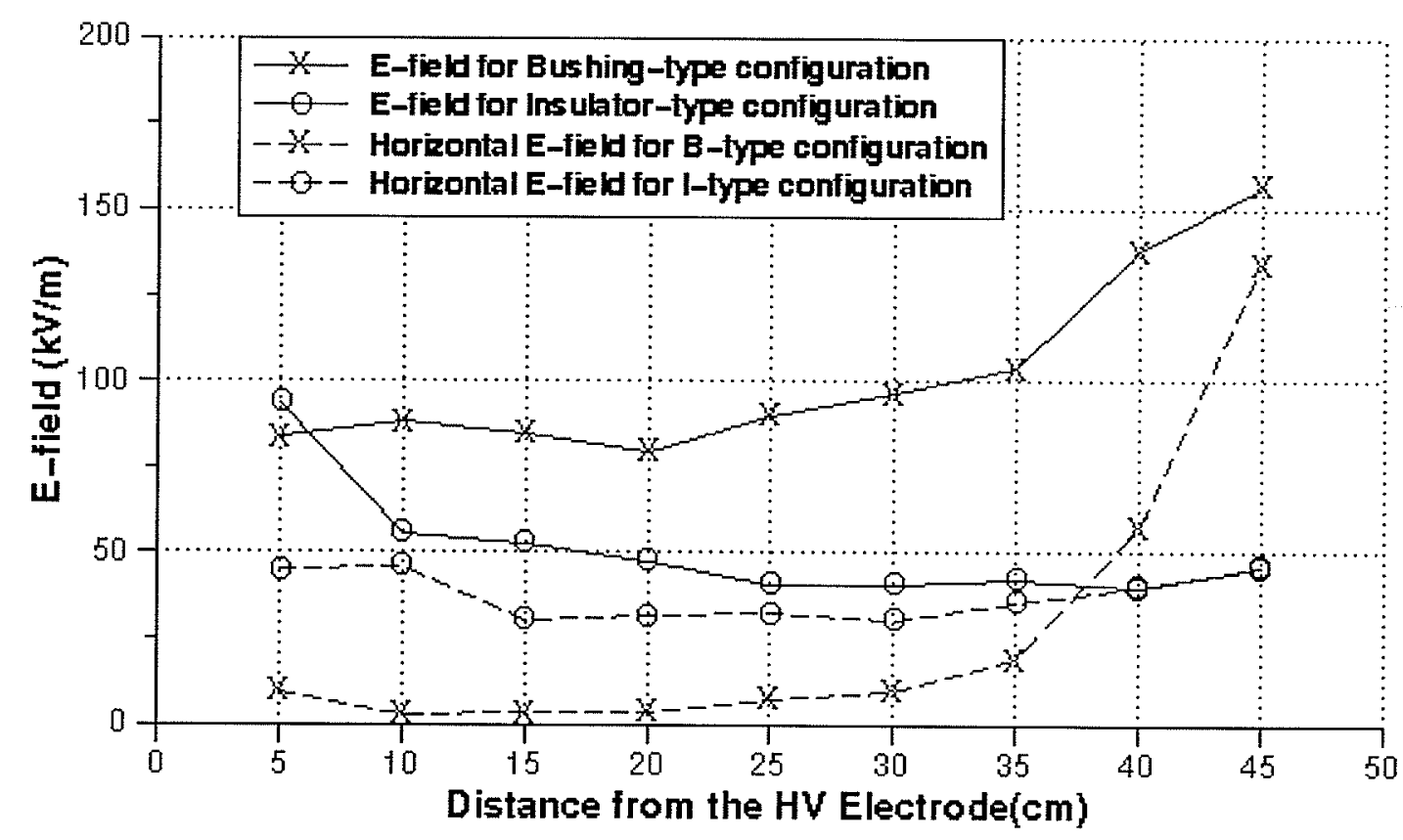

Fig.A.7 Measured E-field distributions $5 \mathrm{~cm}$ from the surface for two types of configurations (completely dry surface, $-25 \mathrm{kV}$, dimensions of configurations shown in Fig. A.1)

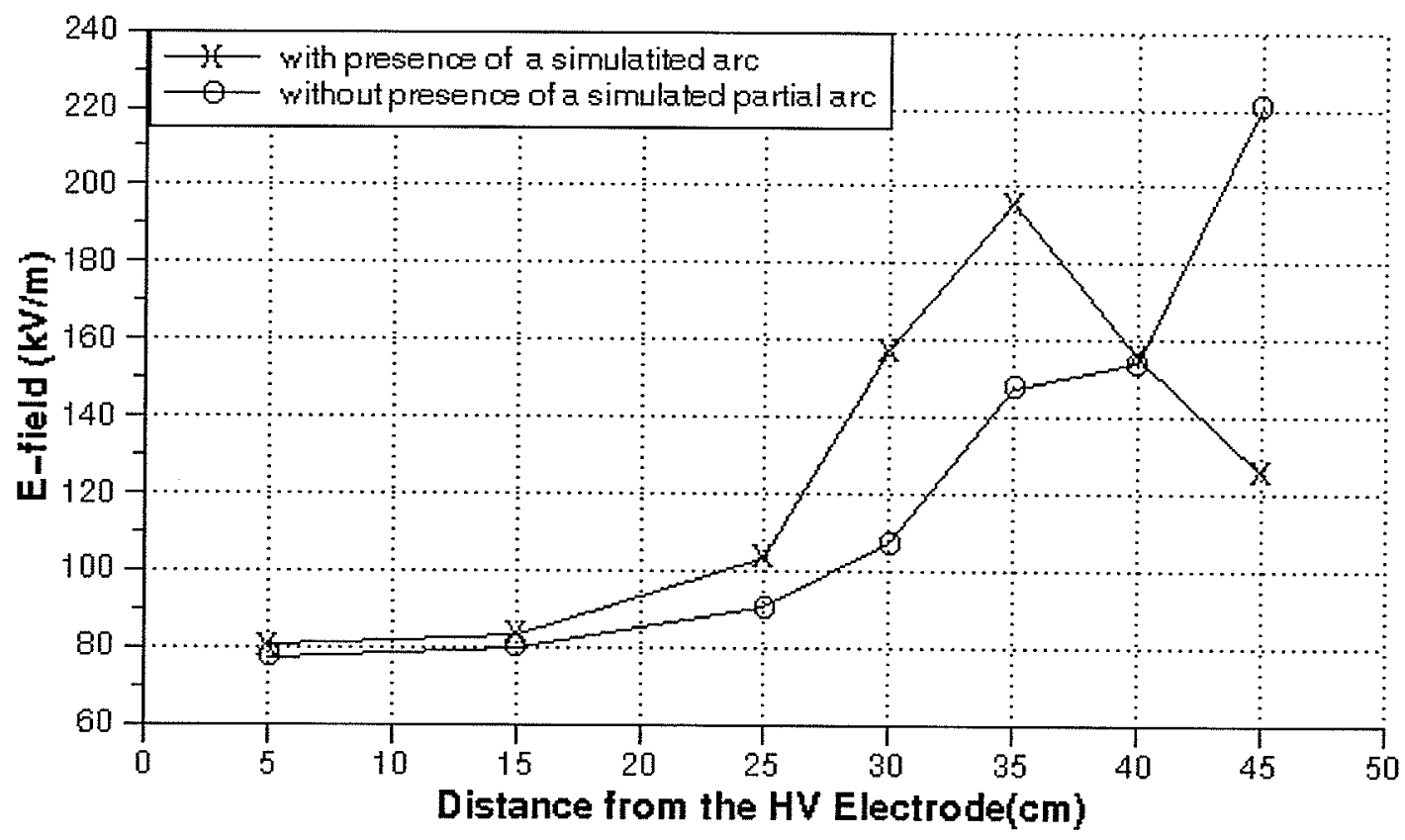

Fig.A.8 Comparison of E-fields for I-type of configuration with and without a simulated partial arc $(30 \%$ length of dry zone, $-40 \mathrm{kV})$ 


\section{A.2.4 Influence of Other Factors}

\section{Voltage Polarity}

E-field measurements were also conducted under different polarities and the results are shown in Fig.A.9. The influence of voltage polarity on the E-field distribution prior to flashover is almost negligible. The voltage polarity selective nature of flashover due to uneren wetting [LaA191] might be mainly caused by the differences between the propagation characteristics of the -ve and +ve streamers.

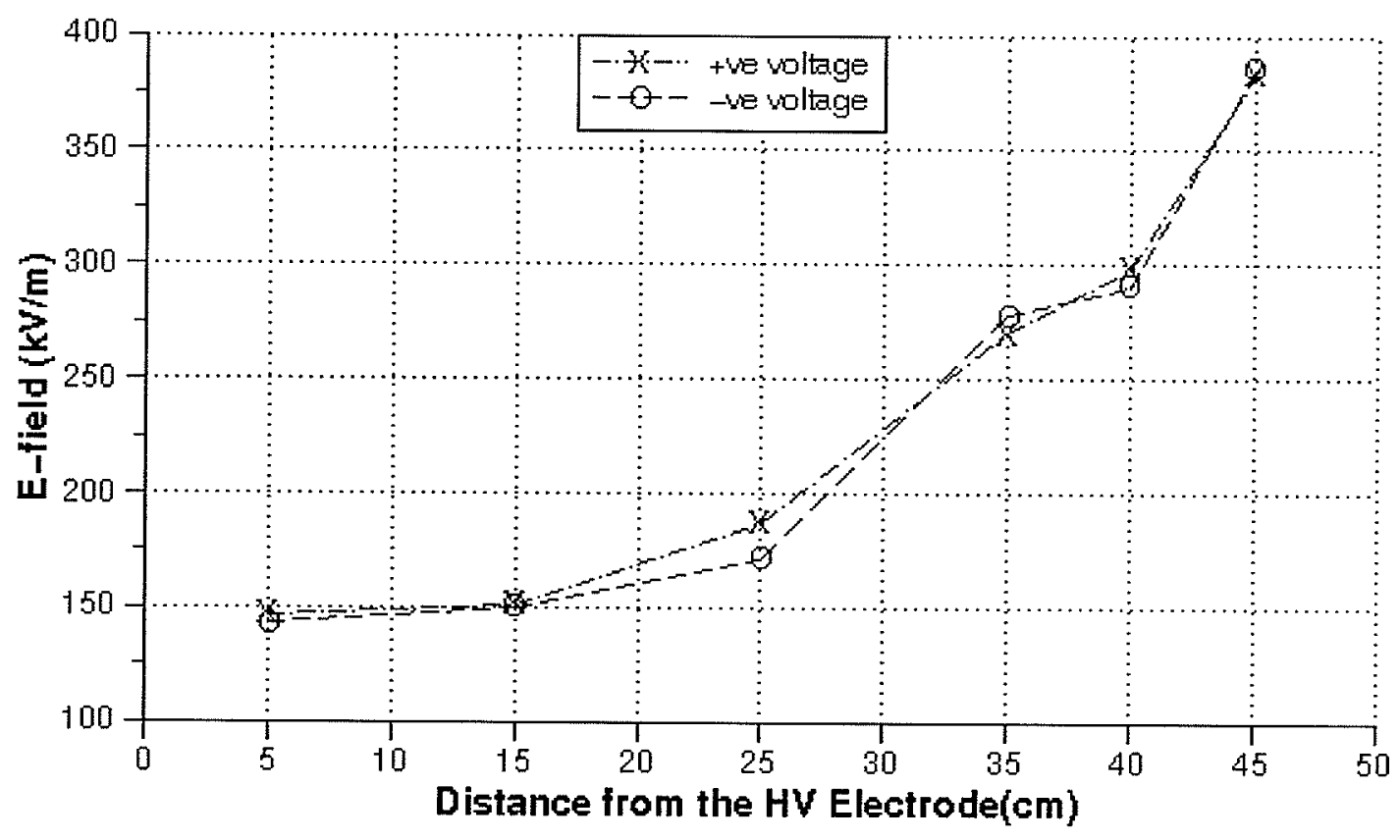

Fig.A.9 Comparison of E-field distribution under voltage of different polarities ( $30 \%$ length of dry zone, I-type configuration, $80 \mathrm{kV}$ )

\section{Water Conductivity}

The influence of water conductivity on the E-field distribution was investigated by using tap and distilled water. It is found that the conductivity of the water has little influence on the electric field distribution prior to flashover. 


\section{Wind Effect}

E-field measurements of a complete dry surface with and without presence of strong wind $(\sim 30 \mathrm{~km} / \mathrm{h})$ for the insulator-type configuration were also conducted at $80 \mathrm{kV}$. It is assumed that the space charges will be blown off by the strong wind. Therefore, the E-field distributions obtained under strong wind can be considered the same as that in the absence of space charges. The results indicate that the presence of strong wind, i.e. space charge, has a negligible influence on the overall electric field distribution.

\section{A.3 Flashover Tests}

For the flashover tests, the voltage was increased in $5 \mathrm{kV}$ steps and held at each level for a period of 5 minutes. The average flashover voltage (FOV) was obtained from the results of 5 tests.

Since the puncture voltage of the glass plate is about $60 \mathrm{kV}$, the gap spacing was reduced to $25 \mathrm{~cm}$ to avoid unwanted puncture. Flashover tests were conducted under different conditions for both types of configurations. The results are summarized in Table A.2.

The dependence of FOV on the dry zone length is shown in Fig. A.10. The FOV decreases with decrease of dry zone length in certain range for both configurations. However after a certain critical length $(15 \% \sim 20 \%)$, further decrease of dry zone length may not lower the FOV. With $10 \%$ length of dry zone a partial arc bridged the dry zone in both configurations without leading to a complete flashover. This might be either due to insufficient energy in the process or due to source weakness. Also, when the dry zone is located next to the -ve HV electrode a higher FOV is recorded compared to the one obtained with dry zone located at the 
ground end. This is because the latter arrangement has a relative higher overall electric field as shown in Fig.A.6.

Table A.2. Summary of Flashover Tests

\begin{tabular}{|c|c|c|c|c|c|}
\hline$T$ & $\mathbf{P}$ & \multicolumn{2}{|c|}{ Dry Zone } & \multirow[b]{2}{*}{ Water Type } & \multirow[b]{2}{*}{ FOV $(\mathrm{kV})$} \\
\hline $\begin{array}{l}\mathrm{Y} \\
\mathrm{P} \\
\mathrm{E}\end{array}$ & $\begin{array}{l}\mathrm{O} \\
\mathrm{L} \\
.\end{array}$ & Length & Position & & \\
\hline \multirow{6}{*}{$\begin{array}{c}\mathrm{I} \\
\mathrm{I} \\
\mathrm{T} \\
\mathrm{Y} \\
\mathbf{P} \\
\mathrm{E}\end{array}$} & - & $20 \%$ & G & $T$ & $42.6(40.0 \sim 45.0)$ \\
\hline & - & $30 \%$ & G & $\bar{T}$ & $59.0(55.0 \sim 60.0)$ \\
\hline & - & $40 \%$ & G & $T$ & $71.0(70.0 \sim 75.0)$ \\
\hline & - & $60 \%$ & G & $T$ & $102.0(5.0 \sim 110)$ \\
\hline & - & $30 \%$ & G & D & $62.0(60.0 \sim 65.0)$ \\
\hline & + & $30 \%$ & G & $T$ & $65.8(60.0 \sim 80.0)$ \\
\hline \multirow{5}{*}{$\begin{array}{l}\text { B } \\
\text { I } \\
T \\
Y \\
P \\
\text { E }\end{array}$} & - & $20 \%$ & G & $T$ & $36.5(35.0 \sim 37.5)$ \\
\hline & - & $30 \%$ & G & $\mathbf{T}$ & $47.9(45.0 \sim 50.0)$ \\
\hline & - & $20 \%$ & G & D & $40.8(39.0 \sim 45.0)$ \\
\hline & - & $20 \%$ & $\mathbf{H}$ & $\bar{T}$ & $37.5(35.0 \sim 40.0)$ \\
\hline & + & $30 \%$ & G & $\mathbf{T}$ & $49.5(47.5 \sim 50.0)$ \\
\hline
\end{tabular}

$\begin{array}{ll}\text { Pol.: } & \text { Polarity } \\ \text { I: } & \text { Insulator } \\ \text { B: } & \text { Bushing } \\ \text { G: } & \text { Ground end } \\ \text { H: } & \text { High voltage end } \\ \text { T: } & \text { Tap water } \\ \text { D: } & \text { Distilled water }\end{array}$


Also as shown in Fig.A.10, the configuration has a significant influence on the FOV, especially for a longer dry zone length. The FOV of the surface with distilled water is $5 \sim 10 \%$ higher than the one with tap water, although there is not much influence of water conductivity on the E-field distribution. For both configurations, the FOVs are lower for negative polatity. This polarity selective nature of FOV might be due to the difference between the propagation of the -ve and +ve streamers.

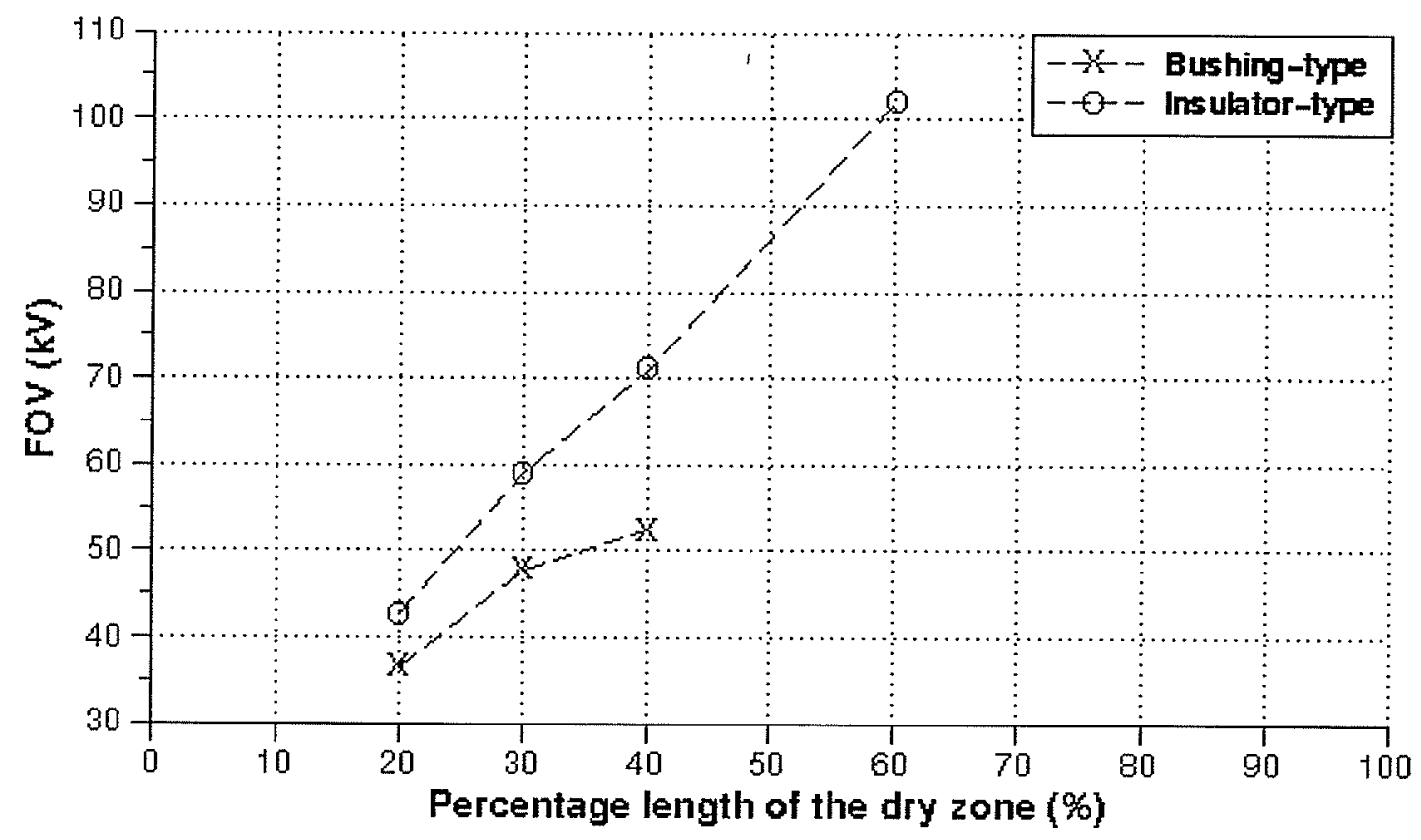

Fig.A.10 Dependence of FOV on the dry zone length (-ve voltage)

\section{A.4 Summary}

The investigation of E-field measurements and flashover under different conditions for two different configurations leads to following conclusions: 
1. Uneven wetting can cause a redistribution and substantial increase of the E-field. Both the length and location of the dry zone influence the E-field distribution, and therefore, the flashover voltage.

2. Non-uniformity of E-field distribution and its relative higher electric field value along the surface cause the initiation of a streamer at a lower voltage in the bushing-type configuration. The FOV is considerable lower compared to that of the insulator-type configuration.

3. Existence of a partial arc can enhance the E-field in front of it, and therefore, favors progress of the arc.

4. Factors such as voltage polarity, water conductivity do not have a significant influence on the E-field distribution prior to flashover, but they do affect the progress of flashover, and therefore the FOV value. 